\title{
Latest Advances in High-Voltage and High-Energy-Density Aqueous Rechargeable Batteries
}

\author{
Xinhai Yuan ${ }^{1}$ - Fuxiang $\mathrm{Ma}^{1} \cdot$ Linqing Zuo $^{1}$ - Jing Wang ${ }^{1} \cdot$ Nengfei Yu $^{1} \cdot$ Yuhui Chen ${ }^{1} \cdot$ Yusong Zhu ${ }^{1}$. \\ Qinghong Huang ${ }^{1} \cdot$ Rudolf Holze $^{1,2,3} \cdot$ Yuping Wu${ }^{1}$ (i) $\cdot$ Teunis van $\mathrm{Ree}^{4}$
}

Received: 11 April 2020 / Revised: 4 June 2020 / Accepted: 3 July 2020 / Published online: 1 September 2020

(c) The Author(s) 2020

\begin{abstract}
Aqueous rechargeable batteries (ARBs) have become a lively research theme due to their advantages of low cost, safety, environmental friendliness, and easy manufacturing. However, since its inception, the aqueous solution energy storage system has always faced some problems, which hinders its development, such as the narrow electrochemical stability window of water, poor percolation of electrode materials, and low energy density. In recent years, to overcome the shortcomings of the aqueous solution-based energy storage system, some very pioneering work has been done, which also provides a great inspiration for further research and development of future high-performance aqueous energy storage systems. In this paper, the latest advances in various ARBs with high voltage and high energy density are reviewed. These include aqueous rechargeable lithium, sodium, potassium, ammonium, zinc, magnesium, calcium, and aluminum batteries. Further challenges are pointed out.
\end{abstract}

Keywords Aqueous rechargeable batteries $\cdot$ Aqueous electrolyte $\cdot$ High voltage $\cdot$ High energy density

\section{Introduction}

In recent years, the continuous consumption of non-renewable energetic resources (oil, coal, natural gas, etc.) has caused serious environmental problems and a continuing energy crisis. The development and utilization of renewable energies (solar, wind, tidal, etc.) can alleviate these problems

Xinhai Yuan and Fuxiang Ma contribute equally to this work.

Qinghong Huang

huangqh@njtech.edu.cn

$\triangle$ Yuping $\mathrm{Wu}$

wuyp@fudan.edu.cn

1 Institute of Advanced Materials (IAM), School of Energy Science and Engineering, China State Key Laboratory of Materials-Oriented Chemical Engineering, Nanjing Tech University, Nanjing 210009, Jiangsu, China

2 Institute of Chemistry, Saint Petersburg State University, St. Petersburg 199034, Russia

3 Institute of Chemistry, Chemnitz University of Technology, AG Elektrochemie, Chemnitz, Germany

4 Department of Chemistry, University of Venda, Thohoyandou 0950, South Africa effectively, but because of the intermittent nature of renewable energy, it is not conducive to effective grid supply, so there is an urgent need for safe and reliable energy storage devices to store energy [1]. Rechargeable battery technologies, such as the lead-acid batteries, nickel-cadmium batteries, nickel-metal hydride (Ni-MH) batteries, redox flow batteries (RFCs) and lithium-ion batteries (LIBs), have found practical application in various fields, but the inherent limitations of these systems hinder their wider application in the large-scale energy storage field, among which operational safety and other ideal characteristics (such as low installation cost, long cycle life, high energy efficiency, and sustainability) are the main constraints [2]. For example, the energy densities of a lead-acid battery and a nickel-cadmium battery are limited $\left(\sim 30 \mathrm{Wh} \mathrm{kg}^{-1}\right)$; in addition, the electrode material contributes to environmental pollution, and the main problems of the $\mathrm{Fe}-\mathrm{Ni}$ battery are its low charge/ discharge efficiency (about 50\%-60\%) and self-discharge caused by negative iron electrode corrosion $(20 \%-40 \%$ per month). Although the MH-Ni battery has a high energy density, its low temperature performance, rate performance, and coulombic efficiency are not ideal. Redox flow cells are easy to assemble, but they have low power/energy densities and special requirements for heat/temperature control, which 
greatly limit their wide application. Lithium-ion batteries have higher energy densities, lower weight, and longer service life and have great application prospects. However, the organic electrolyte used is very flammable, and the electrode material will react with the organic electrolyte in the case of overcharge or short circuit, which leads to serious safety problems such as combustion and explosion. In addition, the cost of lithium ion batteries remains high and the manufacturing process is complex, which greatly restricts its wide application in large-scale energy storage systems. Because of the poor ionic conductivity of organic electrolyte solutions, the power density of a lithium ion battery is limited. To sum up, the development of new battery systems has become an urgent need. These systems should have the advantages of safety, environmental compatibility, and low cost.

Aqueous rechargeable batteries (ARBs) make up for these shortcomings. Although they are restricted by the electrochemical stability window of water and their energy density is limited, in recent years (since 2007), several research groups have done some pioneering work, greatly improving their energy density, making this research direction full of vitality, setting off another wave of research expansion. Although there are some comprehensive literature reviews in this area, there are still some areas in need of closer inspection.

In this review, we summarize new ARB systems with high voltage and high energy density. As there have appeared many good reviews on ARBs, negative electrode/positive electrode materials, battery systems, challenges, and solutions over the past several years, we here focus only on the advances mainly over the last five years.

ARBs are categorized usually according to their charge carriers during the redox reactions as follows: aqueous rechargeable lithium, sodium, potassium, ammonium, zinc, magnesium, calcium, and aluminum batteries. Major recent advances comprise electrolytes and electrode materials that enable higher voltages and higher energy densities. Furthermore, we will discuss the main challenges of these new electrochemical energy storage systems so that further development of these systems can be boosted.

\section{Strategies to Improve the Energy Density of Aqueous Rechargeable Batteries}

According to the equation $E=C \cdot U_{\text {cell }}$ (where $E$ is the energy density, $C$ is the specific capacity of the electrodes and $U_{\text {cell }}$ is the working voltage), we can increase the energy density of ARBs in two ways: (1) by increasing the battery voltage and (2) by using electrode materials with higher specific capacity. It is well known that the main reason for the limited energy density of ARBs is the voltage stability window of water $(1.23 \mathrm{~V})$, and the available electrode materials are limited. Therefore, finding ways to widen the voltage window of aqueous electrolytes is the key to improving the performance of ARBs. So far, many research groups have done outstanding work in this area, along the following strategies: (a) regulating the $\mathrm{pH}$ of the electrolyte; (b) constructing artificial interphase layers; (c) using concentrated aqueous electrolytes; and (d) introducing electrolyte additives with interphase-forming capability. However, a wide voltage window does not necessarily guarantee the construction of high-voltage, high-energy density ARBs. It only makes it possible to select electrode materials with large voltage differences for pairing. Finally, the working voltage of an ARB can be determined by choosing the right negative electrode and positive electrode materials [3]. These strategies are summarized in Fig. 1. In the context, we will combine these strategies together with the latest research on various ARBs.

\section{Aqueous Rechargeable Batteries}

\subsection{Aqueous Rechargeable Lithium Batteries (ARLBs)}

Aqueous rechargeable lithium batteries (ARLBs) have been developed since 1994 [4]. They have an average discharge voltage of about $1.5 \mathrm{~V}$ and function reversibly. They can deliver an energy density of $75 \mathrm{Wh} \mathrm{kg}^{-1}$ (based on the combined mass of the active materials), which is comparable to the performance of lead-acid and nickel-cadmium batteries. As pointed out in this pioneering research paper, hydrogen

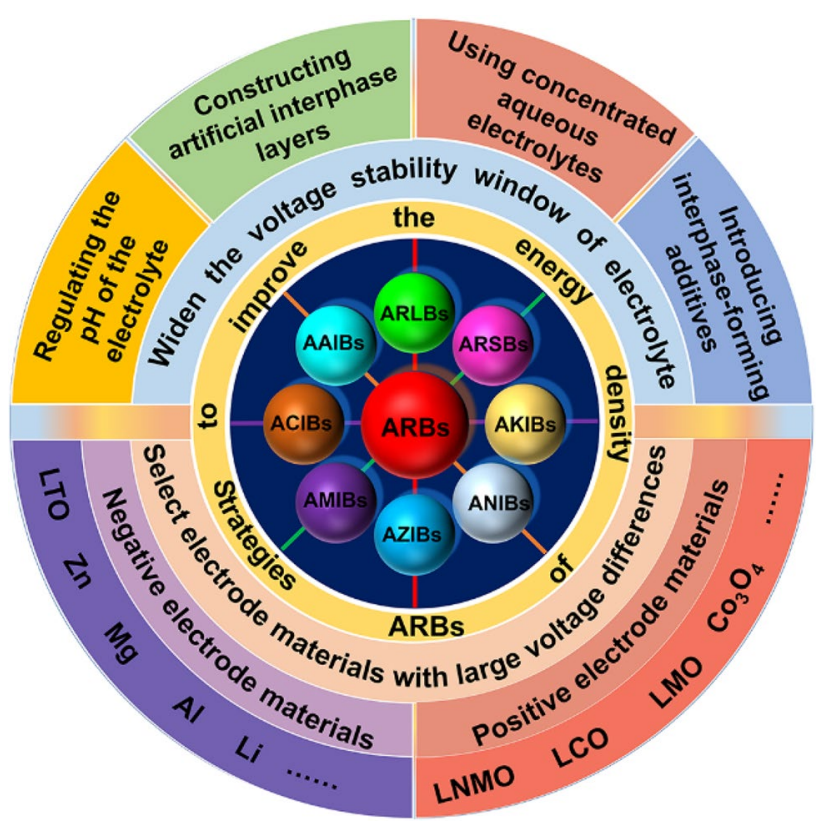

Fig. 1 Schematic diagram of strategies for improving the electrochemical performance of aqueous rechargeable batteries 
(HER) and oxygen (OER) evolution redox potentials are important reference factors in the selection of two electrode materials for ARLBs. That is to say, the working potential of the electrode material should be between the OER and HER to avoid the electrolysis reaction of water. More recently, there have been many comprehensive reviews on the electrode materials of ARLBs [3, 5-9]. Therefore, we will not elaborate on these here. In this part, we only summarize the current work on high voltage and energy density ARLBs.

In order to construct high-voltage and high-energydensity ARLBs, there are several strategies: (1) improving the electrolyte such as using superconcentrated electrolytes and (2) using negative electrode materials (such as sulfur, lithium, zinc and graphite) with high specific capacity and/ or low redox potential [10].

\subsubsection{Superconcentrated Electrolytes}

3.1.1.1 "Water-in-Salt"/"Water-in-Bisalt" Electrolytes A "waterin-salt" (WiS) electrolyte was first used in ARLBs in 2015 by Wang and co-workers, which expanded the electrochemical stability window to ca. $3.0 \mathrm{~V}\left(1.9-4.9 \mathrm{~V}\right.$ vs. $\left.\mathrm{Li}^{+} / \mathrm{Li}\right)$ and opened new avenues in aqueous electrochemistry [11]. Lithium bis(trifluoromethanesulfonyl)imide (LiTFSI) was chosen as the salt because of its high solubility in water ( $>20 \mathrm{~m}$; in this paper, the unit $\mathrm{m}$ refers to $\mathrm{mol} \mathrm{kg}^{-1}$ ), and because of its high concentration with hydrated water having high hydrolytic stability. The WiS definition applies when weight and volume of salt exceed those of the solvent in a binary system. When the concentration of LiTFSI reaches $21 \mathrm{~m}$, its electrochemical stability window extends to $3 \mathrm{~V}$ (Fig. 2a). In this report, $\mathrm{LiMn}_{2} \mathrm{O}_{4}$ and $\mathrm{Mo}_{6} \mathrm{~S}_{8}$ were used as negative electrode materials to assemble ARLBs, which confirmed the feasibility of the $21 \mathrm{~m} \mathrm{WiS} \mathrm{electrolyte.} \mathrm{It} \mathrm{is}$ worth noting that the redox potentials of these electrode materials move to a positive potential with the increase in salt concentration. According to the Nernst equation, this is mainly due to the change in $\mathrm{Li}^{+}$activity therein. These ARLBs can deliver up to $2.3 \mathrm{~V}$ and have a median discharge voltage of $1.83 \mathrm{~V}$, which is significantly higher than the traditional or the 1st generation ARLBs using ordinary aqueous electrolyte solutions. There are two reasons why the WiS electrolyte has such a wide voltage window (see Fig. 2b). On one hand, there are enough free water molecules to fully hydrate lithium ions in dilute aqueous solution. With an increase in salt concentration, fewer non-coordinated water molecules become available, and the solvation or the hydrated layer of the lithium ion changes dramatically. When the concentration increases to $21 \mathrm{~m}$, the ratio of water to lithium ion is only 2.6, signifying that $\mathrm{Li}^{+}$is partially dehydrated and the electrostatic field generated by the formal charge on lithium ion can no longer be neutralized by coordination with water. As a result, $\mathrm{TFSI}^{-}$ions enter the solvation layer of $\mathrm{Li}^{+}$. Since the reduction potential of $\mathrm{TFSI}^{-}$is lower than that of water, $\mathrm{TFSI}^{-}$decomposes on the surface of the negative electrode material to form a dense protective SEI layer (mainly $\mathrm{LiF}$ ) before water decomposition. On the other hand, the activity of water is decreased due to few free water molecules downstream of the high concentration, which is helpful to increase the electrochemical stability of positive and negative electrodes. Therefore, it can be seen that the cooperation of these two factors widens the voltage window of the electrolyte appreciably. However, the positive and negative electrode materials selected for the battery do not make full use of the voltage window of the LiTFSI WiS electrolyte. The $\mathrm{Mo}_{6} \mathrm{~S}_{8} / \mathrm{LiFePO}_{4}$ battery [12] and the $\mathrm{TiS}_{2} / \mathrm{LiMn}_{2} \mathrm{O}_{4}$ battery [13] behave similarly. Therefore, further optimization of the positive and negative electrode materials is needed for further enhancement of the voltage and energy density of the ARLBs. For positive electrode materials, materials with higher potential and/ or higher specific capacity can be selected, such as $\mathrm{LiVPO}_{4} \mathrm{~F}$, $\mathrm{LiCoO}_{2}$, and $\mathrm{LiNi}_{0.5} \mathrm{Mn}_{1.5} \mathrm{O}_{4}$. For negative electrodes, materials with lower potential and/or higher specific capacity, such as $\mathrm{LiVPO}_{4} \mathrm{~F}, \mathrm{TiO}_{2}$ and sulfur, can also be chosen.

Tavorite-type $\mathrm{LiVPO}_{4} \mathrm{~F}$ can be used as both positive and negative electrode materials for ARLBs [14]. The constant-current charge-discharge curve (Fig. 2c) shows that $\mathrm{LiVPO}_{4} \mathrm{~F}$ has two sets of charge and discharge plateaus, which, respectively, correspond to the intercalation and deintercalation of lithium ions. The high potential group corresponds to the $\mathrm{V}^{4+} / \mathrm{V}^{3+}$ redox pair (about $4.26 \mathrm{~V}$ vs. $\mathrm{Li}^{+} / \mathrm{Li}$ ), and the low potential group corresponds to the $\mathrm{V}^{3+} /$ $\mathrm{V}^{2+}$ redox pair (about $1.8 \mathrm{~V}$ vs. $\mathrm{Li}^{+} / \mathrm{Li}$ ). Using this material as both positive and negative electrodes, respectively, and the LiTFSI "water-in-salt" gel electrolyte, a flexible symmetric battery was assembled with $2.46 \mathrm{~V}$ output voltage (average discharge voltage up to $2.4 \mathrm{~V}$ ), showing excellent rate performance.

The performance of the symmetrical cell using the $21 \mathrm{~m}$ LiTFSI WiS electrolyte is poor, and the coulombic efficiency is $96 \%$ after only 50 cycles. A $25 \mathrm{~m}$ LiTFSI WiS gel electrolyte was prepared by adding PVA, and the voltage stability window was widened. The symmetric battery assembled in this way was cycled at a low rate of $0.2 \mathrm{C}$. After only ten cycles, the coulombic efficiency reached $100 \%$. At a rate of $20 \mathrm{C}$, the capacity of the battery was still $87 \%$ after 4000 cycles, and the coulombic efficiency was close to $100 \%$ during the whole cycle (Fig. 2d). It was also found for the first time that the SEI film on the surface of the positive electrode material in the LiTFSI WiS electrolyte was a mixture of $49 \% \mathrm{Li}_{2} \mathrm{CO}_{3}$ and $51 \% \mathrm{LiF}$. This discovery revealed the secret of how $\mathrm{Li}^{+}$can be transported in the SEI, since $\mathrm{LiF}$ is an insulator for both ion and electron conduction. If the SEI consists of mainly $\mathrm{LiF}$, it is obvious that it will not be conducive to $\mathrm{Li}^{+}$transmission. Because $\mathrm{Li}_{2} \mathrm{CO}_{3}$ has better conductivity than $\mathrm{LiF}$, an ultra-high concentration carrier region is generated by space charge at the interface between $\mathrm{Li}_{2} \mathrm{CO}_{3}$ and $\mathrm{LiF}$, which is the channel of fast $\mathrm{Li}^{+}$ion transport. Therefore, even in a dense SEI film, $\mathrm{Li}^{+}$ions can still 


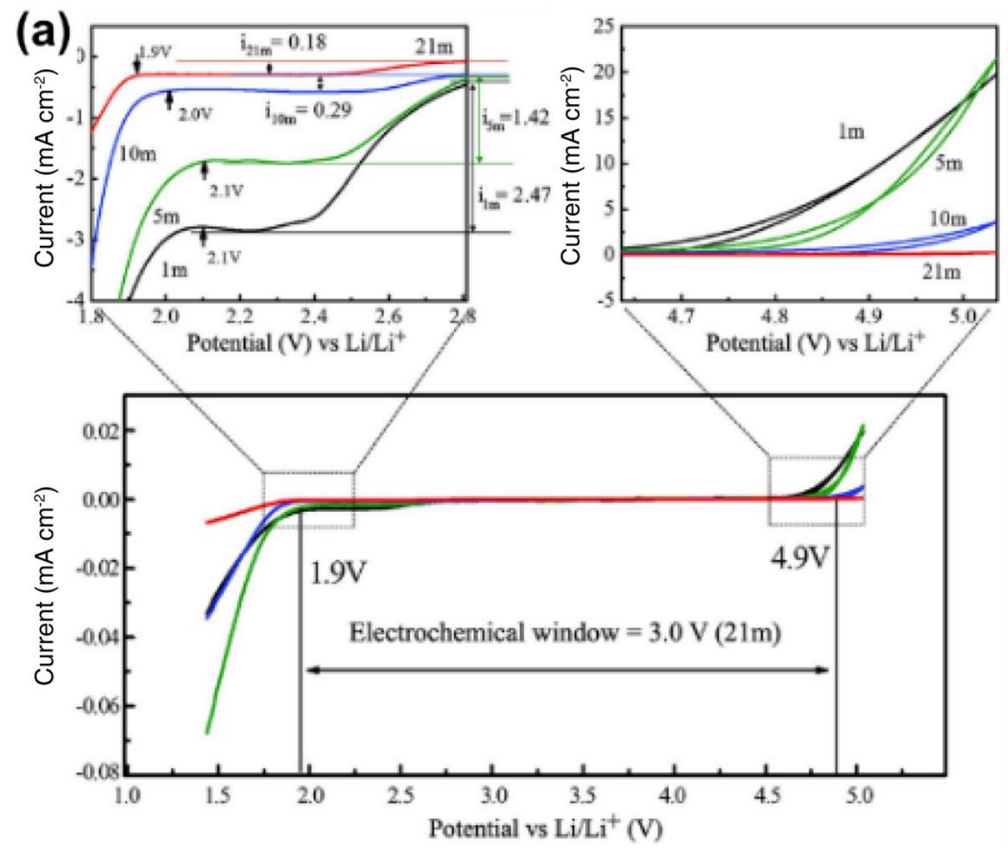

(b)

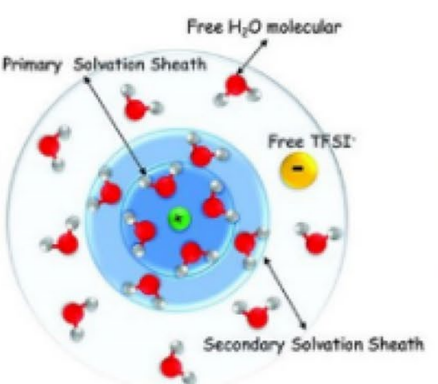

$\left\{\left[\mathrm{Li}\left(\mathrm{H}_{2} \mathrm{O}\right)_{4}\right]\left(\mathrm{H}_{2} \mathrm{O}\right)_{4}\right\}+n \mathrm{H}_{2} \mathrm{O} n \geqslant 1$

Salt-in-Water

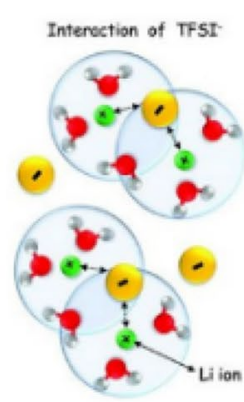

$\mathrm{Li}\left(\mathrm{H}_{2} \mathrm{O}\right)_{2.5}$-TFSI Water-in-Salt

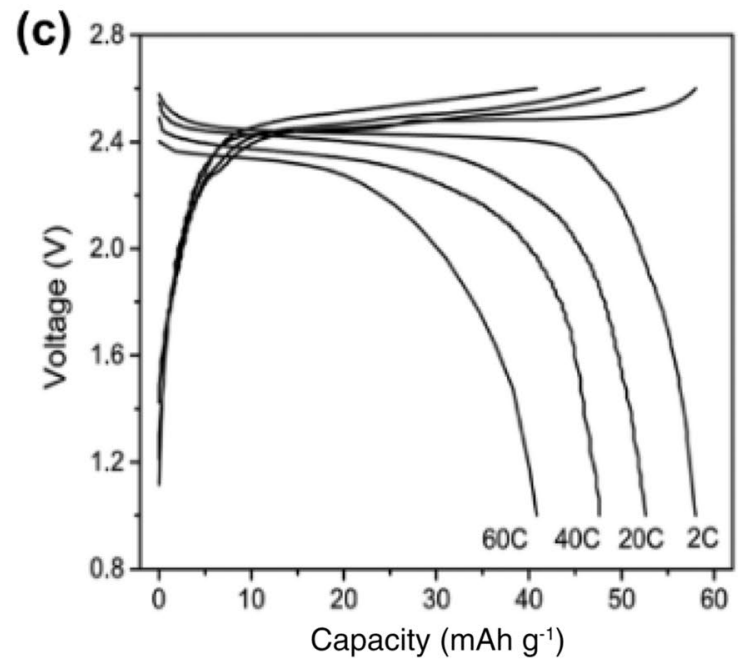

Fig. 2 a Electrochemical stability window of LiTFSI- $\mathrm{H}_{2} \mathrm{O}$ electrolytes with various concentrations. b Schematic diagram of the evolution of the $\mathrm{Li}^{+}$primary solvation sheath in dilute solution and "waterin-salt" electrolyte. Reproduced with permission from Ref. [11].

be transported rapidly along the $\mathrm{LiF} / \mathrm{Li}_{2} \mathrm{CO}_{3}$ grain boundary, explaining the good performance of $\mathrm{LiVPO}_{4} \mathrm{~F}$. The results of AC impedance testing show that the interface resistance of the negative electrode increases only $50 \%$ after 20 cycles, which shows that the $\mathrm{LiF}-\mathrm{Li}_{2} \mathrm{CO}_{3}-\mathrm{SEI}$ still provides a high conductivity for $\mathrm{Li}^{+}$ions.

Layered $\mathrm{LiCoO}_{2}$ electrodes deliver a specific capacity of $140 \mathrm{mAh} \mathrm{g}^{-1}$ when charged to $4.2 \mathrm{~V}$ (vs. $\mathrm{Li}^{+} / \mathrm{Li}$ ), corresponding to $50 \% \mathrm{Li}$ extraction to $\mathrm{Li}_{0.5} \mathrm{CoO}_{2}$, which has been regarded as a relatively stable positive electrode material in ARLBs [15-18]. In organic electrolytes, when charged to

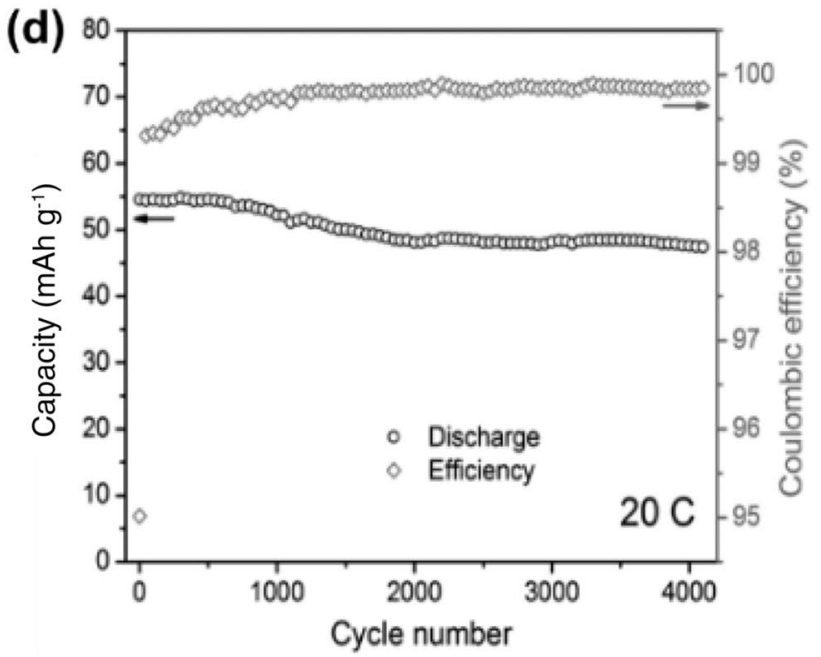

Copyright 2015, AAAS. c Charge and discharge voltage profiles of $\mathrm{LiVPO}_{4} \mathrm{~F}$ full cells at various rates. $\mathbf{d}$ The long cycling performance of $\mathrm{LiVPO}_{4} \mathrm{~F}$ full cells at $20 \mathrm{C}$. Reproduced with permission from Ref. [14]. Copyright 2017, John Wiley and Sons

4.5 V (vs. $\mathrm{Li}^{+} / \mathrm{Li}$ ), a higher specific capacity of $180 \mathrm{mAh}$ $\mathrm{g}^{-1}$ (corresponding to $70 \% \mathrm{Li}$ extraction) is delivered. However, the electrode suffers from serious capacity decay during cycling in aqueous electrolytes due to Co dissolution and the side reaction between $\mathrm{Li}_{0.3} \mathrm{CoO}_{2}$ and the electrolyte. Tris-(trimethylsilyl)borate (TMSB) was introduced into the WiS electrolyte as an additive and was continuously oxidized and decomposed to form a stable cathode electrolyte interphase (CEI) film on the surface of the $\mathrm{LiCoO}_{2}$ positive electrode during the charge process. Wang et al. found that after oxidation, the TMSB formed a protective interphase on 
the $\mathrm{LiCoO}_{2}$ positive electrode [19]. At a high cutoff voltage, the interphase-protected $\mathrm{LiCoO}_{2}$ delivered a high capacity of $170 \mathrm{mAh} \mathrm{g}^{-1}$ with remarkable cycling stability. An ARLB coupling the $\mathrm{LiCoO}_{2}$ positive electrode with the $\mathrm{Mo}_{6} \mathrm{~S}_{8}$ negative electrode exhibited $2.50 \mathrm{~V}$ open circuit voltage and $1.95 \mathrm{~V}$ midpoint voltage, achieving an energy density up to $120 \mathrm{Wh} \mathrm{kg}^{-1}$ and a low capacity decay rate of $0.013 \%$ per cycle, as the protective interphase effectively suppressed OER and cobalt dissolution from the positive electrode into the electrolyte solution.

Commercial spinel $\mathrm{LiNi}_{0.5} \mathrm{Mn}_{1.5} \mathrm{O}_{4}$ has two crystal structures, $\mathrm{P} 4332$ and fd-3 m. Among them, P4332 $\mathrm{LiNi}_{0.5} \mathrm{Mn}_{1.5} \mathrm{O}_{4}$ has a higher redox lithiation/de-lithiation potential plateau, and because of the high salt concentration of the WiS electrolyte, the redox intercalation/delithiation potential platform of $\mathrm{LiNi}_{0.5} \mathrm{Mn}_{1.5} \mathrm{O}_{4}$ has a positive shift of about $0.2 \mathrm{~V}$ to $4.8-5.0 \mathrm{~V}$ (vs. $\mathrm{Li} / \mathrm{Li}^{+}$), which is outside the stability window of the WiS electrolyte. The redox potential of fd-3 m $\mathrm{LiNi}_{0.5} \mathrm{Mn}_{1.5} \mathrm{O}_{4}$ is lower than that of $\mathrm{P} 4332 \mathrm{LiNi}_{0.5} \mathrm{Mn}_{1.5} \mathrm{O}_{4}$. The redox potential of fd-3 m LiNi ${ }_{0.5} \mathrm{Mn}_{1.5} \mathrm{O}_{4}$ is different from that of $\mathrm{P} 4332$ $\mathrm{LiNi}_{0.5} \mathrm{Mn}_{1.5} \mathrm{O}_{4}$ because there is a small amount of $\mathrm{Mn}^{3+}$ in fd-3 $\mathrm{m} \mathrm{LiNi}_{0.5} \mathrm{Mn}_{1.5} \mathrm{O}_{4}$, and the ion radius of $\mathrm{Mn}^{3+}$ is larger than that of $\mathrm{Mn}^{4+}$, which makes the lattice expand and the diffusion of $\mathrm{Li}^{+}$increase. In the WIS electrolyte, the two voltage platforms of fd-3 m LiNi ${ }_{0.5} \mathrm{Mn}_{1.5} \mathrm{O}_{4}$ move to 4.8-5.0 V. Although they exceed the voltage stability window of electrolytes, they can make full use of their capacity by adjusting the $\mathrm{pH}$ value of electrolytes to inhibit the oxygen evolution reaction. It is well known that with the decrease in $\mathrm{pH}$, the potential of HER and OER in water electrolytes will move to higher voltage. When $0.1 \%$ (in volume fractions) of $1 \mathrm{~m}$ bis(trifluoromethylsulfonyl)imide $\left(\mathrm{HN}\left(\mathrm{SO}_{2} \mathrm{CF}_{3}\right)_{2}, \mathrm{HTFSI}\right)$ was added to the WiS electrolyte, the $\mathrm{pH}$ value of the WiS electrolyte decreased to 5 and the window shifted $0.1 \mathrm{~V}$. However, the lowest redox potential $(2.1 \mathrm{~V})$ of $\mathrm{Mo}_{6} \mathrm{~S}_{8}$ is still higher than that of HER $(1.9 \mathrm{~V})$ of WiS electrolytes ( $\mathrm{pH}$ adjusted to 5). The positive material fd-3 m LiNi ${ }_{0.5} \mathrm{Mn}_{1.5} \mathrm{O}_{4}$ can be charged to $5.05 \mathrm{~V} \mathrm{(vs.} \mathrm{Li}^{+} / \mathrm{Li}$ ), and it can work stably. Therefore, $\mathrm{Mo}_{6} \mathrm{~S}_{8} / / \mathrm{LiNi}_{0.5} \mathrm{Mn}_{1.5} \mathrm{O}_{4}$ full cells can be assembled, which has an average discharge voltage of up to $2.35 \mathrm{~V}$ and an energy density of $126 \mathrm{Wh}$ $\mathrm{kg}^{-1}[20]$.

When $7 \mathrm{~m}$ LiOTf (lithium trifluoromethanesulfonate) was continuously added to $21 \mathrm{~m}$ LiTFSI WiS electrolytes (note the original term "dissolve" is not pertinent since it is impossible to get such a real aqueous solution) to obtain "water-in-bisalt" (WibS) electrolytes, in which the $\mathrm{Li}^{+}$-ion concentration reached $28 \mathrm{~m}$, the corresponding ratio of water molecules to salt ions was about 2 [21]. Owing to the higher salt concentration, the density of the SEI layer increased and the activity of water was reduced further, so that it had a wider electrochemical stability window of about $3.1 \mathrm{~V}$
(Fig. 3a). Based on this WibS electrolyte, an ARLB was prepared with $\mathrm{TiO}_{2}$ as the negative electrode and $\mathrm{LiMn}_{2} \mathrm{O}_{4}$ as the positive electrode, with $2.5 \mathrm{~V}$ open circuit voltage, a voltage plateau of $2.07 \mathrm{~V}$, and an energy density of 100 Wh kg-1 (calculated based on the combined mass of electrodes) (Fig. 3b). An acetate-based WibS electrolyte was constructed by mixing inorganic salts of LiOAc and KOAc, which had a water-to-cation ratio as low as 1.3 [22]. The results show that conventional negative electrode materials such as $\mathrm{Li}_{4} \mathrm{Ti}_{5} \mathrm{O}_{12}$ and $\mathrm{TiO}_{2}$ can intercalate/deintercalate $\mathrm{Li}^{+}$ reversibly in this WibS electrolyte, and the assembled $\mathrm{TiO}_{2} /$ $\mathrm{Mn}_{2} \mathrm{O}_{4}$ ARLB has a $2.10 \mathrm{~V}$ flat discharge plateau (Fig. 3c). The electrolyte is inexpensive, environmentally friendly, can be adjusted conveniently, and is highly adaptable and universal.

3.1.1.2 Hydrate-Melt Electrolytes The definition of hydrate melting is similar to that of WibS. In fact, the design of the WibS electrolyte was inspired by the hydrate-melt electrolyte [23]. The hydrate-melt electrolyte is actually an extension of the superconcentrated electrolyte in a system in which water is the solvent. Superconcentrated electrolytes have been used in lithium-ion batteries. It has been found that they can not only improve the stability of batteries, but also increase the operating voltage $(4 \mathrm{~V})$. This concept was first applied by Yamada et al. to aqueous energy storage systems and is known as "hydrate-melt." They explored the eutectic composition of lithium salts $\mathrm{Li}\left(\mathrm{SO}_{2} \mathrm{CF}_{3}\right)_{2}$ (LiTFSI) and lithium salts $\mathrm{Li}\left(\mathrm{SO}_{2} \mathrm{C}_{2} \mathrm{~F}_{5}\right)_{2}$ (LiBETI), both of which have an organic imide anion. The results show that when the composition is $\mathrm{Li}(\mathrm{TFSI})_{0.7}(\mathrm{BETI})_{0.3}$, the mixture solubility with water is the highest, a stable transparent solution can be obtained, and the concentration of water molecule is only $10.1 \mathrm{~m}$ (Fig. 4a). A large number of TFSI/BETI anions isolate free water molecules from each other, and all water molecules can participate in the hydration shell of lithium ions, thus reducing the activity of water molecules and widening the electrochemical stability window of electrolytes. In this solution, all water molecules are coordinated with lithium ions, and intramolecular hydrogen bonds are almost negligible (Fig. 4b). Further, it was found that the equilibrium potential of the lithium ion insertion/delamination reaction was $0.25 \mathrm{~V}$ in the hydrate-melt electrolyte, which was greater than the value in the $22 \mathrm{~m}$ LiTFSI (Fig. 4c). The thermodynamic mechanism (which reduces HOMO levels) and the kinetic mechanism (passivation induced by anions) further widen the potential difference between the anode and the cathode, thus widening the voltage window to $3.8 \mathrm{~V}$ (Fig. 4d). Based on the hydrate-melt electrolyte, the $\mathrm{Li}_{4} \mathrm{Ti}_{5} \mathrm{O}_{12} / / \mathrm{LiCoO}_{2}$ and the $\mathrm{Li}_{4} \mathrm{Ti}_{5} \mathrm{O}_{12} / / \mathrm{LiNi}_{0.5} \mathrm{Mn}_{1.5} \mathrm{O}_{4}$ full ARLBs were established, which exhibited high discharge cell voltage plateaus at $2.26 \mathrm{~V}$ and $3.10 \mathrm{~V}$, respectively. Up to now, there are few other studies on the application 


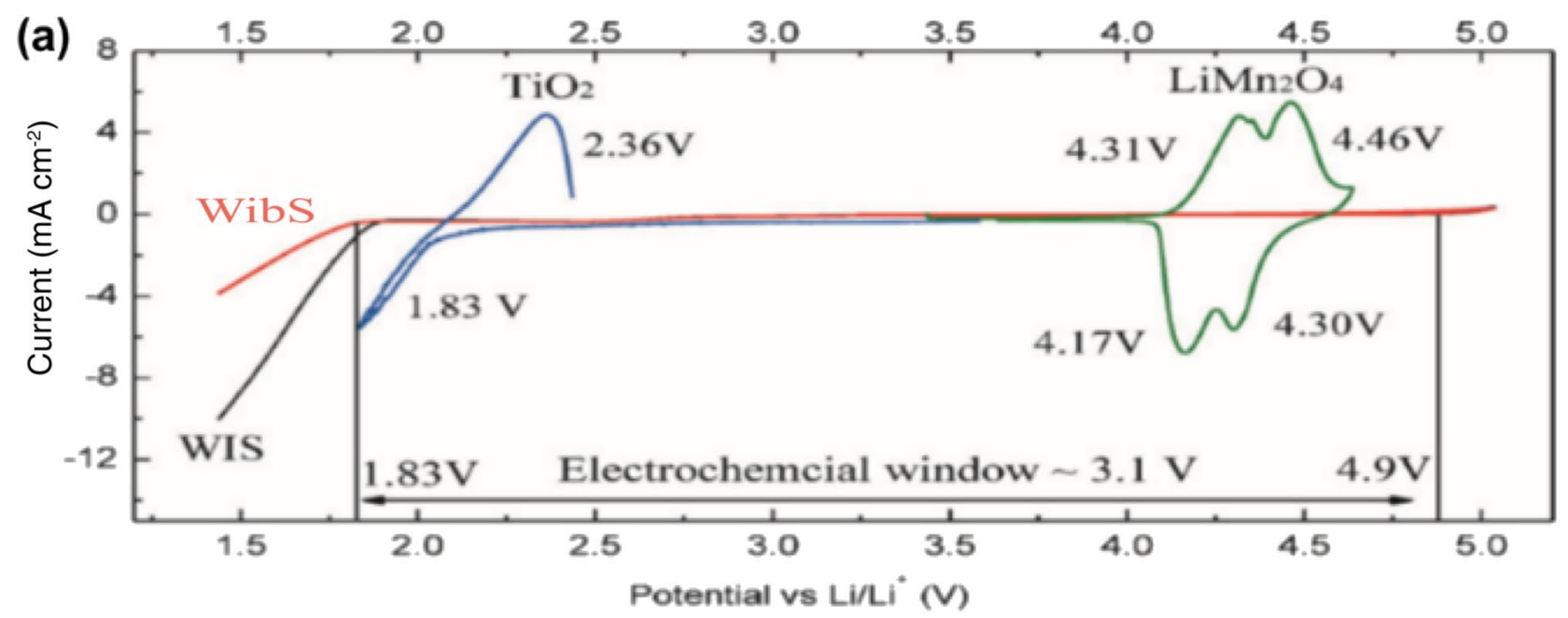

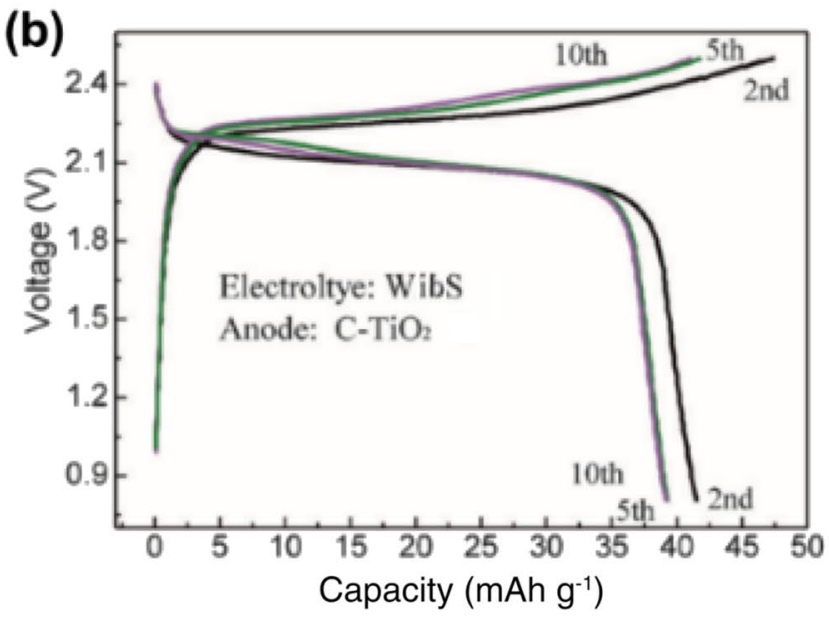

Fig. 3 a Electrochemical windows of WibS and WiS electrolytes at a scanning rate of $10 \mathrm{mV} \mathrm{s}^{-1}$, and the first $\mathrm{CV}$ traces of active electrodes $\left(\mathrm{C}-\mathrm{TiO}_{2}\right.$ and $\left.\mathrm{LiMn}_{2} \mathrm{O}_{4}\right)$ at a scanning rate of $0.1 \mathrm{mV} \mathrm{s}{ }^{-1}$ in WibS electrolytes. b The charge-discharge profiles of $\mathrm{C}_{-} \mathrm{TiO}_{2} /$ $\mathrm{LiMn}_{2} \mathrm{O}_{4}$ batteries in the the 5 th, and the 100 th cycles. Reproduced

of hydrate-melt electrolytes in aqueous batteries. Recently, $\mathrm{Wu}$ et al. have applied electrolytes to $\mathrm{Li}-\mathrm{O}_{2}$ batteries, which has been shown to effectively avoid solvent degradation and by-product formation, thus improving the cycle life of $\mathrm{Li}-$ $\mathrm{O}_{2}$ batteries [24]. In order to further evaluate and improve the practicability of the electrolyte, more and more in-depth research is needed.

\subsubsection{Hybrid Aqueous/Nonaqueous Electrolyte} (HANE) By introducing a nonaqueous solvent, dimethyl carbonate (DMC), into a WiS electrolyte, a hybrid aqueous/nonaqueous electrolyte (HANE) with an expanded electrochemical window of $4.1 \mathrm{~V}$ has been developed. This is a neutral solvent that is less sensitive to negative electrode repulsion

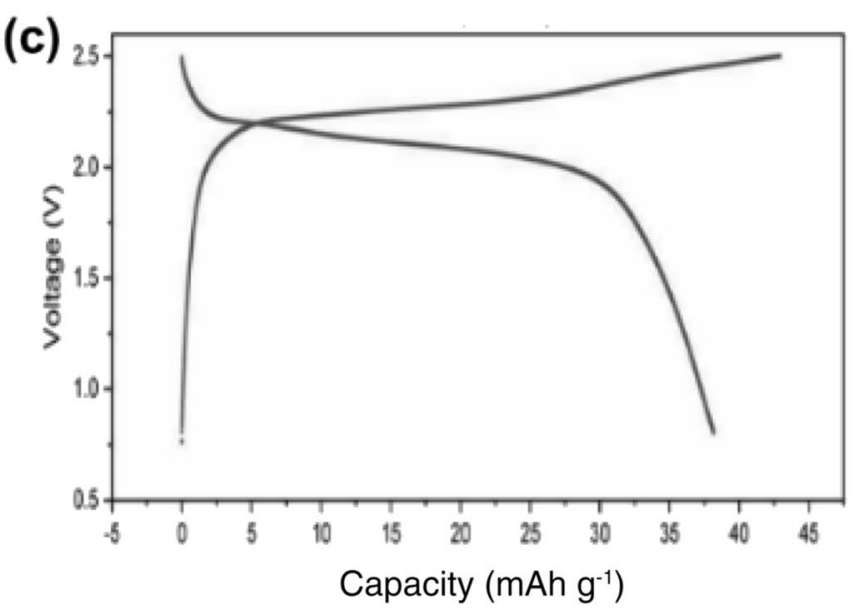

with permission from Ref. [21]. Copyright 2016, Wiley-VCH. c Charge-discharge profile of $\mathrm{c}-\mathrm{TiO}_{2} / \mathrm{LiMn}_{2} \mathrm{O}_{4}$ batteries at $0.5 \mathrm{C}$ in acetate-based WibS electrolytes. Reproduced with permission from Ref. [22]. Copyright 2018, Royal Society of Chemistry

and hence participates more easily in interspatial chemistry than anions [25]. Based on this hybrid electrolyte, an ARLB consisting of $\mathrm{LiNi}_{0.5} \mathrm{Mn}_{1.5} \mathrm{O}_{4}$ positive electrode and a $\mathrm{Li}_{4} \mathrm{Ti}_{5} \mathrm{O}_{12}$ negative electrode was established. This ARLB with a flat discharge plateau at $3.2 \mathrm{~V}$ (Fig. 5a) had an energy density of up to $165 \mathrm{Wh} \mathrm{kg}^{-1}$ and cycling stability of more than 1000 cycles (Fig. 5b). In a similar approach, a hybrid "acetonitrile (AN)/water-in-salt" electrolyte (AN-WiS) system was also reported, providing increased ionic conductivity, reduced viscosity, and expanded temperature ranges [26]. Increasing the LiTFSI salt concentration in AN-WiS to the level of superconcentration $(15.3 \mathrm{~m})$ expands the electrochemical stable window to $4.5 \mathrm{~V}$ [27]. This AN-WiSE enabled ARLBs, such as $\mathrm{Li}_{4} \mathrm{Ti}_{5} \mathrm{O}_{12} / \mathrm{LiMn}_{2} \mathrm{O}_{4}$ and $\mathrm{Li}_{4} \mathrm{Ti}_{5} \mathrm{O}_{12} /$ 

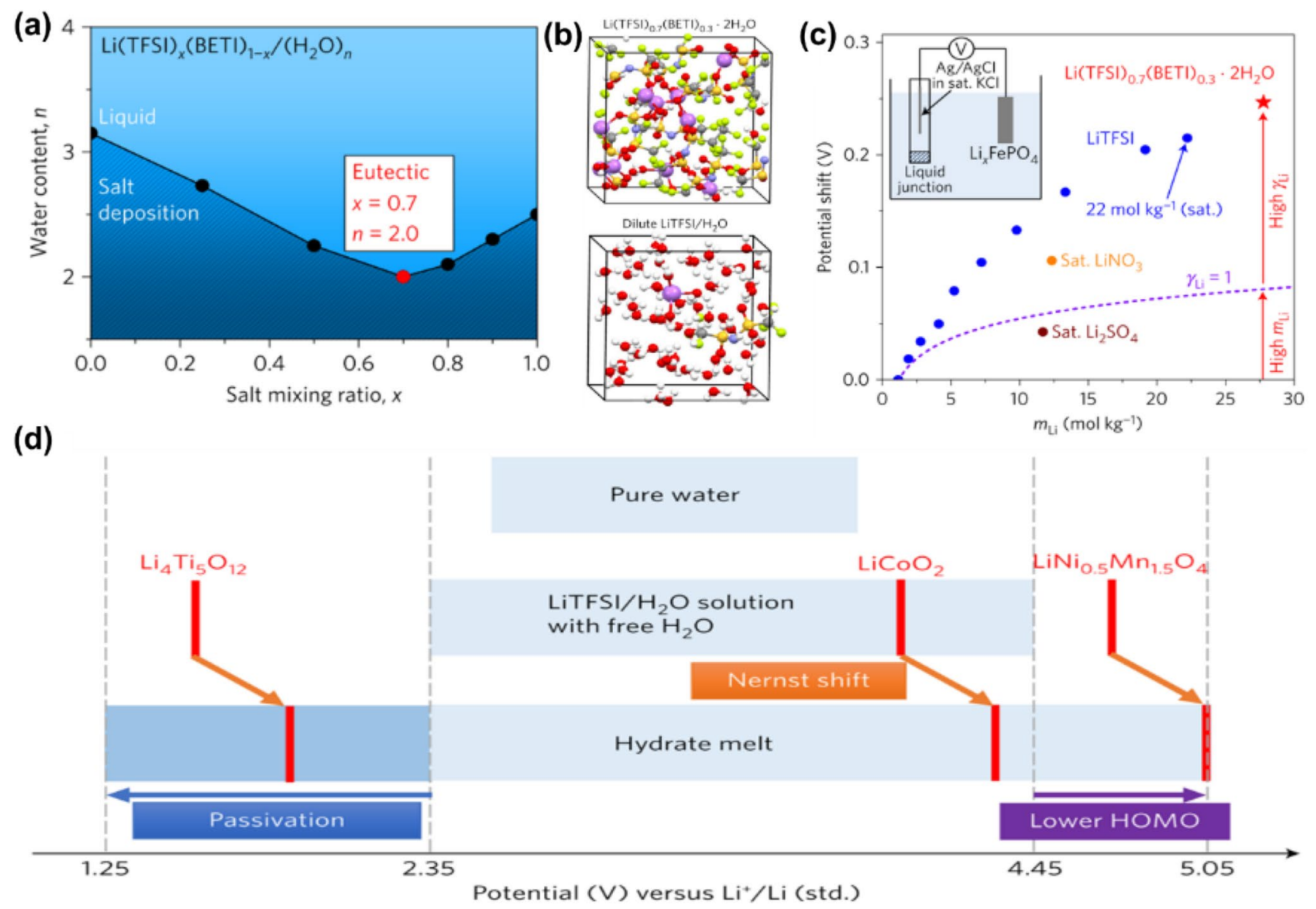

Fig. 4 a Liquidus line of LiTFSI + LiBETI mixtures in water. b Firstprinciple DFTMD simulates the equilibrium trajectory snapshot of $\mathrm{Li}(\mathrm{TFSI})_{0.7}(\mathrm{BETI})_{0.3} \cdot 2 \mathrm{H}_{2} \mathrm{O}$ hydrate melt and dilute $\mathrm{LiTFSI} / \mathrm{H}_{2} \mathrm{O}$. c The relationship between the change of equilibrium potential of lithium intercalation and $\mathrm{Li}^{+}$-concentration of electrolytes. $\mathbf{d}$ The volt-

$\mathrm{LiNi}_{0.8} \mathrm{Co}_{0.15} \mathrm{Al}_{0.05} \mathrm{O}_{2}$ full batteries, with high voltage, high energy density, and excellent cycling performance.

3.1.1.4 Water-in-Ionomer Electrolyte A new type of "water-in-ionomer" electrolytes was introduced by $\mathrm{He}$ et al. [28]. The "water-in-ionomer" electrolyte containing $50 \mathrm{wt} \%$ ionomer has an electrochemical stability window of $2.7 \mathrm{~V}$ (Fig. 5 c). A LiTi $2\left(\mathrm{PO}_{4}\right)_{3} / \mathrm{LiMn}_{2} \mathrm{O}_{4}$ full cell based on this electrolyte showed excellent cycling performance and provided an average discharge voltage $>1.5 \mathrm{~V}$ and specific energy of $77 \mathrm{Wh} \mathrm{kg}^{-1}$. Moreover, using an $\mathrm{Al}$ current collector, a $\mathrm{TiO}_{2} / \mathrm{LiMn}_{2} \mathrm{O}_{4}$ full battery with average output voltage of $2.1 \mathrm{~V}$ and initial specific energy of $124.2 \mathrm{Wh} \mathrm{kg}^{-1}$ was obtained (Fig. 5d). age windows of conventional $\mathrm{LiTFSI} / \mathrm{H}_{2} \mathrm{O}$ electrolytes and hydrated melt electrolytes, and the redox potential of $\mathrm{Li}_{4} \mathrm{Ti}_{5} \mathrm{O}_{12}, \mathrm{LiCoO}_{2}$, $\mathrm{LiNi}_{0.5} \mathrm{Mn}_{1.5} \mathrm{O}_{4}$ in hydrated melt electrolytes. Reproduced with permission from Ref. [23]. Copyright 2016, Nature Publishing Group

\subsubsection{The Role of the SEI}

3.1.2.1 Decomposition of Electrolyte Additives Adding additives to the electrolyte can also form a protective, an SEI-like interface phase in situ. Additives shall meet the following requirements: (1) having chemical stability, that is, stability in a given electrolyte solution, and (2) having electrochemical stability, so that the electrochemical process can occur during decomposition to form interfacial components.

A LiTFSI-HFE (highly fluorinated ether) gel was applied to negative electrode surfaces as an interphase precursor coating, which was consumed to yield a solid interphase consisting of both organic fluorinated hydrocarbon and inorganic fluorides, hence allowing high-capacity/low-potential negative electrode materials (such as silicon, graphite, and 

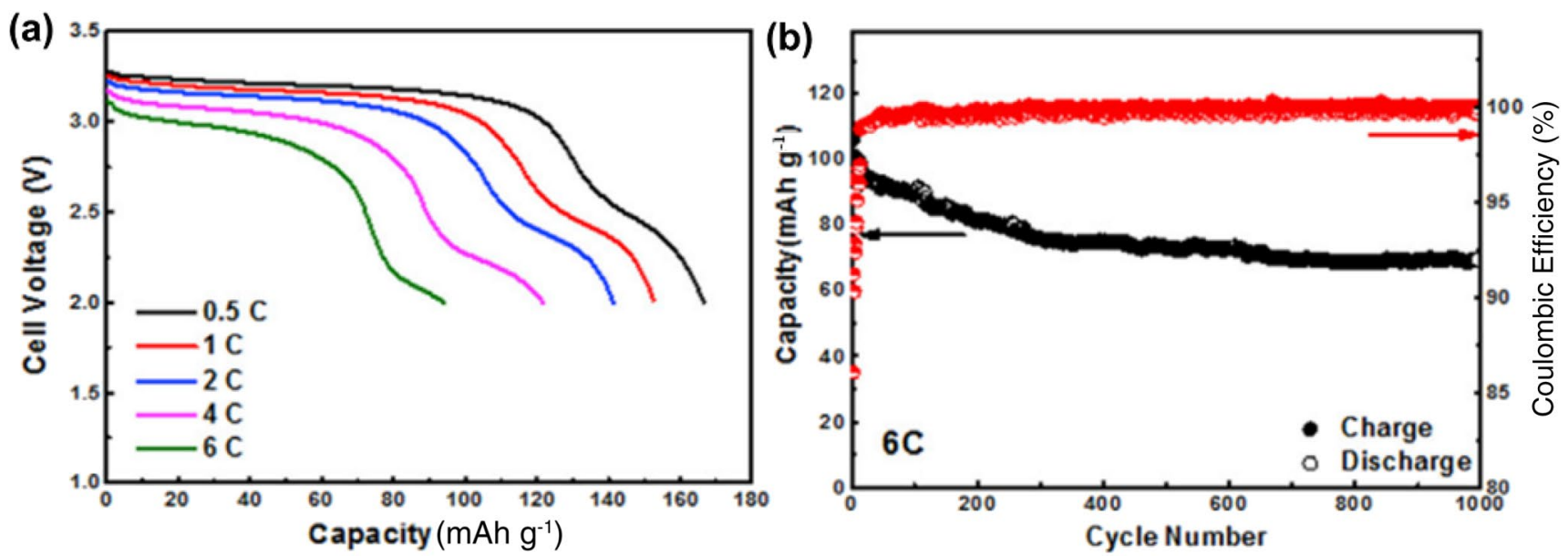

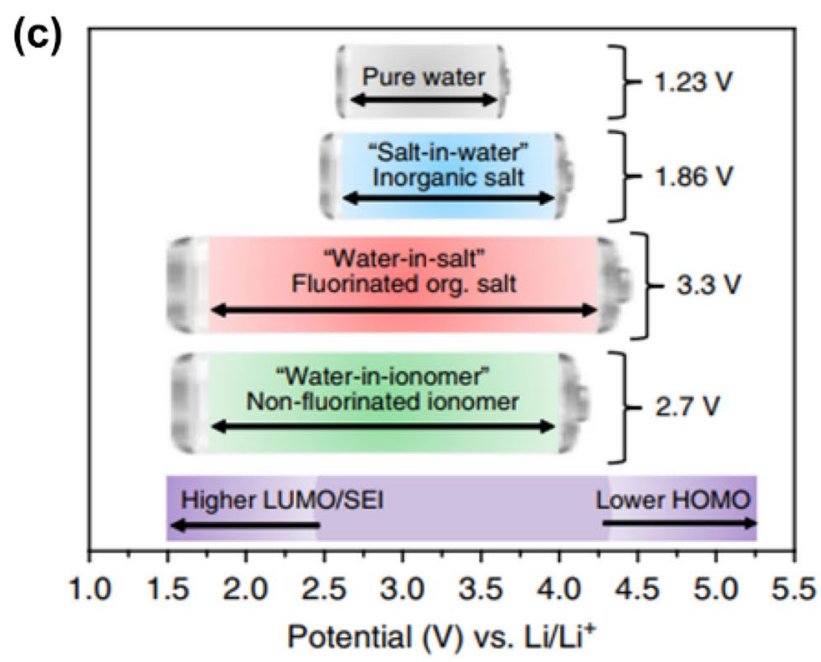

Fig. 5 a Discharge curves of the LTO-LNMO cell at various rates. b Cycling performance of LTO-LNMO full cells at 6 C. Reproduced with permission from Ref. [25]. Copyright 2018, Elsevier B. V. c Comparison of charging termination voltage of various salts

Li metal) to cycle reversibly in $21 \mathrm{~m} \mathrm{LiTFSI}+7 \mathrm{~m} \mathrm{LiOTf}$ WibS gel polymer electrolytes (GPEs) (Fig. 6a) [29]. Coupling the coated negative electrodes with different positive electrode materials, a series of 4.0 V ARLBs with high efficiency and reversibility was obtained, comparable to commercial lithium ion batteries (Fig. 6b-d). Furthermore, an ARLB with an ultrahigh energy density of $460 \mathrm{Wh} \mathrm{kg}^{-1}$ was developed by coupling an HFE gel graphite negative electrode and a conversion-intercalation-type positive electrode $\left(\operatorname{LiBr}_{0.5} \mathrm{Cl}_{0.5}\right)$-graphite (LBC-G) (Fig. 6e, f) [30].

3.1.2.2 Artificial SEI To realize a functional lithium metal electrode in an aqueous electrolyte system, a thin and compact protective interface layer or an artificial SEI can be coated on its surface. This artificial SEI should not only have high ionic conductivity, so that the electrochemical process can be carried out, but also prevent water penetration, so

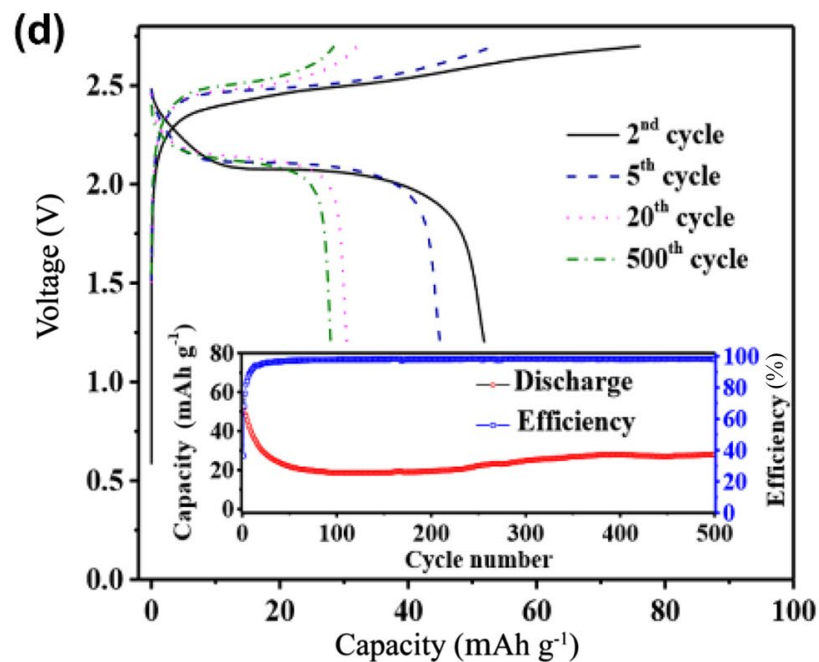

for ARLB. d Charge-discharge curves of a $\mathrm{TiO}_{2} / \mathrm{LiMn}_{2} \mathrm{O}_{4}$ cell at 5 $\mathrm{C}$; the inserted graph is the cycle performance of the battery [28]. Reproduced with permission from Ref. [28]. Copyright 2018, Nature Publishing Group

that water molecules cannot pass through, so as to avoid the reaction between water molecules and lithium metal.

Our group introduced a lithium superionic conductor (LISICON) film on a lithium metal negative electrode (Fig. 6g) [31]. In this study, LISICON served as a combined separator and solid electrolyte with room temperature ionic conductivity about $0.1 \mathrm{mS} \mathrm{cm}{ }^{-1}$. With $\mathrm{LiMn}_{2} \mathrm{O}_{4}$ as a positive electrode and $0.5 \mathrm{M} \mathrm{Li}_{2} \mathrm{SO}_{4}$ (the unit $\mathrm{M}$ is the traditional molar concentration, which is $\mathrm{mol} \mathrm{L}^{-1}$ ) as electrolytes, lithium ions are transported through the aqueous electrolyte from the positive electrode side, pass through the LISICON coating layer, and reach the lithium metal negative electrode. Thanks to the low lithium metal stripping/plating potential, the operating voltage of the resulting ARLBs thus extended to over $4 \mathrm{~V}$ with plateaus at $4.06 \mathrm{~V}$ and $3.85 \mathrm{~V}$ (Fig. $6 \mathrm{~h}$ ). Similar high-voltage ARLBs with high energy densities were also developed, based on a gel polymer membrane with 

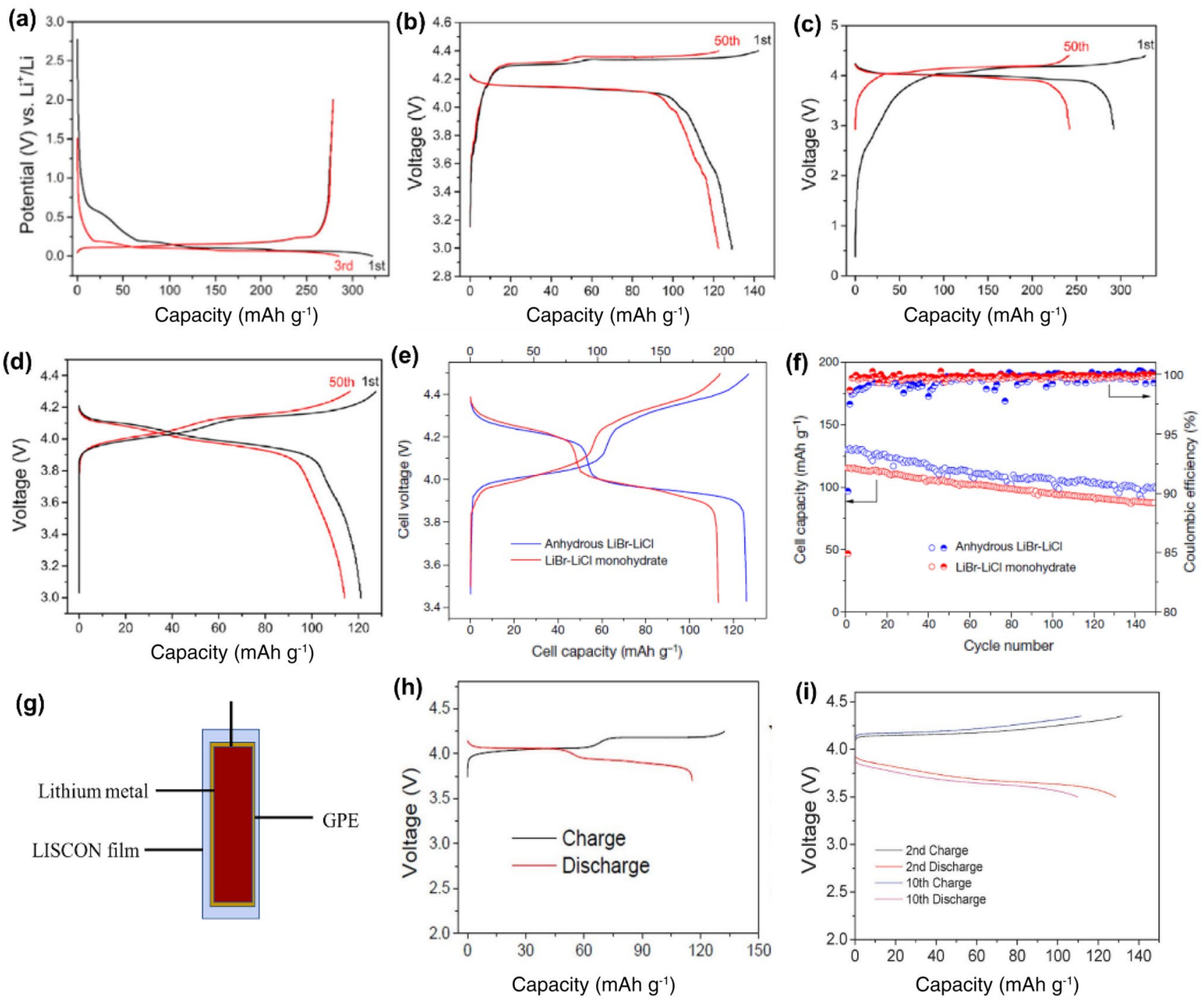

Fig. 6 a Charge-discharge curves of graphite electrodes pre-coated with LiTFSI-HFE gel. The voltage profiles of $\mathbf{b} \mathrm{Li} / \mathrm{LiVPO}_{4} \mathrm{~F}$ batteries, c graphite/LiVPO ${ }_{4} \mathrm{~F}$ batteries, and $\mathbf{d ~ L i} / \mathrm{LiMn}_{2} \mathrm{O}_{4}$ batteries at 0.3 C. e Typical charge-discharge curves (the third cycles) of graphite// $\mathrm{LiBr} / \mathrm{LiCl}$ batteries (blue) or graphite $/ / \mathrm{LiBr} / \mathrm{LiCl}$ monohydrates batteries (red). $\mathbf{f}$ Cycling stability of these full batteries during cycling. Reproduced with permission from Ref. [29]. Copyright 2017, Else-

a LISICON-coated lithium metal graphite negative electrode and $\mathrm{LiCoO} / 2 \mathrm{LiFePO}_{4}$ positive electrode [32, 33]. However, the unsatisfactory ionic conductivity of LISICON could be a challenge in achieving good rate performance. The ionic conductivity of the perovskite structured Al-substituted lithium lanthanum titanite (A-LLTO) electrode developed by Le and co-workers was increased to $0.317 \mathrm{mS} \mathrm{cm}^{-2}$, which is much higher than $0.1 \mathrm{mS} \mathrm{cm}^{-2}$ obtained with LISICON [34]. When A-LLTO was applied as an artificial SEI to a lithium metal negative electrode and this was combined with a $\mathrm{LiCoO}_{2}$ positive electrode, the resultant ARLB had an open circuit voltage of nearly $4.2 \mathrm{~V}$ and a high specific capacity of vier B. V. g Schematic illustration of the LISICON film-coated lithium metal. h Constant-current charge-discharge curve of $\mathrm{Li} / \mathrm{LiMn}_{2} \mathrm{O}_{4}$ batteries in the first cycle. Reproduced with permission from Ref. [31]. Copyright 2013, Nature Research. i Constant-current chargedischarge curves in the second and the tenth cycles of the $\mathrm{Li} / \mathrm{LiCoO}_{2}$ battery. Reproduced with permission from Ref. [32]. Copyright 2013, Royal Society of Chemistry

$164 \mathrm{mAh} \mathrm{g}^{-1}$ at $0.1 \mathrm{C}$ (Fig. 6i). Yet, its rate performance was still not comparable to that of conventional ARLBs and the problem of the low ionic conductivity of the artificial SEI still needs to be solved. Moreover, to develop an artificial SEI on a lithium metal surface, an extra layer is normally needed to prevent direct contact between lithium metal and the conductive separator layer (LISICON, A-LLTO, LATP, etc.), because the latter would otherwise be reduced by lithium metal due to their chemical instability. The extra layer usually is a gel polymer electrolyte consisting of such a thin polymer layer (PVDF/PMMA/PVDF, and PEO, etc.) saturated with organic electrolytes $\left(1 \mathrm{M} \mathrm{LiClO}_{4}\right.$ in $\left.\mathrm{EC} / \mathrm{DMC}\right)$. 
A rechargeable $\mathrm{Ni}-\mathrm{Li}$ battery system was made with $1 \mathrm{M}$ $\mathrm{LiClO}_{4}$ in ethylene carbonate/dimethyl carbonate (EC/DMC) as organic electrolytes for the metallic lithium negative electrode, and $1 \mathrm{M} \mathrm{LiOH}+1 \mathrm{M} \mathrm{KOH}$ as aqueous electrolytes for a Ni(OH) $)_{2}$ positive electrode [35]. The organic and aqueous electrolytes were separated by a thin LISICON film. The battery had a plateau voltage of $3.47 \mathrm{~V}$ and a specific capacity of $268 \mathrm{mAh} \mathrm{g}^{-1}$, resulting in a very high energy density of $935 \mathrm{Wh} \mathrm{kg}^{-1}$ based on the combined mass of active materials. This battery utilized a conversion-type NiO/CNT positive electrode and a metallic lithium negative electrode with a hybrid organic-aqueous electrolyte, separated by a lithium-ion-conductive LATP film $\left(\mathrm{Li}_{1+x+y} \mathrm{Al}_{x} \mathrm{Ti}_{2-x} \mathrm{Si}_{y} \mathrm{P}_{3-y} \mathrm{O}_{12}\right)$ [36]. It had a stable discharge plateau at $3.38 \mathrm{~V}$, but further development is needed to boost its cycling stability.

\subsubsection{Using Negative Materials with High Specific Capacity or Low Redox Potential}

An aqueous rechargeable hybrid battery (ARHB) using a $\mathrm{LiMn}_{2} \mathrm{O}_{4}$ positive electrode and a $\mathrm{Zn}$ metal negative electrode was first proposed in 2012 and operates at about $2 \mathrm{~V}$ exhibiting an acceptable energy density (50-80 $\mathrm{Wh} \mathrm{kg}^{-1}$ ) and good cycling performance $(95 \%$ capacity retention after 4000 cycles) [37]. However, its electrochemical properties such as coulombic efficiency need to be further improved. So far, the following measures have been taken: (1) surface modification and protection of positive electrode materials; (2) improvement of electrolytes; and (3) treatment of the zinc negative electrode.

Due to the low conductivity of $\mathrm{LiMn}_{2} \mathrm{O}_{4}$ and the structural change caused by Jahn-Teller distortion, the hybrid $\mathrm{Zn} /$ $\mathrm{LiMn}_{2} \mathrm{O}_{4}$ battery has poor power performance and undergoes serious capacity degradation. Since carbon can be used generally to prepare composites, it was found that the use of graphene films as an artificial SEI on the surface of $\mathrm{LiMn}_{2} \mathrm{O}_{4}$ suppresses the structural distortion of the $\mathrm{LiMn}_{2} \mathrm{O}_{4}$ effectively and greatly increases the ionic conductivity of $\mathrm{LiMn}_{2} \mathrm{O}_{4}$, thus improving the cycling and rate performance of the hybrid battery [38, 39].

Due to the limitation of the electrochemical stability window, the formation of zinc dendrites, and the corrosion of the negative zinc electrode, modification of the electrolyte is another effective way to improve the electrochemical performance of aqueous $\mathrm{Zn} / \mathrm{LiMn}_{2} \mathrm{O}_{4}$ hybrid batteries. Many additives, including thiourea (TU) [40], $\mathrm{SiO}_{2}$ [41], cyclodextrin (CD) [42], and fumed silica (FS) [43], were introduced into the electrolyte to improve the electrochemical performance of hybrid batteries. Although there are some improvements, the effects are still not satisfactory and further improvement is needed.
Recently, Wang and co-workers reported a WiS electrolyte consisting of $1 \mathrm{~m} \mathrm{Zn(TFSI)})_{2}+20 \mathrm{~m} \mathrm{LiTFSI}$, in which the zinc negative electrode is highly reversible. The hybrid $\mathrm{Zn} / \mathrm{LiMn}_{2} \mathrm{O}_{4}$ battery achieved the highest energy density when the $\mathrm{Zn} / \mathrm{LiMn}_{2} \mathrm{O}_{4}$ mass ratio was decreased to $0.25: 1$. In addition, the charge/discharge curves of different cycles for the hybrid battery are highly coincident, which shows that it has good electrochemical reversibility. At the rate of $4 \mathrm{C}$, the capacity retention after 4000 cycles was $85 \%$, with $\mathrm{CE}$ as high as $99.9 \%$, which is better than all the work on $\mathrm{Zn}-\mathrm{Li}$ batteries reported before [44]. However, the high cost of using large amounts of organic salt may hinder the application of mixed $\mathrm{Zn} / \mathrm{Li}$ ion batteries in large-scale energy storage systems.

A new "water-in-deep eutectic solvent (WiDES)" electrolyte has been reported, which can inhibit the reaction of the negative zinc electrode, reduce the corrosion and passivation of the zinc negative electrode, increase the utilization ratio of zinc, and improve the cycle life [45]. Hence, the $\mathrm{Zn} / \mathrm{LiMn}_{2} \mathrm{O}_{4}$ hybrid battery using this WiDES electrolyte exhibits excellent cycling performance.

In addition to $\mathrm{LiMn}_{2} \mathrm{O}_{4}$, other commercial positive electrode materials for lithium ion batteries, such as $\mathrm{LiFePO}_{4}, \mathrm{LiNi}_{1 / 3} \mathrm{Co}_{1 / 3} \mathrm{Mn}_{1 / 3} \mathrm{O}_{2}, \mathrm{Li}_{3} \mathrm{~V}_{2}\left(\mathrm{PO}_{4}\right)_{3}$ (LVP), and $\mathrm{LiMn}_{0.8} \mathrm{Fe}_{0.2} \mathrm{PO}_{4}$, were also studied as potential positive electrode materials for aqueous rechargeable $\mathrm{Zn}-\mathrm{Li}$ hybrid batteries. Since several articles have reviewed the relevant work in this area, we will not elaborate here. These works are summarized in Table 1 and Fig. 7a.

\subsection{Aqueous Na-Ion Batteries}

The development of aqueous sodium-ion batteries (ASIBs) is mainly due to the fact that the resources of sodium in the Earth's crust are far more abundant than those of lithium. In addition, there are many positive and negative electrode materials available for ASIBs, which show very good electrochemical performance [49-52]. There are many reviews on the research progress of electrode materials, and they are also comprehensive [3, 6, 9]. However, there are no systematic studies on how to build high-energy-density ASIBs. Table 2 and Fig. 7b provide details of the performance of ASIBs reported to date.

As mentioned above, there are two ways to improve the energy density of the aqueous battery chemistry. One is to widen the voltage window, and the other is to select the appropriate negative electrode and positive electrode materials with large potential differences and high specific capacity. 


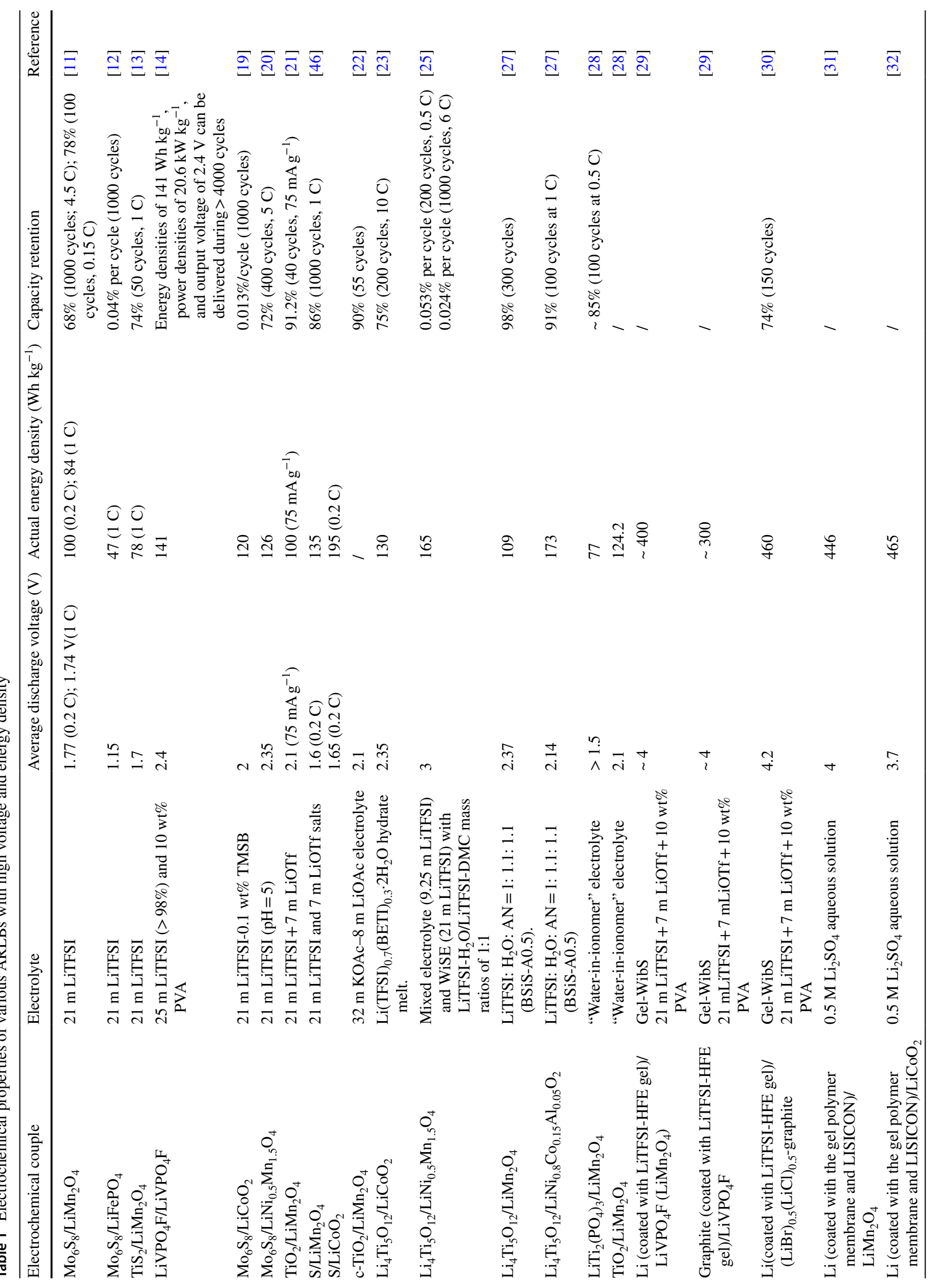




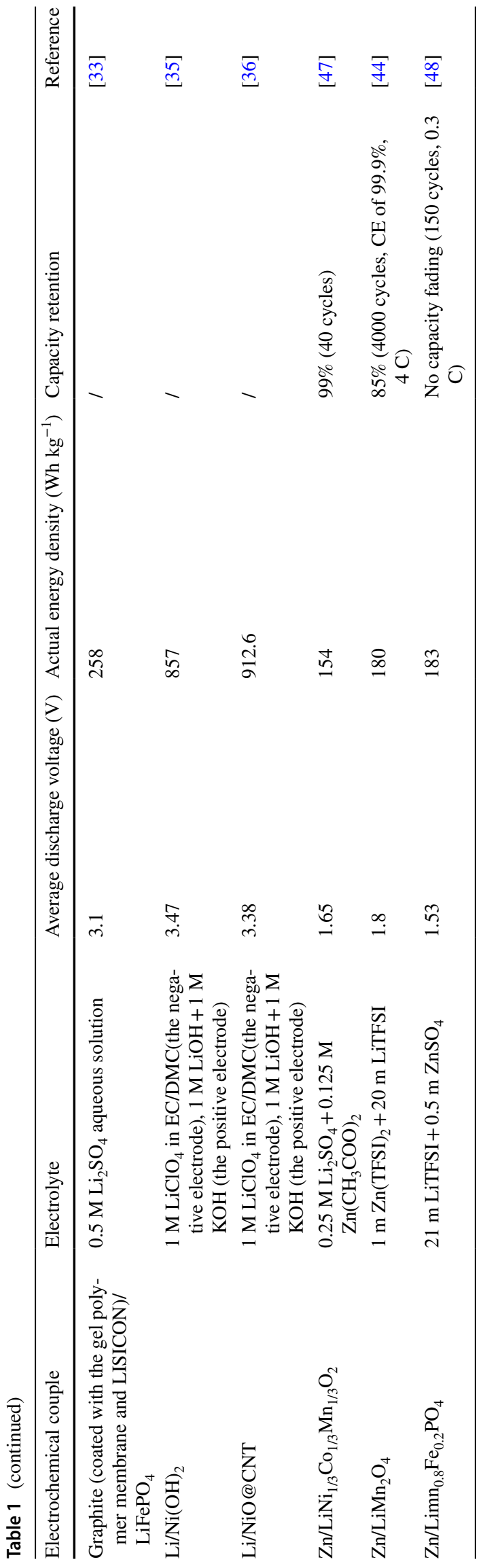

\subsubsection{Superconcentrated Electrolytes}

The development of appropriate WiS sodium electrolytes remains a major challenge for the development of sodium ion batteries in aqueous solutions, as the existing sodium electrolytes do not yet meet the requirements of high salt solubility, SEI containing chemical sources (fluorine-containing salts), and high chemical and electrochemical stability in water. Similar to the ARLBs, WiS electrolytes can also be applied to ASIBs to broaden the electrochemical window. It is found that the force between $\mathrm{Na}^{+}$and $\mathrm{TFSI}^{-}$is much stronger than that between $\mathrm{Li}^{+}$ and $\mathrm{TFSI}^{-}$, so although the aqueous solution of NaTFSI salt can only reach $9.26 \mathrm{~m}$, it can form an SEI of $\mathrm{Na}^{+}$conductivity, and the electrochemical stability window can reach $2.5 \mathrm{~V}$ [53]. Based on this electrolyte, a $\mathrm{NaTi}_{2}\left(\mathrm{PO}_{4}\right)_{3} / /$ $\mathrm{Na}_{0.66}\left[\mathrm{Mn}_{0.66} \mathrm{Ti}_{0.34}\right] \mathrm{O}_{2}$ full battery was assembled with stable cycling performance and an energy density of $31 \mathrm{Wh}$ $\mathrm{kg}^{-1}$. At room temperature, sodium trifluoride (NaOTf) and bis(trifluoromethanesulfonyl)imide (NaTFSI) solution concentrations are low $(9-10 \mathrm{~m})$ and the advantage of superconcentrated electrolytes cannot be fully exploited. Therefore, in order to further develop high-voltage ASIBs, appropriate sodium salts are needed to produce high-concentration WiS electrolytes. It is found that NaFSI has a high solubility (up to $37 \mathrm{~m}$ ) in aqueous solution and a stable electrochemical window of $2.6 \mathrm{~V}$ when the concentration is up to $35 \mathrm{~m}$. Further studies show that $\mathrm{NaTi}_{2}\left(\mathrm{PO}_{4}\right)_{3}$ cathodes and $\mathrm{Na}_{3}\left(\mathrm{VOPO}_{4}\right)_{2} \mathrm{~F}$ cathodes can be used in ASIBs with a voltage of more than $2 \mathrm{~V}$ [54]. Mixed cationic disodium mixtures can be used to prepare electrolytes at higher concentrations, such as $9 \mathrm{~m} \mathrm{NaOTf}+8 \mathrm{~m} \mathrm{KOTf}$ and $22 \mathrm{~m} \mathrm{KOTf}+4 \mathrm{~m} \mathrm{NaOTf}$. However, the presence of multiple cations may cause the mixed cations to be embedded in the electrode material, affecting the performance of the cell. To address this problem, the researchers developed a new class of interaction-assisted WiS electrolytes containing tetraethylammonium trifluoride (TEAOTf) salts that, because of the large ionic radius of $\mathrm{TEA}^{+}$, are difficult to be intercalated into most electrode materials [including Prussian Blue analogue (PBA)], thereby avoiding multi-cation co-intercalation in the cyclic process [55]. This interaction-assisted WiS electrolyte has a concentration of up to $31 \mathrm{~m}$ ( $9 \mathrm{~m} \mathrm{NaOTf}-22 \mathrm{~m}$ TEAOTf $)$ and an electrochemical stabilization window of up to $3.3 \mathrm{~V}$ (Fig. 8a). A Na ${ }_{1.88} \mathrm{Mn}\left[\mathrm{Fe}(\mathrm{CN})_{6}\right]_{0.97} \cdot 1.35 \mathrm{H}_{2} \mathrm{O} / / \mathrm{Na}$-based IC-WiS//NaTiOPO ${ }_{4}$ full battery with high cutoff voltage $(2.5 \mathrm{~V})$ and high energy density of $71 \mathrm{Wh} \mathrm{kg}^{-1}$ was established, which showed outstanding cycling stability at both low and high rates (Fig. 8b-e).

Theoretical calculations have shown that the deposition of the $\mathrm{Al}_{2} \mathrm{O}_{3}$ film on $\mathrm{Al}$ or the $\mathrm{TiO}_{2}$ film on Ti can increase the energy barrier of water splitting (Fig. 9a) [56]. 

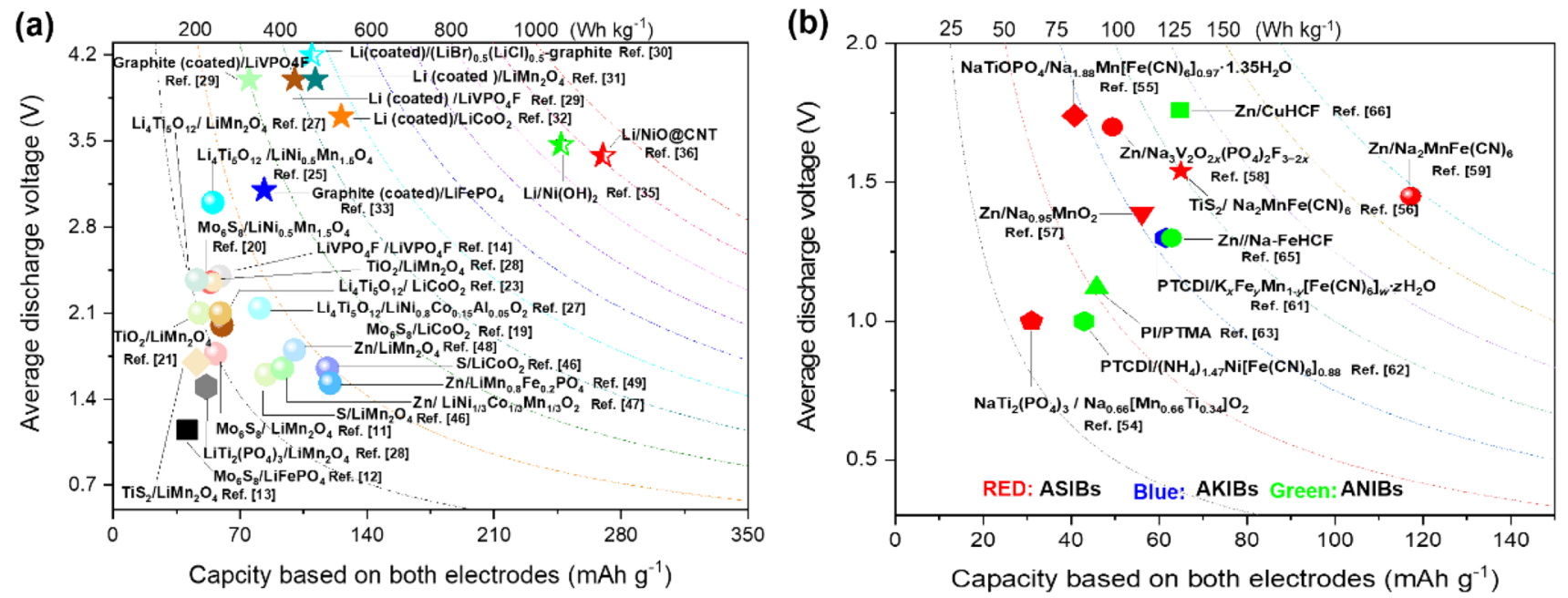

Fig. 7 Energy density and average discharge capacity of various a ARLBs, b ASIBs, AKIBS and ANIBs with high voltage and energy density

Table 2 Electrochemical properties for various ASIBs, AKIBS, and ANIBs with high voltage and energy density

\begin{tabular}{|c|c|c|c|c|c|}
\hline Electrochemical couple & Electrolyte & $\begin{array}{l}\text { Average dis- } \\
\text { charge voltage } \\
\text { (V) }\end{array}$ & $\begin{array}{l}\text { Actual energy } \\
\text { density (Wh } \\
\left.\mathrm{kg}^{-1}\right)\end{array}$ & Capacity retention & Reference \\
\hline \multicolumn{6}{|l|}{ ASIBs } \\
\hline $\begin{array}{l}\mathrm{NaTi}_{2}\left(\mathrm{PO}_{4}\right)_{3} / \mathrm{Na}_{0.66}\left(\mathrm{Mn}_{0.66} \mathrm{Ti}_{0.34}\right) \\
\mathrm{O}_{2}\end{array}$ & $9.26 \mathrm{~m} \mathrm{NaCF}_{3} \mathrm{SO}_{3}$ & 1.0 & 31 & $92.7 \%$ (1200 cycles at $1 \mathrm{C})$ & {$[53]$} \\
\hline $\begin{array}{l}\mathrm{NaTiOPO}_{4} / \\
\quad \mathrm{Na}_{1.88} \mathrm{Mn}\left[\mathrm{Fe}(\mathrm{CN})_{6}\right]_{0.97} \cdot 1.35 \mathrm{H}_{2} \mathrm{O}\end{array}$ & $9 \mathrm{~m} \mathrm{NaOTF}+22 \mathrm{~m}$ TEAOTf & 1.74 & 71 & $\begin{array}{l}90 \%(200 \text { cycles at } 0.25 \mathrm{C}) \\
76 \%(800 \text { cycles at } 1 \mathrm{C})\end{array}$ & {$[55]$} \\
\hline $\mathrm{TiS}_{2} / \mathrm{Na}_{2} \mathrm{MnFe}(\mathrm{CN})_{6}$ & $15 \mathrm{~m} \mathrm{NaClO}_{4}$ aqueous solution & 1.54 & 100 & $90 \%$ ( 150 cycles $)$ & {$[56]$} \\
\hline $\mathrm{Zn} / \mathrm{Na}_{0.95} \mathrm{MnO}_{2}$ & $\begin{array}{l}0.5 \mathrm{M} \mathrm{Zn}\left(\mathrm{CH}_{3} \mathrm{COO}\right)_{2}+0.5 \mathrm{M} \\
\mathrm{CH}_{3} \mathrm{COONa}\end{array}$ & 1.39 & 78 & $92 \%(1000$ cycles at $4 \mathrm{C})$ & {$[57]$} \\
\hline $\mathrm{Zn} / \mathrm{Na}_{3} \mathrm{~V}_{2} \mathrm{O}_{2 x}\left(\mathrm{PO}_{4}\right)_{2} \mathrm{~F}_{3-2 x}$ & $10 \mathrm{~m} \mathrm{NaClO}_{4}$ & 1.7 & 84 & $75 \%$ (400 cycles) & {$[58]$} \\
\hline $\mathrm{Zn} / \mathrm{Na}_{2} \mathrm{MnFe}(\mathrm{CN})_{6}$ & $\begin{array}{l}1 \mathrm{M} \mathrm{Na}_{2} \mathrm{SO}_{4} \text { and } \mathrm{ZnSO}_{4} \text { hybrid } \\
\text { electrolytes + SDS }\end{array}$ & 1.45 & 170 & $75 \%$ (2000 cycles) & {$[59]$} \\
\hline \multicolumn{6}{|l|}{ AKIBs } \\
\hline $\begin{array}{l}\text { PTCDI/ } \\
\quad \mathrm{K}_{x} \mathrm{Fe}_{y} \mathrm{Mn}_{1-y}\left[\mathrm{Fe}(\mathrm{CN})_{6}\right]_{w} \cdot z \mathrm{H}_{2} \mathrm{O}\end{array}$ & $22 \mathrm{~m} \mathrm{KCF}_{3} \mathrm{SO}_{3} \mathrm{WiS}$ electrolyte & 1.3 & 80 & $73 \%$ (2000 cycles) & {$[60]$} \\
\hline \multicolumn{6}{|l|}{ ANIBs } \\
\hline $\mathrm{PTCDI} /\left(\mathrm{NH}_{4}\right)_{1.47} \mathrm{Ni}\left[\mathrm{Fe}(\mathrm{CN})_{6}\right]_{0.88}$ & $\begin{array}{l}1.0 \mathrm{M}\left(\mathrm{NH}_{4}\right)_{2} \mathrm{SO}_{4} \text { aqueous } \\
\text { solution }\end{array}$ & 1 & 43 & $67 \%$ (1000 cycles $)$ & {$[61]$} \\
\hline PI/PTMA & $\begin{array}{l}1.0 \mathrm{M}\left(\mathrm{NH}_{4}\right)_{2} \mathrm{SO}_{4} \text { aqueous } \\
\text { solution }\end{array}$ & 1.12 & 51.3 & $86.4 \%$ (10000 cycles) & {$[62]$} \\
\hline $\mathrm{Zn} / \mathrm{Na}-\mathrm{FeHCF}$ & $\begin{array}{l}1 \mathrm{M}\left(\mathrm{NH}_{4}\right)_{2} \mathrm{SO}_{4}+20 \mathrm{mM} \\
\mathrm{ZnSO}_{4}\end{array}$ & 1.3 & 81.7 & $92.1 \%$ (2000 cycles) & {$[64]$} \\
\hline $\mathrm{Zn} / \mathrm{CuHCF}$ & $1 \mathrm{M}\left(\mathrm{NH}_{4}\right)_{2} \mathrm{SO}_{4}+0.1 \mathrm{M} \mathrm{ZnSO}_{4}$ & $\sim 1.76$ & 114 & $72.8 \%$ (1000 cycles) & [65] \\
\hline
\end{tabular}

At the thicknesses of about $3 \mathrm{~nm}$ and $5 \mathrm{~nm}$, respectively, for the $\mathrm{Al}_{2} \mathrm{O}_{3}$ and $\mathrm{TiO}_{2}$ films, the electrochemical stability window is widened to $3.5 \mathrm{~V}$ when the metals covered by these oxide films are used as collectors and $15 \mathrm{~m} \mathrm{NaClO}_{4}$ aqueous solution is used as the electrolyte (Fig. 13b). Moreover, in concentrated electrolytes $\left(15 \mathrm{~m} \mathrm{NaClO}_{4}\right)$, a dense electrode-electrolyte interphase is formed on
$\mathrm{TiS}_{2}$ surfaces. Therefore, $\mathrm{TiS}_{2}$, which has a low reaction potential, was demonstrated for the first time as negative electrode material in an aqueous battery (Fig. 9c). The resultant ASIB using $\mathrm{TiS}_{2}$ as the negative electrode and MFCN (sodium manganese hexacyanoferrate) as the positive electrode delivers an energy density of $100 \mathrm{Wh} \mathrm{kg}^{-1}$ with an open circuit voltage (OCV) of up to $2.6 \mathrm{~V}$ and was 

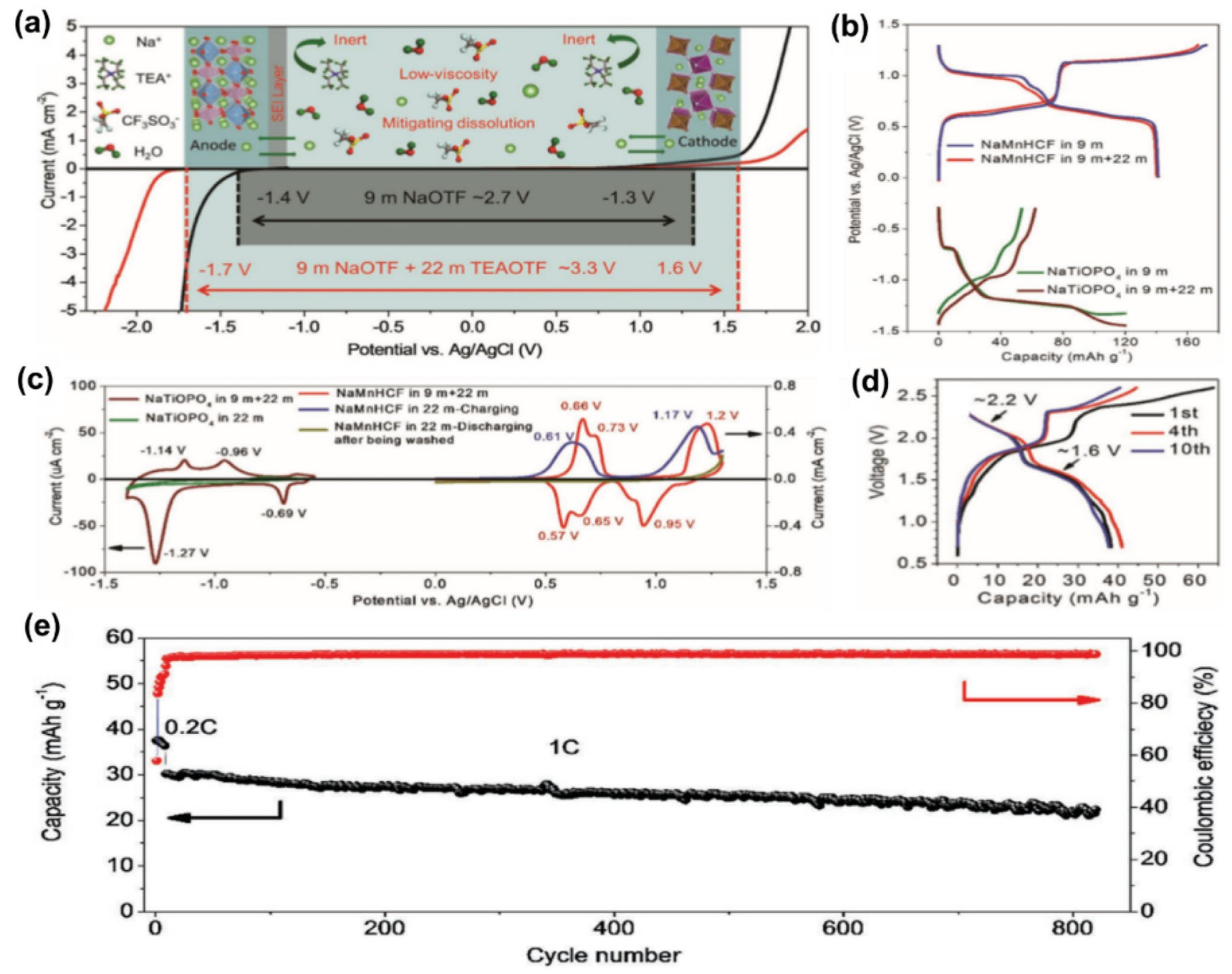

Fig. 8 a Electrochemical stability window of $9 \mathrm{~mol} \mathrm{~kg}^{-1} \mathrm{NaOTf}$ electrolytes and $\mathrm{Na}$ IC-WiS electrolytes $(9 \mathrm{~m} \mathrm{NaOTf}+22 \mathrm{~m}$ TEAOTf $)$ at the scanning rate of $10 \mathrm{mV} \mathrm{s}^{-1}$, in which $\mathrm{Ti}$ and $\mathrm{Al}$ are used as the positive and the negative collectors, respectively. b The firstcycle charge-discharge curves of NaMnHCF (1 C) positive electrodes and $\mathrm{NaTiOPO}_{4}(0.2 \mathrm{C})$ negative electrodes in $9 \mathrm{~m} \mathrm{NaOTf}$ and $9 \mathrm{~m}$ NaOTf +22 mTEAOTf electrolytes, respectively. c CV curves of

cycled at nearly $100 \%$ coulombic efficiency for up to 1000 cycles (Fig. 9d).

\subsubsection{Zn-Na Hybrid Batteries}

Because sodium salts are less expensive than lithium salts, an aqueous $\mathrm{Zn}-\mathrm{Na}$ hybrid ion battery is a very promising prospect to replace aqueous $\mathrm{Zn}-\mathrm{Li}$ hybrid batteries and has become an attractive sustainable energy storage device. The first aqueous $\mathrm{Zn}-\mathrm{Na}$ hybrid ion battery was reported by our group and consisted of rod-like $\mathrm{Na}_{0.95} \mathrm{MnO}_{2}$ positive electrode material and a $\mathrm{Zn}$ metal negative electrode, which
$\mathrm{NaTiOPO}_{4}$ negative electrodes and $\mathrm{NaMnHCF}$ positive electrodes at $1 \mathrm{mV} \mathrm{s}^{-1}$ in $22 \mathrm{~m}$ TEAOTf and $9 \mathrm{~m} \mathrm{NaOTf}+22 \mathrm{~m}$ TEAOTf electrolytes, respectively. d Charge-discharge curves of NaMnHCF// $\mathrm{NaTiOPO}_{4}$ batteries in the first, the fourth, and the tenth cycles. e Cycling performance of the $\mathrm{NaMnHCF} / / \mathrm{NaTiOPO}_{4}$ battery at $1 \mathrm{C}$ [55]. Reproduced with permission from Ref. [55]. Copyright 2019, Wiley-VCH

exhibited an average discharge voltage of $1.4 \mathrm{~V}$ and energy density of up to $78 \mathrm{Wh} \mathrm{kg}^{-1}$ (Fig. 10a, b) [57].

$\mathrm{Na}^{+}$-ion superionic conductor (NASICON)-structured $\mathrm{Na}_{3} \mathrm{~V}_{2}\left(\mathrm{PO}_{4}\right)_{3}$ (NVP) with a high theoretical capacity of $118 \mathrm{mAh} \mathrm{g}^{-1}$ has become a new potential candidate as a positive electrode for aqueous $\mathrm{Na}-\mathrm{Zn}$ hybrid batteries. The Zn-NVP hybrid battery can deliver an energy density of 67 $\mathrm{Wh} \mathrm{kg}^{-1}$. However, the capacity of $\mathrm{Na}_{3} \mathrm{~V}_{2}\left(\mathrm{PO}_{4}\right)_{3}$ in $\mathrm{Zn}-\mathrm{Na}$ hybrid aqueous rechargeable batteries remains a significant challenge. Apart from NVP/C positive electrode materials, other polyanion compounds [such as carbon-coated $\mathrm{Na}_{3} \mathrm{~V}_{2}\left(\mathrm{PO}_{4}\right)_{2} \mathrm{~F}_{3}$ ] have been considered as positive electrodes to further improve the voltage of aqueous $\mathrm{Na}-\mathrm{Zn}$ hybrid 


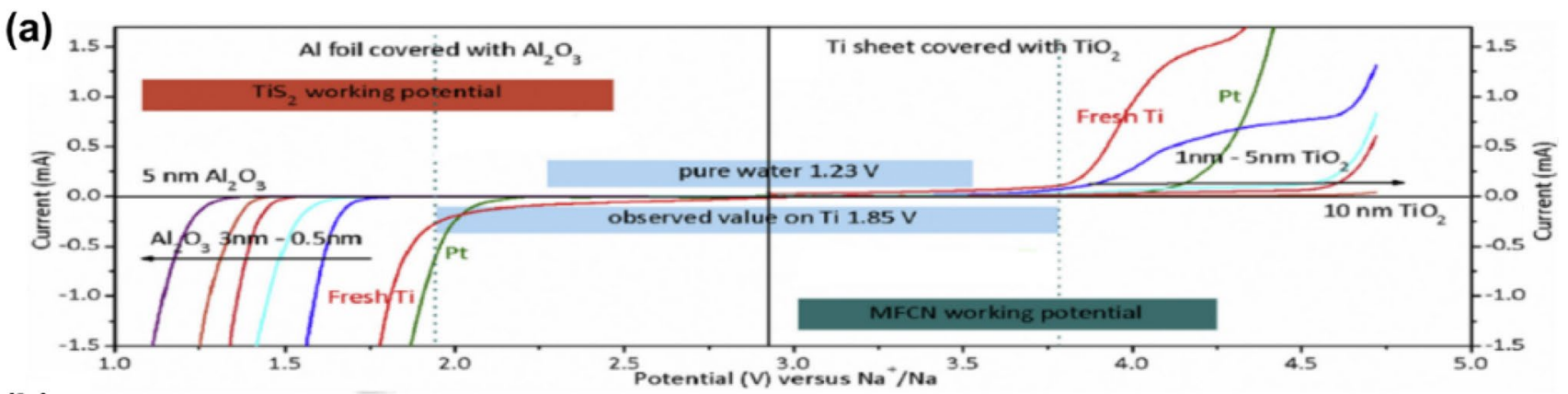

(b)

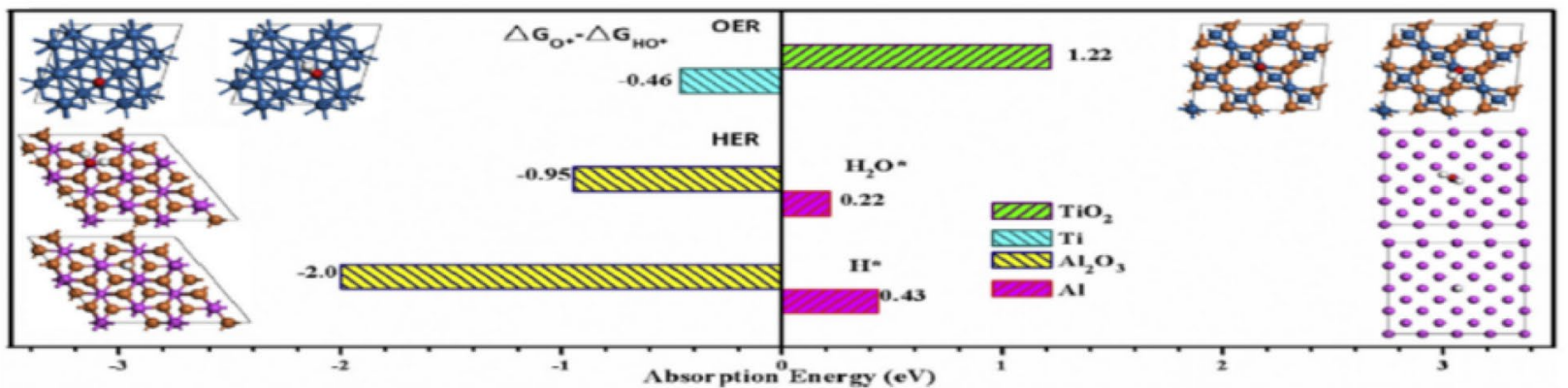

(c)

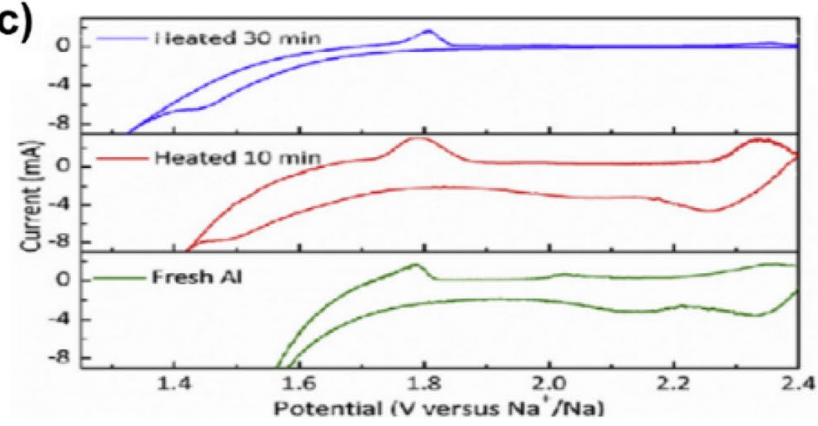

Fig. 9 a Electrochemical stability window of $15 \mathrm{~m} \mathrm{NaClO}_{4}$ aqueous solution when $\mathrm{Pt}, \mathrm{Ti}, \mathrm{Al}$ coated with $\mathrm{Al}_{2} \mathrm{O}_{3}$ with different thicknesses and $\mathrm{Ti}$ coated with $\mathrm{TiO}_{2}$ with different thicknesses are used as current collectors. $\mathbf{b}$ The adsorption energy of $\mathrm{O}^{*}$ and $\mathrm{HO}^{*}$ on the surface of $\mathrm{Ti}$ or $\mathrm{TiO}_{2}$ and $\mathrm{H}_{2} \mathrm{O}^{*}$ and $\mathrm{H}^{*}$ on the surface of $\mathrm{Al}$ or $\mathrm{Al}_{2} \mathrm{O}_{3}$, respec-

batteries [58]. The hybrid $\mathrm{Zn}-\mathrm{Na}_{3} \mathrm{~V}_{2} \mathrm{O}_{2 x}\left(\mathrm{PO}_{4}\right)_{2} \mathrm{~F}_{3-2 x}$ battery possesses a high output voltage of $1.7 \mathrm{~V}$ and a high energy density of $84 \mathrm{Wh} \mathrm{kg}^{-1}$.

Prussian blue and its analogues are the most attractive materials for aqueous-based hybrid batteries due to their large channel and open framework structure, which facilitates the rapid diffusion of ions. The working voltage of the aqueous $\mathrm{Na}-\mathrm{Zn}$ hybrid batteries is high, and the cycle life of the battery is greatly affected by the side reaction of hydrogen evolution or oxygen evolution. It has been found that the electrochemical stability window of the electrolyte can be increased from 1.8 to $2.55 \mathrm{~V}$ by adding surfactants into the mixed electrolyte (Fig. 10a, b) [59]. Through density functional theory simulation, it is found that the energy barrier of water molecules passing through the SDS adsorption layer

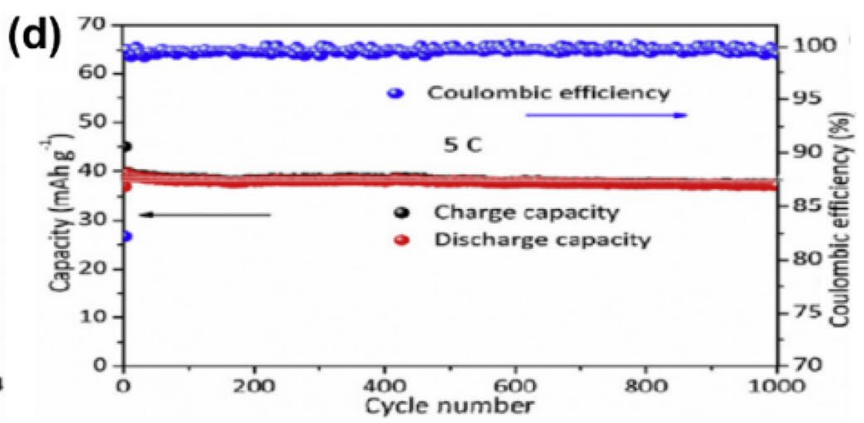

tively. c CV curve of $\mathrm{TiS}_{2}$ negative electrodes when using aluminum foil with variable heat treatment time as current collectors. d Cycling performance of $\mathrm{TiS}_{2} / \mathrm{MFCN}$ batteries at $5 \mathrm{C}$ [56]. Reproduced with permission from Ref. [56]. Copyright 2019, Elsevier B. V.

is higher than that of sodium ions passing through the SDS adsorption layer. Sodium ions are easier to pass through the hydrophobic layer than water molecules, thus inhibiting the decomposition of water, thus improving the electrochemical stability window of the electrolyte. Based on this electrolyte, a water-based rechargeable mixed zinc sodium ion battery with $\mathrm{Na}_{2} \mathrm{MnFe}(\mathrm{CN})_{6}$ nanocubes as cathodes and zincs sheets as negative electrodes was successfully assembled. The battery has a working voltage of up to $2 \mathrm{~V}$ and a high energy density of $170 \mathrm{Wh} \mathrm{kg}^{-1}$ (Fig. 10c, d). The design strategy of improving the electrochemical stability window of electrolytes by adding additives achieves the efficacy close to that of WiS electrolytes, and the cost is low. It provides new 

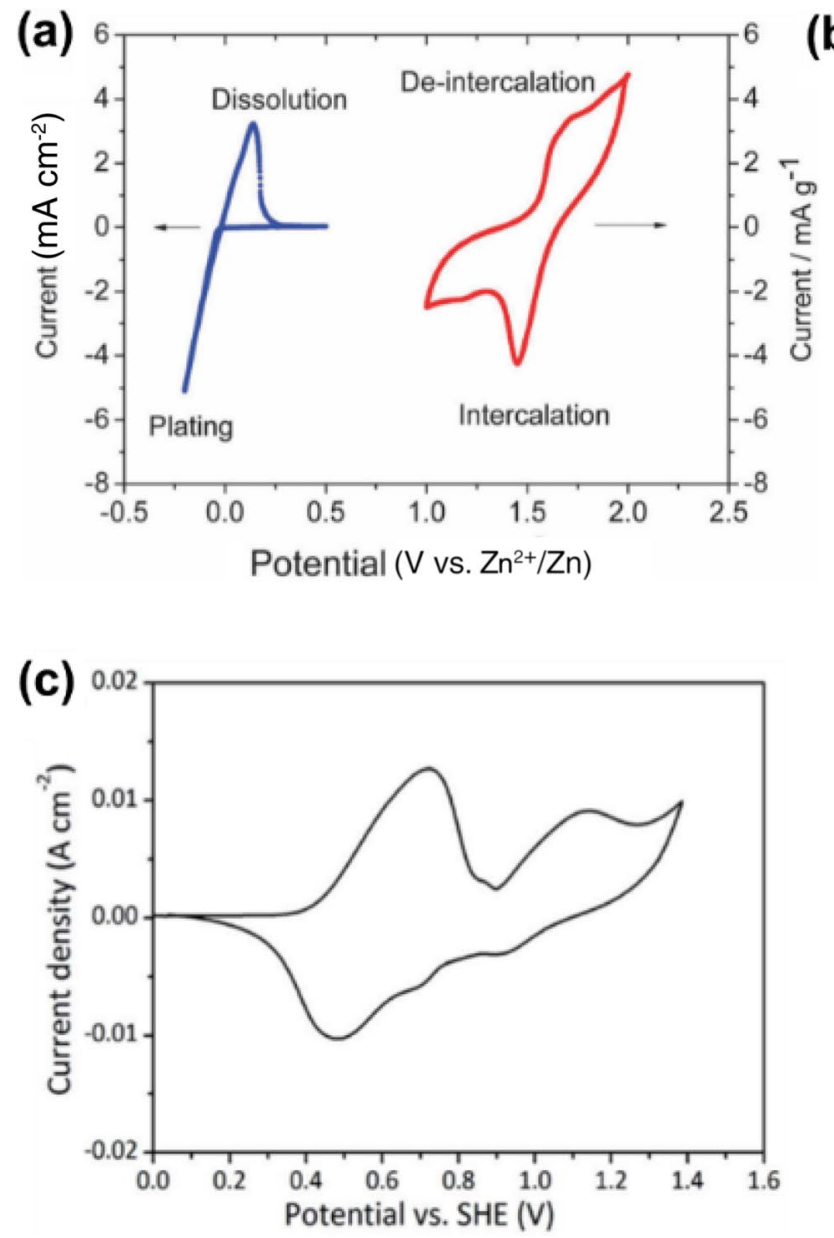

Fig. 10 a $\mathrm{CV}$ curves of $\mathrm{Zn}$ and $\mathrm{Na}_{0.95} \mathrm{MnO}_{2}$ in $0.5 \mathrm{M}$ $\mathrm{Zn}\left(\mathrm{CH}_{3} \mathrm{COO}\right)_{2}+0.5 \mathrm{M} \mathrm{CH}_{3} \mathrm{COONa}$ aqueous solution $\left(0.5 \mathrm{mV} \mathrm{s}^{-1}\right)$. b Cycling performance of the $\mathrm{Zn} / / \mathrm{Na}_{0.95} \mathrm{MnO}_{2}$ ASIB at $4 \mathrm{C}$ rates [56]. Reproduced with permission from Ref. [57]. Copyright 2014, Royal Society of Chemistry. c CV curve of $\mathrm{Na}_{2} \mathrm{MnFe}(\mathrm{CN})_{6}$ positive elec-

enlightenment for the further development of low-cost and high-voltage aqueous solution batteries in the future.

\subsection{Aqueous K-Ion Batteries (AKIBs)}

The high ionization potential and the large ion radius $(0.138 \mathrm{~nm})$ of $\mathrm{K}$ are the main reasons for the limited development of high-performance AKIBs electrode materials. Up to now, the most promising positive electrode materials for AKIBs are Prussian Blue analogues (PBAs).

Among various positive electrode materials, the PBA has a broad application prospect because of its stability in water, easy preparation, and excellent electrochemical performance. A variety of PBA positive electrodes have been reported in AKIBs, but few materials have completely satisfactory properties. Due to the lack of candidate materials with suitable redox potentials, few promising materials have
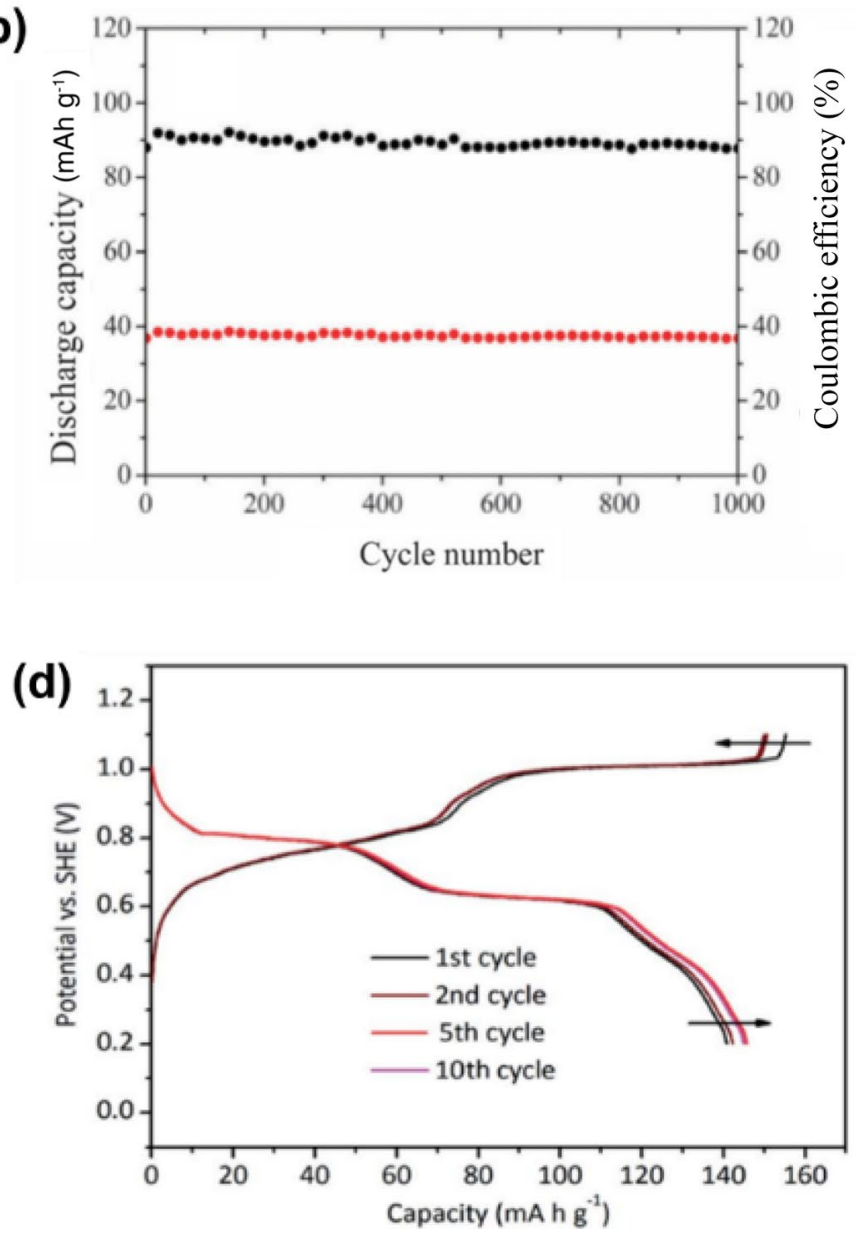

trodes in electrolytes with added SDS $\left(5 \mathrm{mV} \mathrm{s}^{-1}\right)$. d Charge/discharge curves of $\mathrm{Na}_{2} \mathrm{MnFe}(\mathrm{CN})_{6}$ positive electrodes in SDS-added electrolytes (0.5 C) [59]. Reproduced with permission from Ref. [59]. Copyright 2017, Royal Society of Chemistry

been reported as the negative electrode material of AKIBs. The previously reported WiS electrolyte based on potassium acetate has a wide electrochemical stability window, but the $\mathrm{pH}$ of the electrolyte is slightly alkaline $(\mathrm{pH}=9)$, which is not suitable for positive electrode materials. Therefore, it is of great significance to explore a new type of electrodes with better compatibility with a $\mathrm{K}^{+}$-based WiS electrolyte. Overall, due to the limitations of electrodes and electrolytes, there are few reports about the variety of AKIBs. Recently, a full AKIB was fabricated, and it consisted of a Fe-substituted Mn-rich PBA $\left\{\mathrm{K}_{x} \mathrm{Fe}_{y} \mathrm{Mn}_{1-y}\left[\mathrm{Fe}(\mathrm{CN})_{6}\right]_{w} \cdot z \mathrm{H}_{2} \mathrm{O}\right\}$ positive electrode, an organic 3,4,9,10-perylenetetracarboxylic diimide (PTCDI) negative electrode, and a $22 \mathrm{~m} \mathrm{KCF}_{3} \mathrm{SO}_{3} \mathrm{WiS}$ electrolyte [60]. The $22 \mathrm{~m} \mathrm{KCF}_{3} \mathrm{SO}_{3} \mathrm{WiS}$ electrolyte has a wide voltage window of $3 \mathrm{~V}$, which not only inhibits the dissolution of both positive electrodes and negative electrodes during cycling, ensuring good cycling stability of the full 


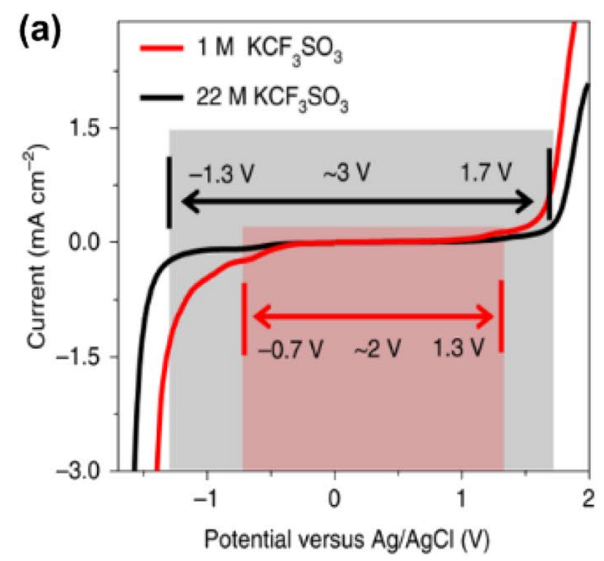

Fig. 11 a Electrochemical stability window of $1 \mathrm{~m}$ and $22 \mathrm{~m}$ $\mathrm{KCF}_{3} \mathrm{SO}_{3}$ electrolytes at a scan rate of $10 \mathrm{mV} \mathrm{s}^{-1}$ when using Ti mesh as the current collector. b Cycling performance of PTCDI/

battery, but also enables the full battery to operate above $2 \mathrm{~V}$ at the low rate of $0.1 \mathrm{C}$ (Fig. 11a). Moreover, both positive and negative electrodes have high capacity, high rate performance, and good cycling stability. Therefore, the full battery achieved a high energy density of $80 \mathrm{Wh} \mathrm{kg}^{-1}$ and excellent cycling stability, with $73 \%$ capacity retention over 2000 cycles at $4 \mathrm{C}$ (Fig. 11b). Although this battery system has many advantages, there are still many areas to be further improved to promote its practical application. First of all, for electrode materials, although $\mathrm{Fe}$ is the best choice to replace the Mn rich PBA positive electrode, the negative electrode materials should be optimized with high capacity and low redox potential to further increase the energy density of AKIBs. In addition, to reduce the cost of the whole battery and at the same time to ensure its superior high-power performance and high working voltage, less expensive salts with high solubility should be explored such as lowering the electrolyte concentration by changing the interface and using mixed water/nonaqueous solvents.

\subsection{Aqueous Ammonium-Ion Batteries (ANIBs)}

The aqueous ammonium-ion battery (ANIB, ANIB is used to distinguish from aqueous aluminum ion batteries) is a new type of battery using $\mathrm{NH}_{4}^{+}$as charge carriers. Compared to other charge carriers (including $\mathrm{Li}^{+}, \mathrm{Na}^{+}, \mathrm{K}^{+}$, $\mathrm{Mg}^{2+}, \mathrm{Ca}^{2+}, \mathrm{Al}^{3+}$, and $\left.\mathrm{Zn}^{2+}\right), \mathrm{NH}_{4}^{+}$is a sustainable charge carrier, because $\mathrm{NH}_{4}^{+}$can be synthesized from hydrogen and nitrogen, which are essentially unlimited on the Earth. Although the ion radius of $\mathrm{NH}_{4}{ }^{+}$is very large $(1.48 \AA$, $\mathrm{CN}=6$ ), its hydrated ion size is the smallest, which is conducive to its rapid diffusion in aqueous electrolytes. In recent years, some pioneering work on the topological chemistry of $\mathrm{NH}_{4}^{+}$ions in half-cell electrodes has been
$\mathrm{K}_{x} \mathrm{Fe}_{y} \mathrm{Mn}_{1-y}\left[\mathrm{Fe}(\mathrm{CN})_{6}\right]_{w} \cdot z \mathrm{H}_{2} \mathrm{O}$ full cells at $4 \mathrm{C}$. Reproduced with permission from Ref. [60]. Copyright 2019, Nature Publishing Group

reported. Table 2 and Fig. 7b provide details of the performance of AAIBs reported to date.

It has been found that the Prussian Blue analogue $\mathrm{KM}\left[\mathrm{Fe}(\mathrm{CN})_{6}\right](\mathrm{M}=\mathrm{Ni}$ and $\mathrm{Cu})$ can reversibly intercalate and deintercalate $\mathrm{NH}_{4}^{+}$ions. Moreover, the intercalation potential of $\mathrm{NH}_{4}^{+}$is higher than those of $\mathrm{Na}^{+}$and $\mathrm{K}^{+}$ions, and the cycling performance of $\mathrm{KM}\left[\mathrm{Fe}(\mathrm{CN})_{6}\right](\mathrm{M}=\mathrm{Ni}$ and $\mathrm{Cu}$ ) in $\mathrm{NH}_{4}^{+}$aqueous electrolytes is comparable to samples in $\mathrm{Na}^{+}$and $\mathrm{K}^{+}$aqueous electrolytes. The first $\mathrm{NH}_{4}^{+}$ ion battery was reported by $\mathrm{Wu}$ and coworkers in 2017, with $\left(\mathrm{NH}_{4}\right)_{1.47} \mathrm{Ni}\left[\mathrm{Fe}(\mathrm{CN})_{6}\right]_{0.88}$ as the positive electrode, and PTCDI (3,4,9,10-perylenetetracarboxylic diimide) as the negative electrode (Fig. 12) [61]. This battery had an average working voltage of only $1.0 \mathrm{~V}$ and a low energy density of $43 \mathrm{Wh} \mathrm{kg}^{-1}$. An aqueous ammonium dual-ion battery with maximum operating voltage of $1.9 \mathrm{~V}$ and a high energy density of $51.3 \mathrm{Wh} \mathrm{kg}^{-1}$ was constructed by using organic polymer electrodes [62]. However, the voltage and the energy density of these batteries were limited and need further improvement. This can be achieved in two ways: (a) widening the electrochemical stability window of the electrolyte and (b) selecting negative electrode materials with higher specific capacities and lower redox potentials because all the reported embedded $\mathrm{NH}_{4}^{+}$positive electrodes have higher redox potentials.

As is the case with ARLBs, WiS electrolytes can be used to widen the voltage window. Recently, a new WiS electrolyte $\left(25 \mathrm{~m} \mathrm{CH}_{3} \mathrm{COONH}_{4}\right)$ was used in an AAIB, which has a potential window of $2.95 \mathrm{~V}$ (Fig. 12d) [63]. An amorphous titanic acid $\left[\mathrm{TiO}_{1.85}(\mathrm{OH})_{0.30} \cdot 0.28 \mathrm{H}_{2} \mathrm{O}\right]$ was applied as negative electrodes with a relatively negative redox potential and a reversible capacity of $70 \mathrm{mAh} \mathrm{g}^{-1}$. It exhibited good rate performance and stable cycling performance (Fig. 12e). Using zinc metal as negative electrode material to assemble a $\mathrm{Zn}^{2+} / \mathrm{NH}_{4}^{+}$hybrid ion battery is also an effective way to 

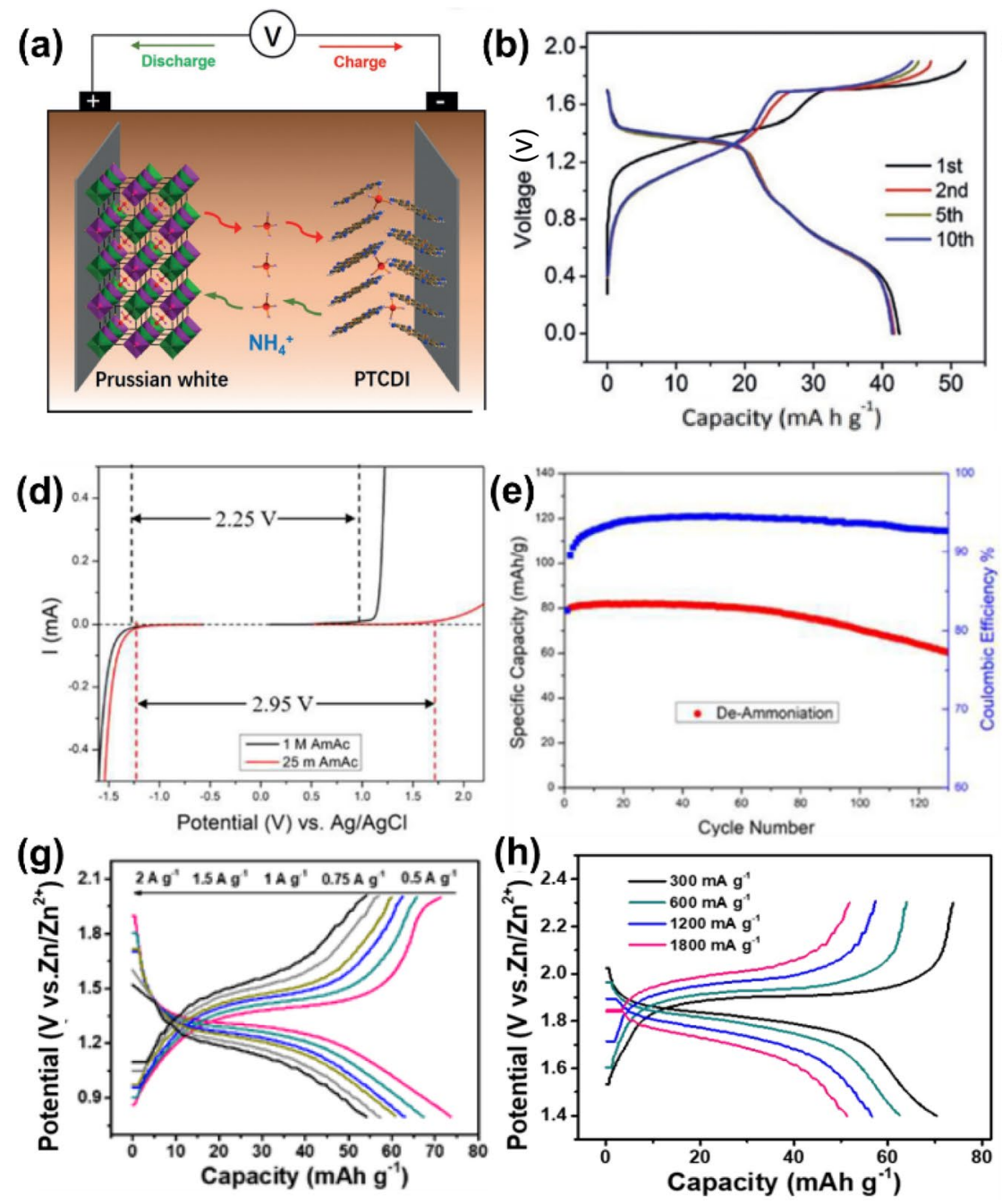
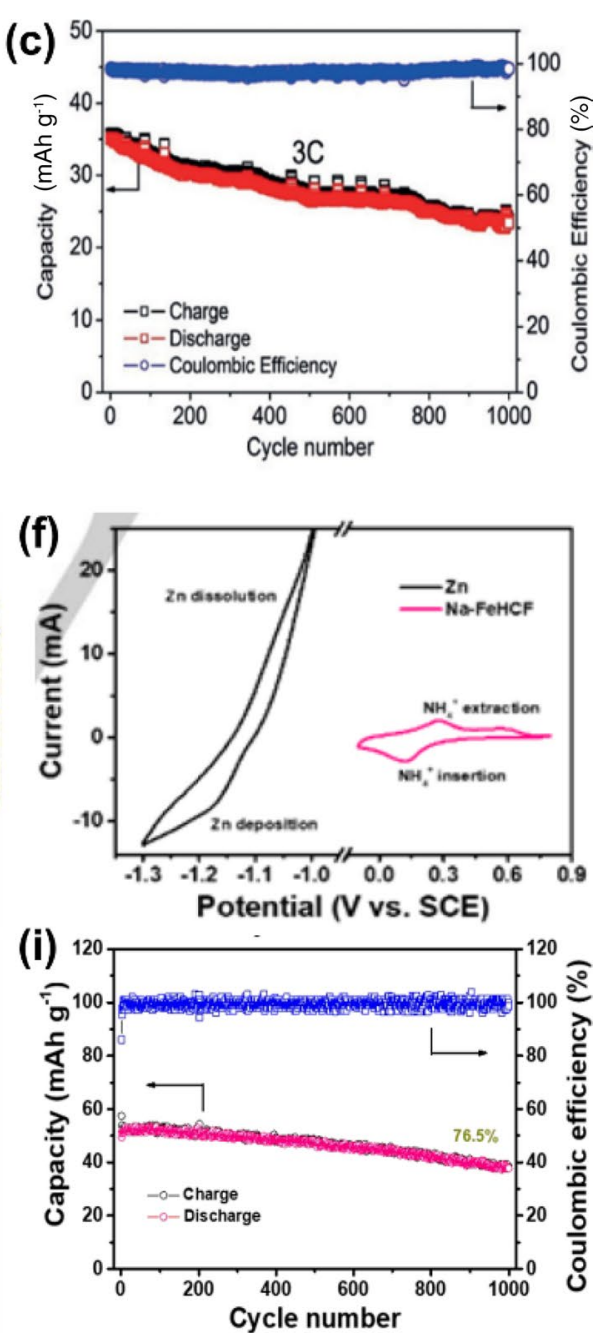

Fig. 12 a Schematic diagram of the working principle of aqueous $\mathrm{NH}_{4}{ }^{+}$ion batteries based on Prussian White positive electrodes and PTCDI negative electrodes. b Charge-discharge curves of the aqueous $\mathrm{NH}_{4}{ }^{+}$-ion battery in the first, the second, the fifth, and the tenth cycles $\left(60 \mathrm{~mA} \mathrm{~g}^{-1}\right)$. c Cycling performance at a $3 \mathrm{C}$ rate [61]. Reproduced with permission from Ref. [61]. Copyright 2017, Wiley-VCH. d Electrochemical stability window of $1 \mathrm{M}$ and $25 \mathrm{~m}$ AmAc electrolytes $\left(1 \mathrm{mV} \mathrm{s}^{-1}\right)$. e Cycling performance of $\mathrm{TiO}_{1.85}(\mathrm{OH})_{0.30} \cdot 0.28 \mathrm{H}_{2} \mathrm{O}$ electrode in $25 \mathrm{~m} \mathrm{AmAc}\left(1 \mathrm{~A} \mathrm{~g}^{-1}\right)$ [63]. Reproduced with permission

increase the energy density of the AAIB [64, 65]. Our group was the first to report an aqueous rechargeable ammonium zinc hybrid battery (ARAHB) comprising a highly durable sodium iron hexacyanoferrate $\mathrm{NaFe}^{\mathrm{III}} \mathrm{Fe}^{\mathrm{II}}(\mathrm{CN})_{6}(\mathrm{Na}-\mathrm{FeHCF})$ nanocube positive electrode and a low-cost zinc negative electrode, with a working voltage of $1.3 \mathrm{~V}$ and high energy density of $81.7 \mathrm{Wh} \mathrm{kg}^{-1}$ (based on the total mass of active materials) (Fig. 12f, g). We then further increased the energy density of the ARAHB to $114 \mathrm{Wh} \mathrm{kg}^{-1}$ using CuHCF nanoparticles as the positive electrode material (Fig. 12h, i). from Ref. [63]. Copyright 2017, Wiley-VCH. (f) CV curves of $\mathrm{Zn}$ and $\mathrm{Na}$-FeHCF electrodes in $1 \mathrm{M}\left(\mathrm{NH}_{4}\right)_{2} \mathrm{SO}_{4}+20 \mathrm{mM} \mathrm{ZnSO}_{4}$ aqueous solution at the scan rate of $3 \mathrm{mV} \mathrm{s}^{-1}$. $\mathrm{g}$ Charge-discharge curves of $\mathrm{Zn} / \mathrm{Na}-\mathrm{FeHCF}$ hybrid batteries. Reproduced with permission from Ref. [64]. Copyright 2019, John Wiley and Sons. h Charge-discharge curves at various current densities and $\mathbf{i}$ cycling performance of $\mathrm{Zn} / \mathrm{CuHCF}$ hybrid batteries at the current density of $1800 \mathrm{~mA} \mathrm{~g}^{-1}$. Reproduced with permission from Ref. [65]. Copyright 2019, American Chemical Society

\subsection{Aqueous Zn-Ion Batteries (AZIBs)}

Zinc is the most ideal negative electrode material for aqueous batteries because of its low redox potential $(-0.76 \mathrm{~V}$ vs. SHE), high specific capacity ( $\left.820 \mathrm{mAh}^{-1}\right)$, abundant reserves, and nontoxic properties. It is widely used as negative electrodes in alkaline Zn-based batteries (such as alkaline zinc- $\mathrm{MnO}_{2}$ batteries [66], zinc-nickel batteries [67, 68], and $\mathrm{Zn} / / \mathrm{Co}_{3} \mathrm{O}_{4}$ batteries [69, 70], zinc-air batteries [71, 72], zinc-ion batteries, and zinc hybrid batteries. Recently, there have been many reviews on these aspects, so we will not elaborate on them from the perspective of electrode 
Table 3 Electrochemical properties of various AZIBs, AMIBs, ACIBs, and AAIBs with high voltage and energy density

\begin{tabular}{|c|c|c|c|c|c|}
\hline Electrochemical couple & Electrolyte & $\begin{array}{l}\text { Average dis- } \\
\text { charge voltage } \\
\text { (V) }\end{array}$ & $\begin{array}{l}\text { Actual energy } \\
\text { density (Wh } \\
\mathrm{kg}^{-1} \text { ) }\end{array}$ & Capacity retention & Reference \\
\hline \multicolumn{6}{|l|}{ AZIBs } \\
\hline $\mathrm{Zn}-\mathrm{MnO}_{2}$ & $3 \mathrm{M} \mathrm{Zn}\left(\mathrm{CF}_{3} \mathrm{SO}_{3}\right)_{2}+0.1 \mathrm{M} \mathrm{MnSO}_{4}$ & 1.294 & 254 & $92 \%(5000$ cycles at $5 \mathrm{C})$ & {$[88]$} \\
\hline $\mathrm{Zn}-\mathrm{MnO}_{2}$ & $\begin{array}{l}1 \mathrm{M} \mathrm{ZnSO}_{4}+1 \mathrm{M} \mathrm{MnSO}_{4}+0.1 \mathrm{M} \\
\mathrm{H}_{2} \mathrm{SO}_{4}\end{array}$ & 1.95 & 409 & $92 \%$ (1800 cycles) & {$[90]$} \\
\hline $\mathrm{Zn}-\mathrm{MnO}_{2}$ & $\begin{array}{l}\text { Alkaline }(1 \mathrm{M} \mathrm{NaOH} \text { and } 0.01 \mathrm{M} \\
\left.\mathrm{Zn}(\mathrm{Ac})_{2}\right) \text {-mild }\left(2 \mathrm{M} \mathrm{ZnSO}_{4}+0.1 \mathrm{M}\right. \\
\left.\mathrm{MnSO}_{4}\right) \text { hybrid electrolyte }\end{array}$ & 1.7 & 487 & & {$[92]$} \\
\hline $\mathrm{Zn}-\mathrm{Mn}^{2+}$ battery & $\begin{array}{l}\text { 2.4 M KOH and } 0.1 \mathrm{M} \mathrm{Zn}\left(\mathrm{CH}_{3} \mathrm{COO}\right)_{2} \text {; } \\
0.5 \mathrm{M} \mathrm{H}_{2} \mathrm{SO}_{4} \text { and } 1.0 \mathrm{M} \mathrm{MnSO}_{4}\end{array}$ & $\sim 2.3$ & 836 & $97.5 \%$ ( 1500 cycles $)$ & [93] \\
\hline $\mathrm{Zn} / \mathrm{CoFe}(\mathrm{CN})_{6}$ & $4 \mathrm{M} \mathrm{Zn}(\mathrm{OTf})_{2}$ & 1.75 & 250 & $100 \%$ (2200 cycles) & [94] \\
\hline $\mathrm{Zn} / \mathrm{Co}_{0.247} \mathrm{~V}_{2} \mathrm{O}_{5} \cdot 0.944 \mathrm{H}_{2} \mathrm{O}$ & $0.5 \mathrm{M} \mathrm{ZnSO}_{4}$ & $\sim 1$ & $458.7\left(0.1 \mathrm{~A} \mathrm{~g}^{-1}\right)$ & $90.26 \%$ (7500 cycles) & [102] \\
\hline $\mathrm{Zn} / \mathrm{Na}_{3} \mathrm{~V}_{2}\left(\mathrm{PO}_{4}\right)_{2} \mathrm{~F}_{3}$ & $2 \mathrm{M} \mathrm{Zn}\left(\mathrm{CF}_{3} \mathrm{SO}_{3}\right)_{2}$ & 1.62 & 97.5 & $95 \%$ (4000 cycles) & [104] \\
\hline $\mathrm{Zn} / \mathrm{Co}_{3} \mathrm{O}_{4}$ & $2 \mathrm{M} \mathrm{ZnSO}_{4}+0.2 \mathrm{M} \mathrm{CoSO}_{4}$ & $\sim 1.8$ & $\sim 290$ & $92 \%$ (5000 cycles) & [105] \\
\hline \multicolumn{6}{|l|}{ AMIBs } \\
\hline $\mathrm{PPMDA} / \mathrm{Li}_{3} \mathrm{~V}_{2}\left(\mathrm{PO}_{4}\right)_{3}$ & $4 \mathrm{~m} \mathrm{Mg}(\mathrm{TFSI})_{2}$ & 1.2 & 62.4 & $92 \%$ (6000 cycles) & {$[106]$} \\
\hline $\mathrm{Mg} / \mathrm{LiFePO}_{4}$ & $\begin{array}{l}1 \mathrm{M} \mathrm{PhMgBr} \text { and } 0.1 \mathrm{M} \mathrm{LiBr} \text { in tetrahy- } \\
\text { drofuran (negative electrode); } 0.5 \mathrm{M} \\
\mathrm{Li}_{2} \mathrm{SO}_{4} \text { (positive electrode); LISICON } \\
\text { film }\end{array}$ & 2.1 & 245 & $90 \%$ (20 cycles) & {$[107]$} \\
\hline $\mathrm{Mg} / \mathrm{V}_{2} \mathrm{O}_{5}$ & $\begin{array}{l}0.5 \mathrm{M} \mathrm{Mg}(\mathrm{TFSI})_{2} / \mathrm{PC}+3 \mathrm{M} \mathrm{H}_{2} \mathrm{O} \text { elec- } \\
\text { trolyte }\end{array}$ & $\sim 1.1$ & $\sim 144$ & 71\% (40 cycles) & {$[108]$} \\
\hline \multicolumn{6}{|l|}{ ACIBs } \\
\hline $\begin{array}{l}\mathrm{PNDIE} / / \mathrm{Ca}_{0.3} \mathrm{CuHCF} \\
\text { AAIBs }\end{array}$ & $\mathrm{Ca}\left(\mathrm{NO}_{3}\right)_{2}$ aqueous solution & 1.24 & 54 & $88 \%$ (1000 cycles) & [112] \\
\hline $\mathrm{Al} / \mathrm{Al}_{x} \mathrm{MnO}_{2} \cdot n \mathrm{H}_{2} \mathrm{O}$ & $5 \mathrm{~m} \mathrm{Al}(\mathrm{OTf})_{3}$ & 1.1 & 481 & $58 \%$ (60 cycles) & [116] \\
\hline $\mathrm{TAlll}^{\mathrm{MnO}_{2}}$ & $2 \mathrm{~m} \mathrm{Al}(\mathrm{OTf})_{3}$ & 1.3 & 500 & $50 \%$ (40 cycles) & [117] \\
\hline $\mathrm{T}-\mathrm{Al} / \mathrm{Bir}-\mathrm{MnO}_{2}$ & $1 \mathrm{~m} \mathrm{Al}(\mathrm{OTf})_{3}+0.5 \mathrm{~m} \mathrm{MnSO}_{4}$ & 1.35 & 620 & $67 \%$ (65 cycles) & [133] \\
\hline $\mathrm{Al} /$ graphite & "Water-in-salt" aqueous $\mathrm{AlCl}_{3}$ & 1.44 & 220 & $>95 \%(1000$ cycles $)$ & [134] \\
\hline Al-S & $\begin{array}{l}1 \mathrm{~m} \mathrm{Al}(\mathrm{OTf})_{3}+17 \mathrm{~m} \mathrm{LiTFSI}+0.02 \mathrm{M} \\
\mathrm{HCl}\end{array}$ & $\sim 0.6$ & $\sim 574$ & $29.8 \%$ (30 cycles) & {$[135]$} \\
\hline
\end{tabular}

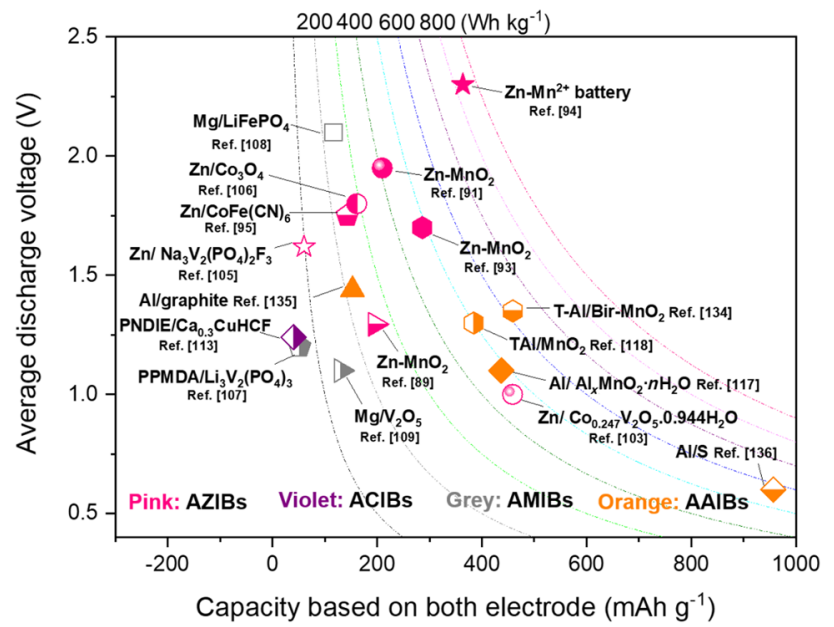

Fig. 13 Energy density and average discharge capacity of various AZIBs, AMIBs, ACIBs, and AAIBs with high voltage and energy density materials [73-86]. Here, we summarize the recent progress on zinc-based batteries with high voltage and high energy density. Table 3 and Fig. 13 provide details of the performance of AZIBs reported to date.

$\mathrm{Zn}-\mathrm{MnO}_{2}$ batteries based on mild zinc salt aqueous electrolytes are currently an important research topic [87-89]. Despite significant progress, the reaction mechanism of $\mathrm{Zn}^{2+}$ storage in Mn-based materials remains controversial. A previous review summarized three charge storage mechanisms [73]: (a) reversible insertion/extraction of $\mathrm{Zn}$ ions in bulk materials; (b) reversible proton reactions accompanied by zinc hydroxide sulfate deposition; and (c) $\mathrm{H}^{+}$and $\mathrm{Zn}^{2+}$ successively embedded/de-embedded at different charge-discharge stages. Based on these mechanisms (Fig. 14a), the $\mathrm{Zn}-\mathrm{MnO}_{2}$ battery utilizes only the capacity and voltage provided by the redox reaction of the $\mathrm{Mn}^{4+} / \mathrm{Mn}^{3+}$ pair, limiting the battery capacity and output voltage. This puts forward new requirements for the electrochemistry of zinc and 
(a)

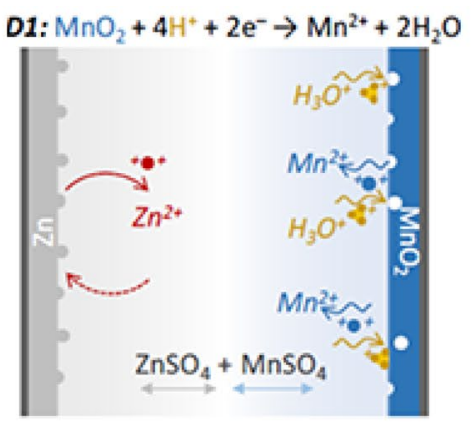

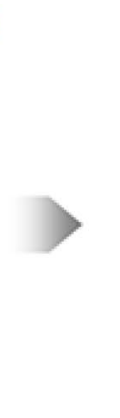
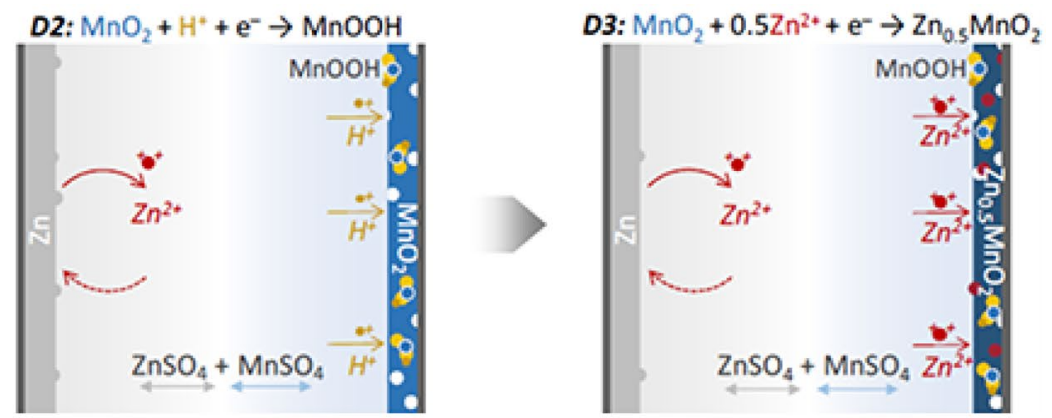

(b)

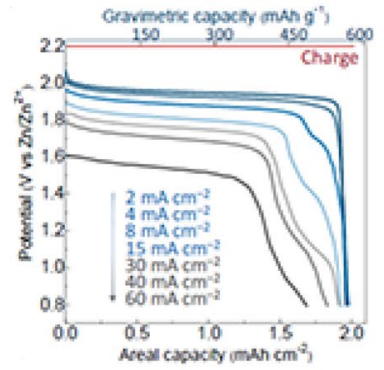

(c)

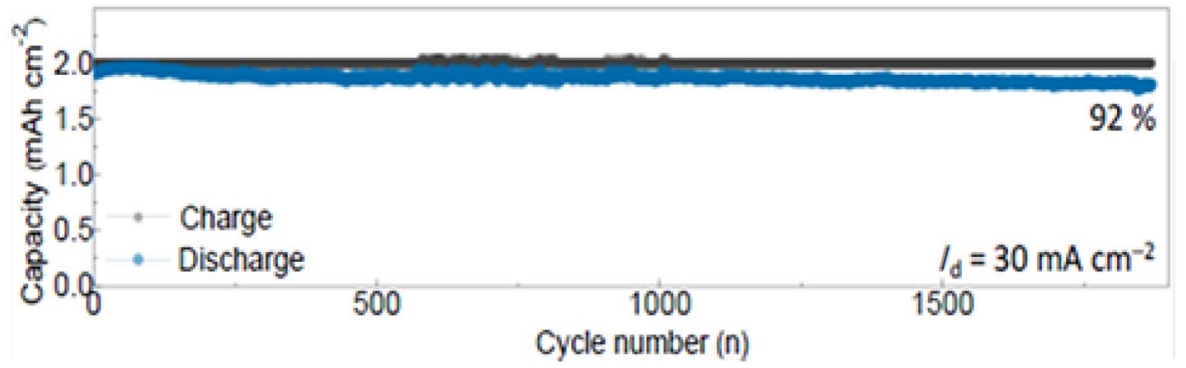

Fig. 14 a Diagram of three-step galvanostatic discharge processes. b Galvanostatic discharge curves. c Cycling performance at $30 \mathrm{~mA}$ $\mathrm{cm}^{-2} . \mathrm{Zn}-\mathrm{MnO}_{2}$ electrolytic cells are charged at a constant voltage

manganese. Since the $\mathrm{Mn}$ ion is multivalent $(+2,+3$, and $+4)$, a two-electron $\mathrm{Mn}^{4+} / \mathrm{Mn}^{2+}$ reaction with a capacity of $616 \mathrm{~mA} \mathrm{~g}^{-1}$ and a higher voltage platform can be postulated. Recently, a new mechanism has been proposed that includes $\mathrm{Mn}^{2+} / \mathrm{MnO}_{2}$ reversible deposition/dissolution, chemical conversion (between $\mathrm{MnO}_{2}$ and $\mathrm{MnOOH}$ ), and $\mathrm{Zn}^{2+}$ insertion [90]. Based on the unique two-electron redox reaction of $\mathrm{Mn}^{4+} / \mathrm{Mn}^{2+}$, a high-voltage electrolytic zinc manganese battery was assembled, which had a high discharge plateau of $1.95 \mathrm{~V}$, high energy density of $409 \mathrm{Wh} \mathrm{kg}^{-1}$, and excellent cycling performance $(92 \%$ capacity retention after 1800 cycles) (Fig. 14b, c).

To further increase the voltage and energy density of a $\mathrm{Zn}-\mathrm{MnO}_{2}$ battery, we can use a hybrid electrolyte with different $\mathrm{pH}$ values, such as alkaline-neutral electrolytes and alkaline-acidic electrolytes. Recently, our group reported a $\mathrm{Zn} / / \mathrm{MnO}_{2}$ battery with an alkaline $(1 \mathrm{M} \mathrm{NaOH}$ and $0.01 \mathrm{M}$ $\mathrm{Zn}(\mathrm{Ac})_{2}$ )-neutral (2 $\mathrm{M} \mathrm{ZnSO}_{4}+0.1 \mathrm{M} \mathrm{MnSO}_{4}$ ) hybrid electrolyte and a $\mathrm{Na}^{+}-\mathrm{Nafion}$ membrane from DKJ Co. Ltd. Its working principle is shown in Fig. 15a. Using a $\mathrm{Zn} /$ $\mathrm{Zn}(\mathrm{OH})_{4}^{2-}$ negative electrode in alkaline solution, which has a relatively low redox potential, the voltage of the battery is greatly increased. The assembled battery possesses an average discharge voltage plateau of $1.7 \mathrm{~V}$ and energy density of $487 \mathrm{Wh} \mathrm{kg}^{-1}$ [92]. In addition, by combining the two dissolution/deposition electrode redox reactions of $\mathrm{MnO}_{2} / \mathrm{Mn}^{2+}$ and $\mathrm{Zn} / \mathrm{Zn}(\mathrm{OH})_{4}^{2-}$ using acid-alkaline dual electrolytes and an ion-selective membrane, a high-energy $\mathrm{Zn}-\mathrm{MnO}_{2}$ battery was constructed [93]. The working mechanism is illustrated of $2.2 \mathrm{~V}$ (vs. $\mathrm{Zn} / \mathrm{Zn}^{2+}$ ) [91]. Reproduced with permission from Ref. [91]. Copyright 2017, American Chemical Society)

in Fig. 15b. When charging, $\mathrm{Zn}(\mathrm{OH})_{4}^{2-}$ is reduced to $\mathrm{Zn}$ and $\mathrm{Mn}^{2+}$ is oxidized to $\mathrm{MnO}_{2}$. At the same time, the cations $\left(\mathrm{K}^{+}\right)$and anions $\left(\mathrm{SO}_{4}{ }^{2-}\right)$ stored in the BPM return to the positive and negative electrodes, respectively, achieving charge balance. During the discharge process, these two processes develop in the opposite direction. The $\mathrm{Zn}-\mathrm{Mn}^{2+}$ battery had a high operating voltage of $2.44 \mathrm{~V}$, high coulombic efficiency of $98.4 \%$, and discharge capacity retention of $97.5 \%$ after 1500 cycles. Specifically, its energy density is extremely high $\left(\approx 1503 \mathrm{Wh} \mathrm{kg}^{-1}\right.$, calculated based on positive electrode material), which is the highest among all the aqueous $\mathrm{Zn}$-based batteries reported so far and is even comparable to those of $\mathrm{Zn}$-air batteries.

PBAs have a three-dimensional open framework and a large gap structure and are considered to be reversible $\mathrm{Zn}^{2+}$ intercalation/deintercalation host materials with fast charge and discharge ability, high working potential, and ideal electrochemical properties. In PBA electrode materials, usually only a single transition metal ion (in most cases iron) is considered to be electrochemically active in the aqueous electrolyte system, resulting in its limited specific capacity in $\mathrm{Zn}^{2+}$ aqueous solution $\left(\approx 60 \mathrm{mAh} \mathrm{g}^{-1}\right)$, whereas in most cases the voltage is low $\left(\sim 1.2 \mathrm{~V} \mathrm{Zn} / \mathrm{Zn}^{2+}\right)$ and therefore the energy density of the battery is low. Recently, a new kind of $\mathrm{Co} / \mathrm{Fe} \mathrm{PBAs}$ cubes (cobalt hexacyanoferrate, $\mathrm{CoFe}(\mathrm{CN})_{6}$ ) were developed, in which both $\mathrm{Co}$ and $\mathrm{Fe}$ ions are expected to effectively contribute to the two-electron energy storage process, resulting in enhancement of the specific capacity [94]. As illustrated in Fig. 16a, the vacancies produced by 
(a)

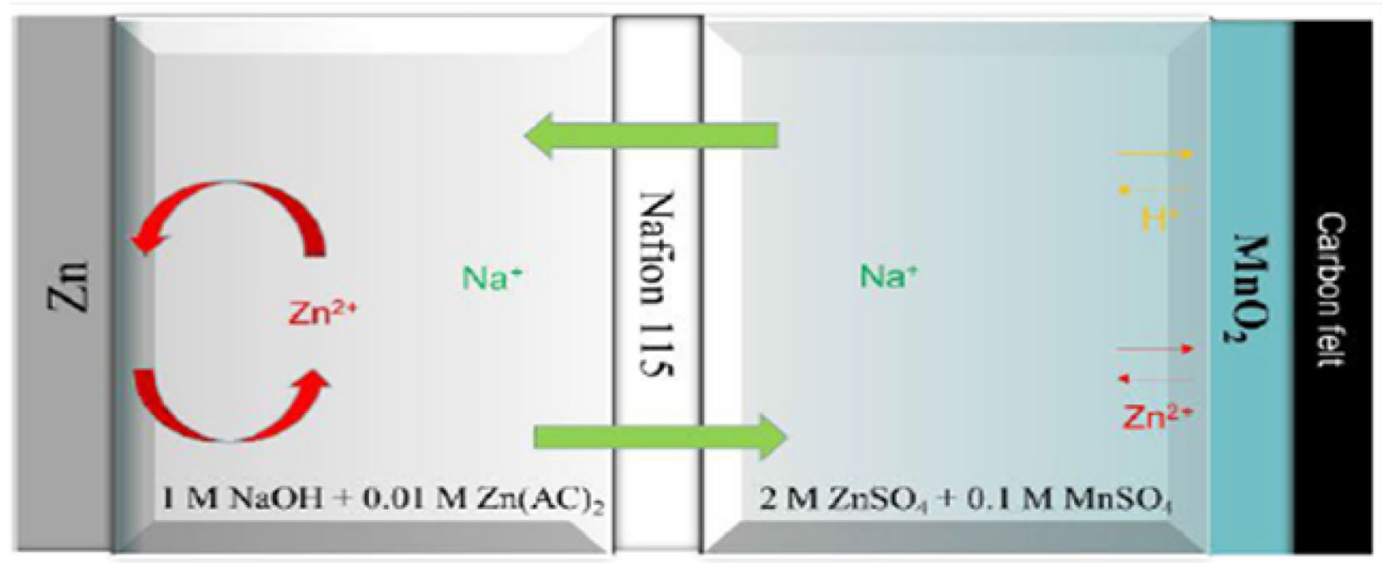

(b)

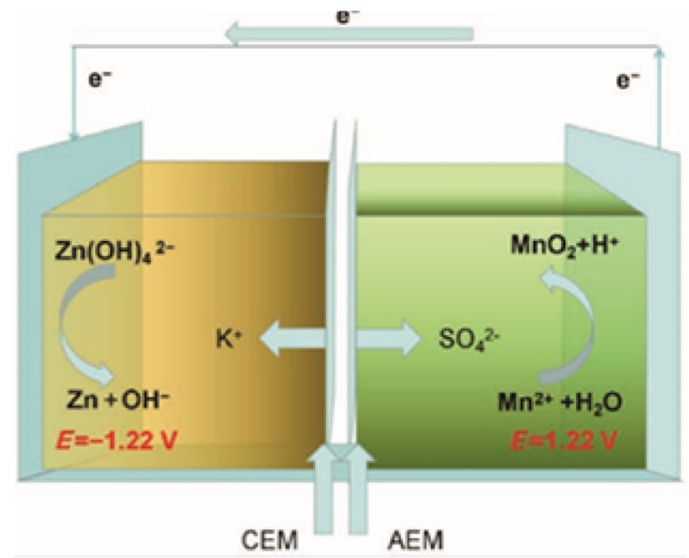

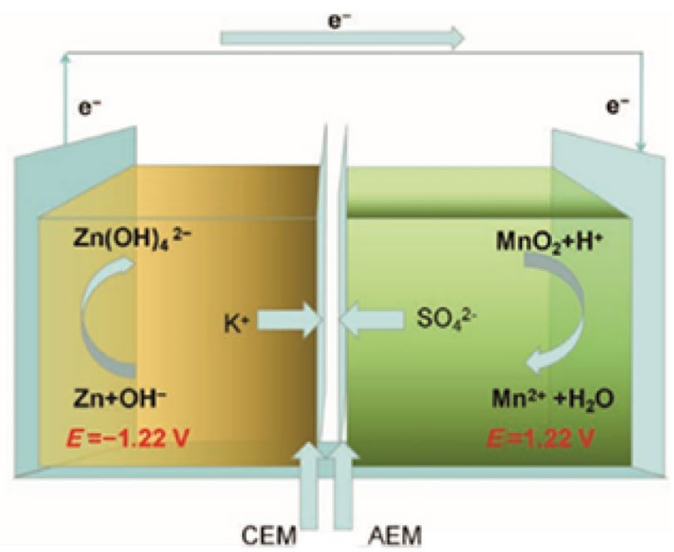

anism of the $\mathrm{Zn}-\mathrm{MnO}_{2}$ battery using the acid-base dual electrolyte under charge and discharge conditions. [93] Reproduced with permission from Ref. [93]. Copyright 2020, Wiley-VCH

$\left(<250 \mathrm{Wh} \mathrm{kg}^{-1}\right)$, which is in sharp contrast to their large capacity. Zhi and coworkers reported a zinc-ion battery based on a $\mathrm{Co}_{0.247} \mathrm{~V}_{2} \mathrm{O}_{5} \cdot 0.944 \mathrm{H}_{2} \mathrm{O}$ nanobelt positive electrode, which delivered $52.5 \%$ of the total capacity above $1.0 \mathrm{~V}$, and hence a high energy density of $432 \mathrm{Wh} \mathrm{kg}^{-1}$ was obtained [102]. The results show that the large capacity of $\mathrm{Co}_{0.247} \mathrm{~V}_{2} \mathrm{O}_{5} \cdot 0.944 \mathrm{H}_{2} \mathrm{O}$ is due to its stronger adsorption capacity for $\mathrm{Zn}^{2+}$, and the high voltage of the battery is mainly due to the interaction between the $\mathrm{Co}_{3 \mathrm{~d}}$ and $\mathrm{V}_{3 \mathrm{~d}}$ orbitals, which moves the relative redox potential of the $\mathrm{V}^{5+} / \mathrm{V}^{4+}$ pair to a higher level (Fig. 16d).

NASICON-type materials have large channels and rapid ion diffusion capability and are very appealing as $\mathrm{Zn}^{2+}$-ion storage hosts. $\mathrm{Na}_{3} \mathrm{~V}_{2}\left(\mathrm{PO}_{4}\right)_{3}$ was reported as an aqueous $\mathrm{Zn}$-ion battery positive electrode, with $1.1 \mathrm{~V}$ voltage, 97.5 $\mathrm{mAh} \mathrm{g}^{-1}$ capacity but inadequate cyclability (74\% capacity retention after 100 cycles) [103]. Recently, another NASICON-type material, $\mathrm{Na}_{3} \mathrm{~V}_{2}\left(\mathrm{PO}_{4}\right)_{2} \mathrm{~F}_{3}$, was reported as a high-voltage positive electrode (more than $1.6 \mathrm{~V}$ ) for a zinc-ion battery, with a redox potential $0.5 \mathrm{~V}$ higher than is situated below $1.0 \mathrm{~V}$, resulting in low energy density 
(a)
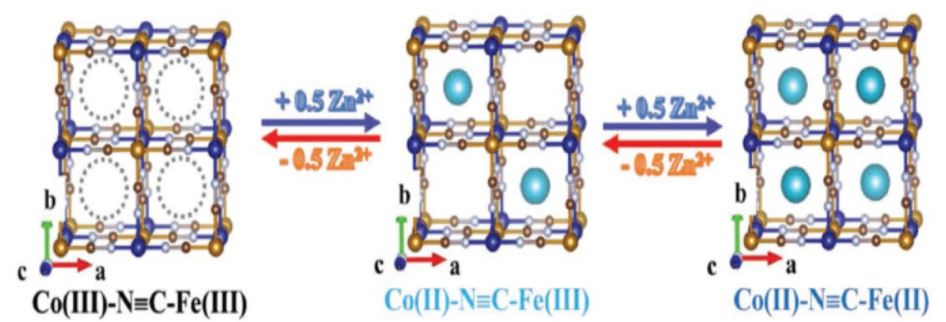

(b)

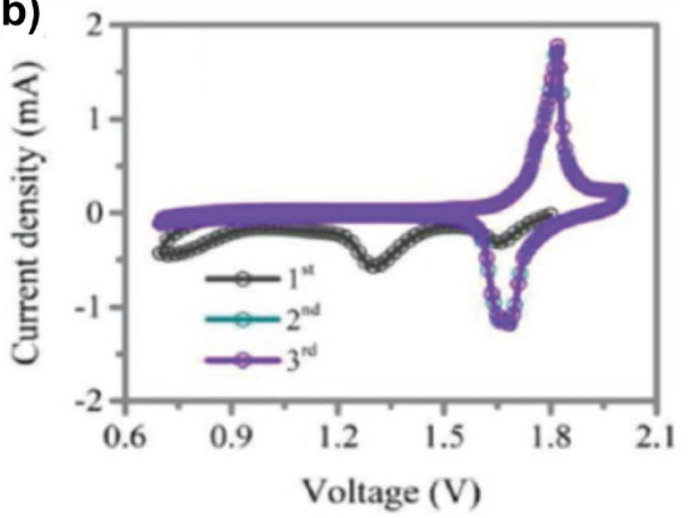

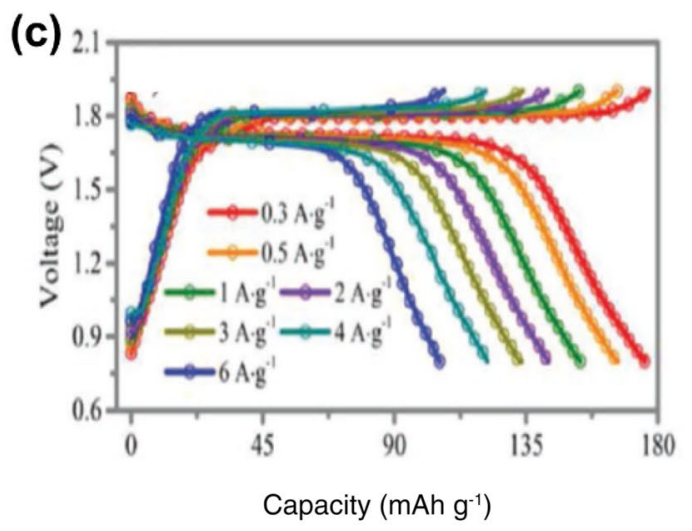

(d)

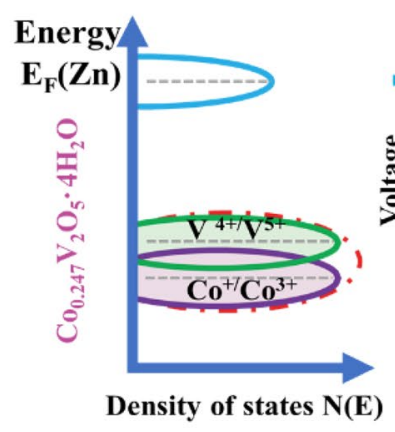

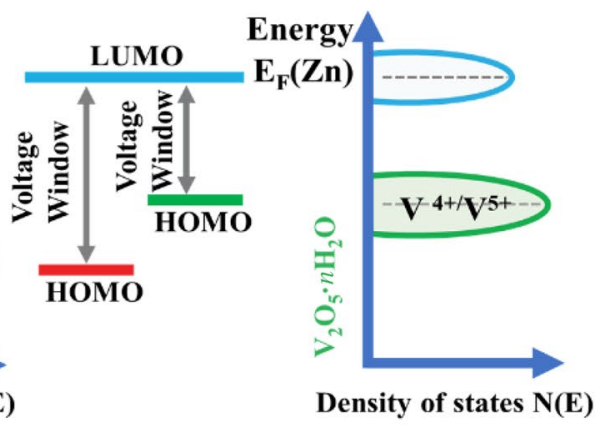

Fig. 16 a Schematic diagram of reversible $\mathrm{Zn}^{2+}$ intercalation/deintercalation in the $\mathrm{CoFe}(\mathrm{CN})_{6}$ framework during charging and discharging processes. b First three cycles of $\mathrm{CV}$ curves $\left(1 \mathrm{mV} \mathrm{s}^{-1}\right)$. c Constant-current charge-discharge curves at various current densities [94]. Reproduced with permission from Ref. [94]. Copyright
2019, Wiley-VCH. d Schematic diagram of the relationship between energy and density of states (DOS) in $\mathrm{Co}_{0.247} \mathrm{~V}_{2} \mathrm{O}_{5} \cdot 0.944 \mathrm{H}_{2} \mathrm{O}$ and $\mathrm{V}_{2} \mathrm{O}_{5} \cdot n \mathrm{H}_{2} \mathrm{O}$ positive electrodes. Reproduced with permission from Ref. [102]. Copyright 2019, Wiley-VCH that of $\mathrm{Na}_{3} \mathrm{~V}_{2}\left(\mathrm{PO}_{4}\right)_{3}$ [104]. The assembled zinc-ion battery has a high potential of $1.62 \mathrm{~V}$ and high energy density of $97.5 \mathrm{Wh} \mathrm{kg}^{-1}$ (Fig. 17a). More importantly, at a current density of $1 \mathrm{~A} \mathrm{~g}^{-1}$, the zinc-ion battery showed highly stable cycling performance, maintaining $95 \%$ capacity over 4000 cycles (Fig. 17b).

Generally, zinc/cobalt batteries use an alkaline electrolyte, which displays poor cycling stability and causes environmental pollution. A redox reaction between $\mathrm{CoO}$ and $\mathrm{Co}_{3} \mathrm{O}_{4}$ was revealed in a $\mathrm{Zn} / \mathrm{Co}_{3} \mathrm{O}_{4}$ battery with a mild aqueous electrolyte [105]. The $\mathrm{CoO}$ layer formed during the discharge process reveals the conversion process of $\mathrm{H}^{+}$ion insertion into $\mathrm{Co}_{3} \mathrm{O}_{4}$. The $\mathrm{Zn} / \mathrm{Co}(\mathrm{III})$-rich $\mathrm{Co}_{3} \mathrm{O}_{4}$ battery using a mild aqueous electrolyte showed a voltage window of about $2.2 \mathrm{~V}$ (Fig. 17c, d), much broader than that of a battery with alkaline electrolytes (about $1.9 \mathrm{~V}$ ).

\subsection{Aqueous Magnesium-Ion Batteries (AMIBs)}

Magnesium-ion batteries are gradually becoming another popular research area, because the Earth's resources are rich in magnesium, which is inexpensive and suitable for the development of energy storage devices. The magnesium ion is similar to that of the lithium ion. However, the main problems of nonaqueous rechargeable $\mathrm{Mg}$-ion batteries hinder their development: (a) their electrolyte is water-sensitive and has complex chemical properties; (b) lacking high-performance electrode materials also limits the practicability of $\mathrm{Mg}$ batteries due to the slow diffusion of $\mathrm{Mg}^{2+}$ in solids. In contrast, aqueous magnesium-ion batteries (AMIBs) have many advantages, such as low cost, no corrosion, good safety, and good conductivity. However, due to the lack of suitable negative and positive electrode materials, most of the reported electrode materials for AMIBs were only evaluated in the half-cell setup. Limited by the voltage stability window of traditional aqueous electrolytes $(1.23 \mathrm{~V})$, the voltage and energy density of AMIBs are also very limited [106]. It is common knowledge that $\mathrm{Mg}$ can hardly be deposited and stripped reversibly in aqueous solution because $\mathrm{Mg}$ is an active metal and has a low redox potential $(-2.37 \mathrm{~V}$ vs. SHE). Recent research has shown that reversible magnesium metal deposition/stripping in a $\mathrm{H}_{2} \mathrm{O}$-containing electrolyte 

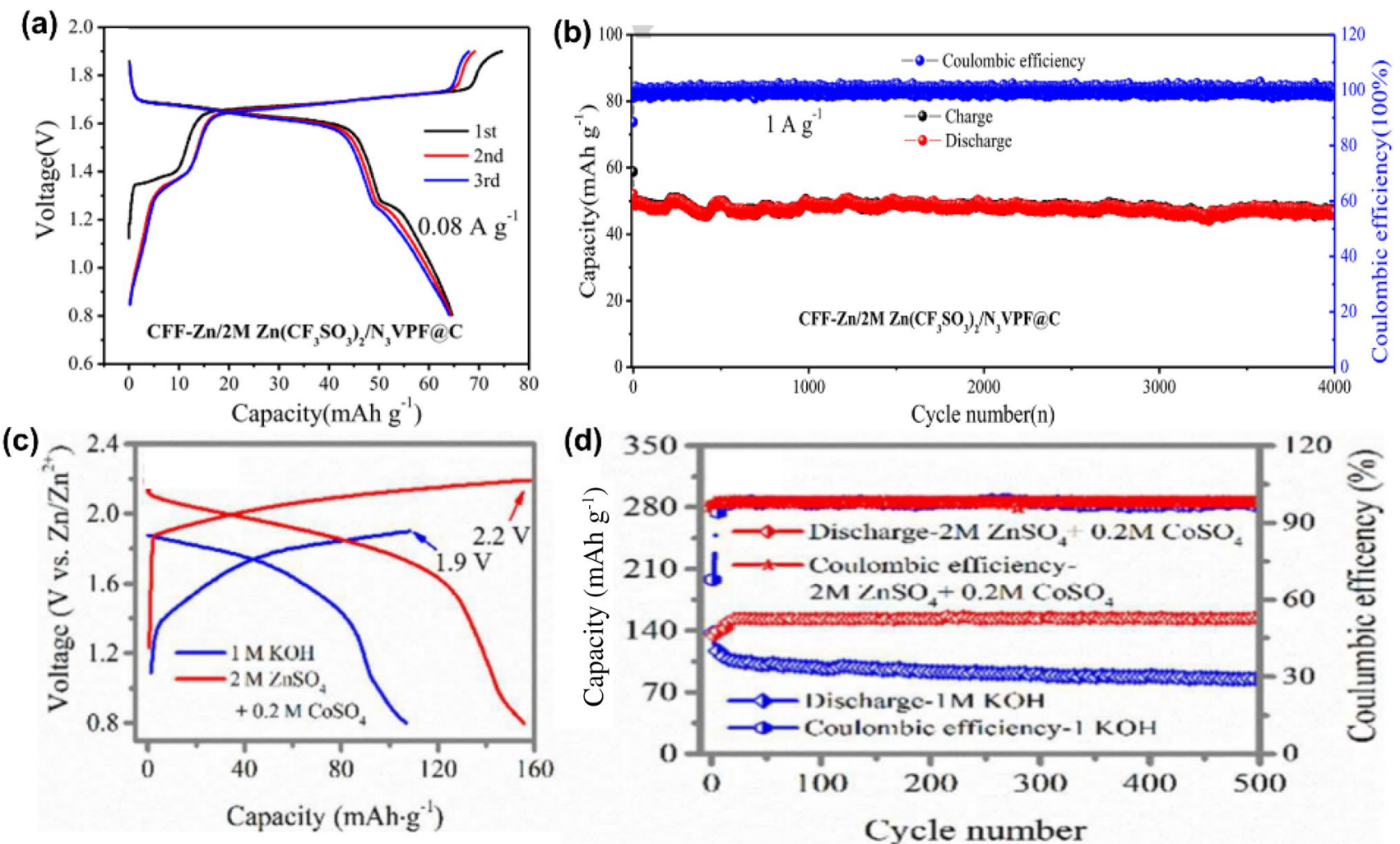

Fig. 17 a Charge-discharge curves of the first three cycles of CFF-Zn// $/ \mathrm{Na}_{3} \mathrm{~V}_{2}\left(\mathrm{PO}_{4}\right)_{2} \mathrm{~F}_{3} @ \mathrm{C}$ batteries $\left(0.08 \mathrm{~A} \mathrm{~g}^{-1}\right)$. b Cycling performance of CFF-Zn (carbon film functionalizing $\mathrm{Zn}$ )// $\mathrm{Na}_{3} \mathrm{~V}_{2}\left(\mathrm{PO}_{4}\right)_{2} \mathrm{~F}_{3} @ \mathrm{C}$ batteries $\left(1 \mathrm{~A} \mathrm{~g} \mathrm{~g}^{-1}\right)$ [104]. Reproduced with permission from Ref. [104]. Copyright 2018, Elsevier B. V. Performance comparison of $\mathrm{Zn} / \mathrm{Co}(\mathrm{III})$ rich- $\mathrm{Co}_{3} \mathrm{O}_{4}$ batteries in $1 \mathrm{M} \mathrm{KOH}$ and $2 \mathrm{M}$ $\mathrm{ZnSO}_{4}$ with $0.2 \mathrm{M} \mathrm{CoSO}_{4}$ : a charge-discharge curves, b cycle performance of the first 500 cycles $\left(1 \mathrm{~A} \mathrm{~g} \mathrm{~g}^{-1}\right)$ [105]. Reproduced with permission from Ref. [105]. Copyright 2018, Royal Society of Chemistry (a)

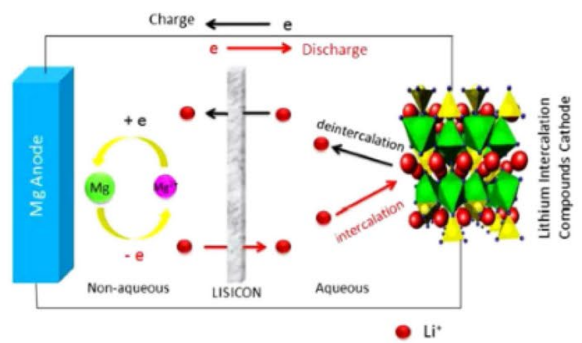

(d)

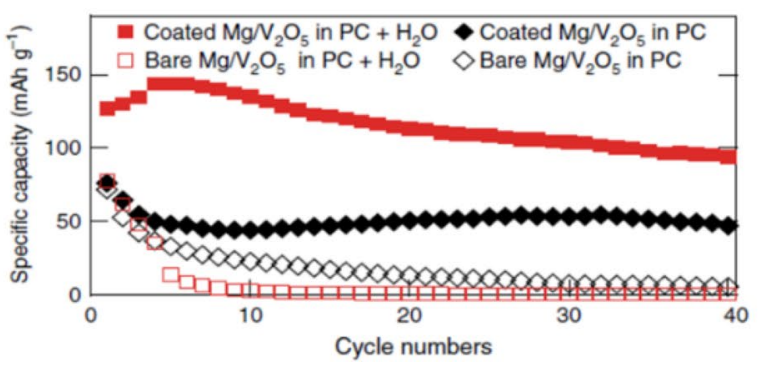

Fig. 18 a Schematic illustration of an aqueous $\mathrm{Mg} / \mathrm{LiFePO}$ battery. b Charge-discharge curve of the first cycle $\left(50 \mathrm{mAh} \mathrm{g}^{-1}, 1.7-3.4 \mathrm{~V}\right)$. c Cycling performance (50 mAh g $\left.{ }^{-1}, 1.7-3.4 \mathrm{~V}\right)$ [107]. Reproduced with permission from Ref. [107]. Copyright 2015, Nature Publishing Group. d Comparison of cycling performance of $\mathrm{Mg} / \mathrm{V}_{2} \mathrm{O}_{5}$ and
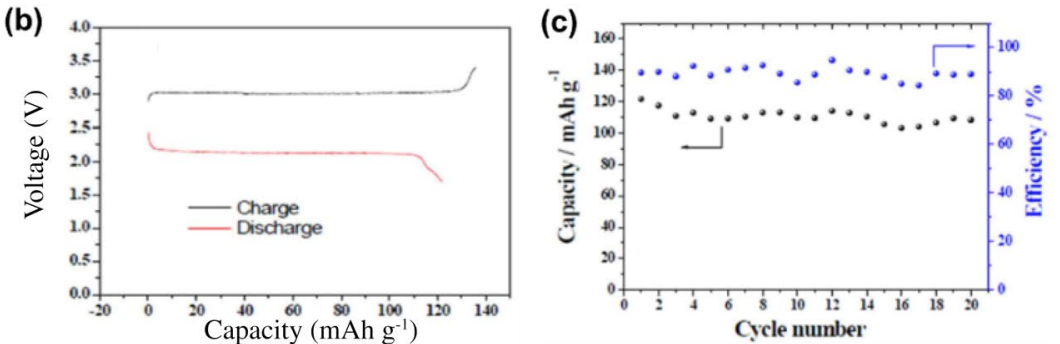

(e)

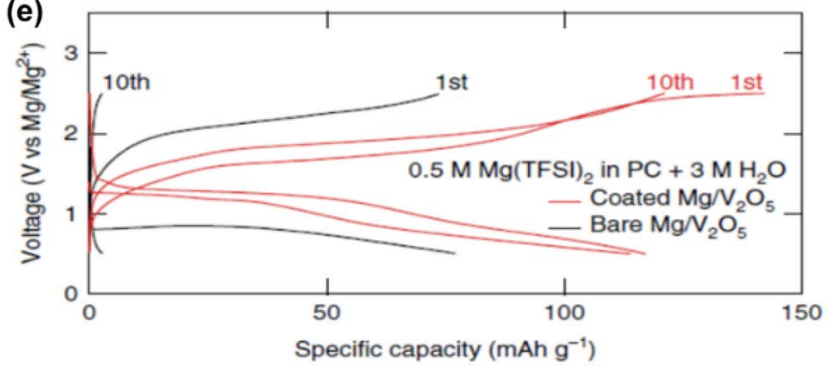

$\mathrm{Mg}$ (interphase-protected) $/ \mathrm{V}_{2} \mathrm{O}_{5}$ in $0.5 \mathrm{M} \mathrm{Mg}(\mathrm{TFSI})_{2} / \mathrm{PC}$ electrolytes without/with water. e Charge-discharge curves of $\mathrm{Mg} / \mathrm{V}_{2} \mathrm{O}_{5}$ and $\mathrm{Mg}$ (interphase-protected) $/ \mathrm{V}_{2} \mathrm{O}_{5}$ in $0.5 \mathrm{M} \mathrm{Mg}(\mathrm{TFSI})_{2} / \mathrm{PC}+3 \mathrm{M} \mathrm{H}_{2} \mathrm{O}$ electrolytes $\left(0.5-2.5 \mathrm{~V}, 29.4 \mathrm{~mA} \mathrm{~g}^{-1}\right)$. Reproduced with permission from Ref. [108]. Copyright 2018, Nature Publishing Group 
is possible by introducing an artificial solid interface. Our group has reported a hybrid $\mathrm{Mg} / \mathrm{LiFePO}_{4}$ battery, in which a $\mathrm{Mg}$-based Grignard reagent was applied as a negative electrode for a nonaqueous electrolyte, while LISICON served as a combined separator/solid electrolyte. This hybrid battery exhibited an average discharge voltage of $2.1 \mathrm{~V}$ with a stable discharge plateau and good cycling behavior (Fig. 18a-c) [107].

Recently, an artificial $\mathrm{Mg}^{2+}$-conductive interphase on a $\mathrm{Mg}$ negative electrode surface was synthesized by thermal cycling of polyacrylonitrile and $\mathrm{Mg}(\mathrm{OTf})_{2}$. The artificial interphase enabled the reversible cycling of a $\mathrm{Mg} / \mathrm{V}_{2} \mathrm{O}_{5}$ full cell in a water-containing, carbonate-based electrolyte (Fig. 18d, e) [108]. Table 3 and Fig. 18 list details of the performance of AMIBs reported to date.

\subsection{Aqueous Ca-Ion Batteries (ACIBs)}

The chemical properties of $\mathrm{Ca}^{2+}$ are very similar to those of $\mathrm{Mg}^{2+}$. Although the $\mathrm{Ca}^{2+}$ cation radius $(0.100 \mathrm{~nm})$ is larger than those of $\mathrm{Li}^{+}(0.076 \mathrm{~nm})$ and $\mathrm{Mg}^{2+}(0.072 \mathrm{~nm})$ cations, its redox potential is low $(-2.87 \mathrm{~V}$ vs. SHE), rich in reserves, and low in ionic charge density, making it an alternative anode material for post $\mathrm{Li}$-ion batteries. The ACIB is also a potential electrochemical system. Few calcium intercalation electrode materials are known, mainly due to the sluggish diffusion of $\mathrm{Ca}^{2+}$. At present, the few reported positive electrode materials for ACIBs are mainly PBAs [including $\mathrm{NiHCF}$ [109], $\mathrm{K}_{2} \mathrm{BaFe}(\mathrm{CN})_{6}$ [110] and $\mathrm{CuHCF}$ [111]], and the reported negative materials are mainly organic electrode materials, such as PNDIE \{poly-[N, $\mathrm{N}^{\prime}$-(ethane-1,2-diyl) 1,4,5,8-naphthalenetetracarboxi-imide]\} [112].

So far, only one ACIB was reported, consisting of the PNDIE negative electrode and the PBA, copper hexacyanoferrate $\left\{\mathrm{CuHCF}, \mathrm{K}_{0.02} \mathrm{Cu}\left[\mathrm{Fe}(\mathrm{Cu})_{6}\right]_{0.66} \cdot 3.7 \mathrm{H}_{2} \mathrm{O}\right\}$, as the positive electrode and $\mathrm{Ca}\left(\mathrm{NO}_{3}\right)_{2}$ aqueous solution as the electrolyte (Fig. 19) [112]. The full battery exhibited a specific capacity of $40 \mathrm{mAh} \mathrm{g}^{-1}$ at $1 \mathrm{C}\left(1 \mathrm{C}=40 \mathrm{mAh} \mathrm{g}^{-1}\right)$ with an average operating voltage of $1.24 \mathrm{~V}$, corresponding to an energy density of $54 \mathrm{Wh} \mathrm{kg}^{-1}$, and $88 \%$ capacity retention with almost $100 \%$ coulombic efficiency after 1000 cycles at $10 \mathrm{C}$.
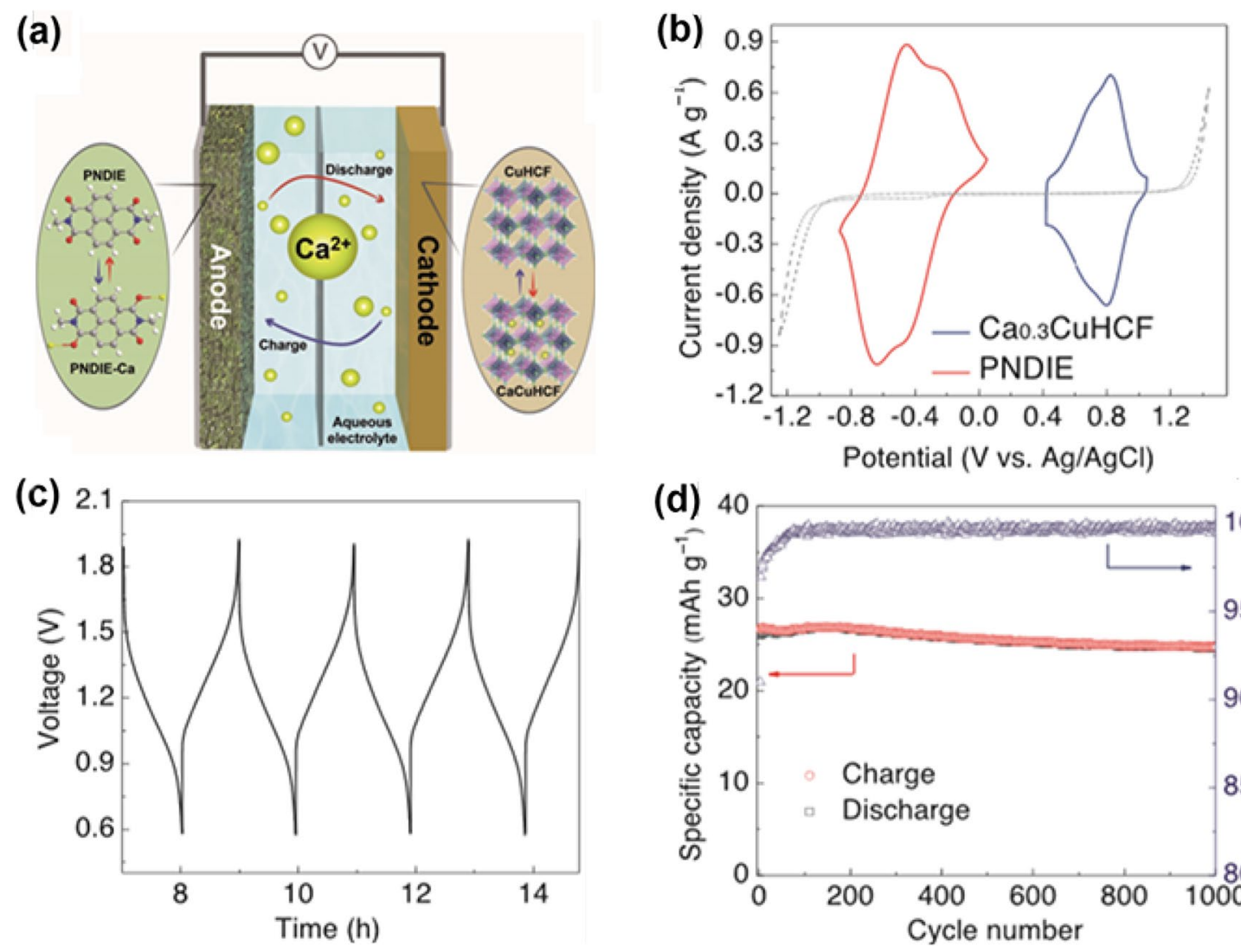

Fig. 19 a Schematic diagram of charge and discharge principles of an aqueous rechargeable Ca-ion battery (PNDIE//Ca ${ }_{0.3} \mathrm{CuHCF}$ ). b $\mathrm{CV}$ curves of the electrodes and the electrochemical stability of the electrolyte $\left[2.5 \mathrm{M} \mathrm{Ca}\left(\mathrm{NO}_{3}\right)_{2}, 1 \mathrm{mV} \mathrm{s}^{-1}\right]$. c Voltage-time curve of

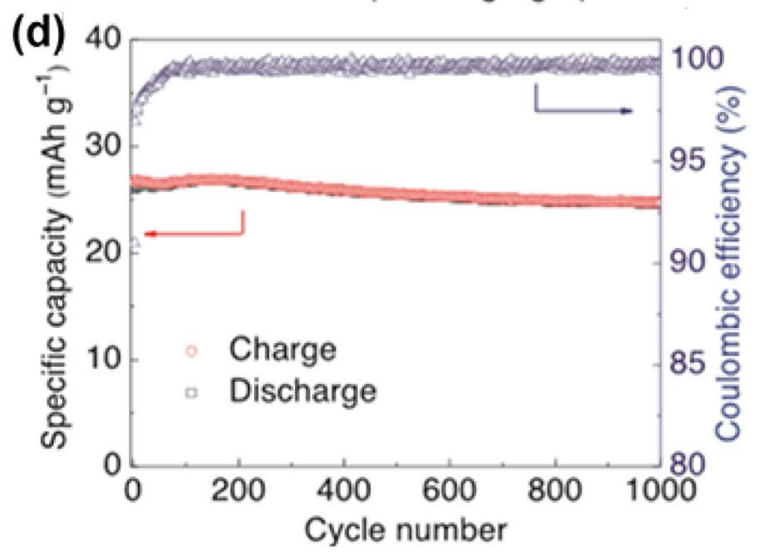

PNDIE//Ca ${ }_{0.3} \mathrm{CuHCF}$ batteries (450 $\mathrm{mAh} \mathrm{g}^{-1}$ ). d Cycling performance of PNDIE//Ca ${ }_{0.3} \mathrm{CuHCF}$ batteries $\left(400 \mathrm{mAh} \mathrm{g}^{-1}\right.$ ). Reproduced with permission from Ref. [112]. Copyright 2017, Wiley-VCH 


\subsection{Aqueous Aluminum-Ion Batteries (AAIBs)}

Aluminum possesses a high specific volumetric capacity $\left(8046 \mathrm{mAh} \mathrm{cm}^{-3}\right)$ and high gravimetric capacity (2980 mAh $\mathrm{g}^{-1}$ ), which is comparable to that of Li metal, and it has high abundance (ca. 8 wt\% of the Earth's crust) and is cheapest in production except iron. In addition, aluminum metal has better air stability than lithium, reducing potential safety risks, and it is also environmentally friendly. The introduction of room-temperature ionic liquids (RTILs) with a wide electrochemical window of stability improved the reversibility of the stripping/plating process of $\mathrm{Al}$ - a breakthrough opening up a viable track for rechargeable aluminum-ion batteries (AIBs) [113-115]. In recent years, successful preparation of new electrolytes and improved understanding of the nature of the SEI led to the development of AAIBs $[116,117]$. Many researchers have explored new electrode materials for AAIBs such as $\mathrm{TiO}_{2}[118-121], \mathrm{MoO}_{3}[122,123], \mathrm{WO}_{3}$ [124], $\mathrm{FeVO}_{4}$ [125] and PBAs [126-128]), and some reviews have summarized this work comprehensively [129-132]. We therefore discuss this aspect only briefly and focus on recent research progress on high-energy rechargeable AAIBs based on $\mathrm{Al}$ metal. Table 3 provides details of the performance of AAIBs reported to date.

Using aluminum as the negative electrode of an AAIB is an exciting breakthrough. $5 \mathrm{~m}$ aluminum trifluoromethanesulfonate $\left[\mathrm{Al}(\mathrm{OTf})_{3}\right]$ aqueous solution was reported as an electrolyte with a potential window of -0.3 to $3.3 \mathrm{~V}$ (vs. $\mathrm{Al}^{3+} / \mathrm{Al}$ ) and ability to obtain reversible deposition/stripping of aluminum (Fig. 20) [116]. Based on this electrolyte, an AAIB was assembled with an $\mathrm{Al}$ metal negative electrode and an $\mathrm{Al}_{x} \mathrm{MnO}_{2} \cdot n \mathrm{H}_{2} \mathrm{O}$ positive electrode, which had an average potential $(1.1 \mathrm{~V})$ and an outstanding energy density of $481 \mathrm{Wh} \mathrm{kg}^{-1}$ [117].

It is well known that a passivating $\mathrm{Al}_{2} \mathrm{O}_{3}$ layer is formed rapidly and irreversibly on the surface of $\mathrm{Al}$ metal in air, which hampers efforts to make highly reversible waterbased aluminum electrochemical cells. Recently, it was reported that an ionic liquid (IL)-enriched interphase on an $\mathrm{Al}$ surface could be obtained by immersing $\mathrm{Al}$ in the acidic (a)

Potential vs $\mathrm{Ag} / \mathrm{AgCl}(\mathrm{V})$

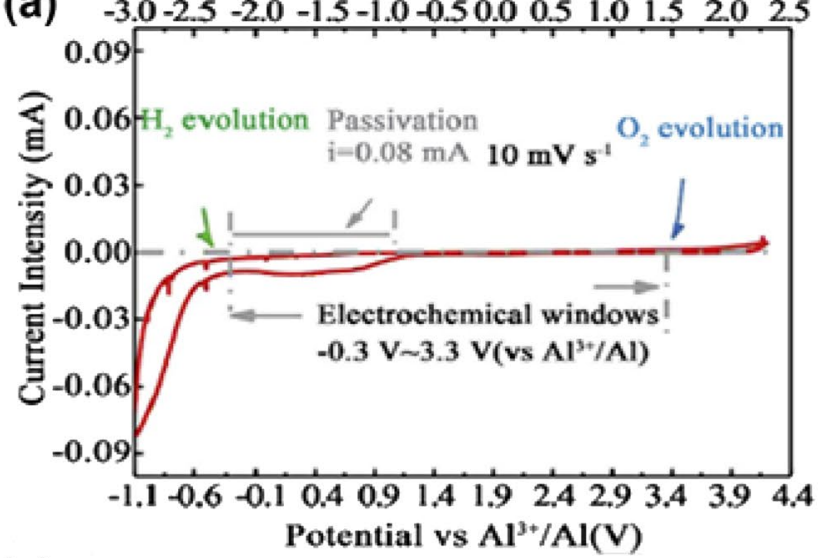

(c)

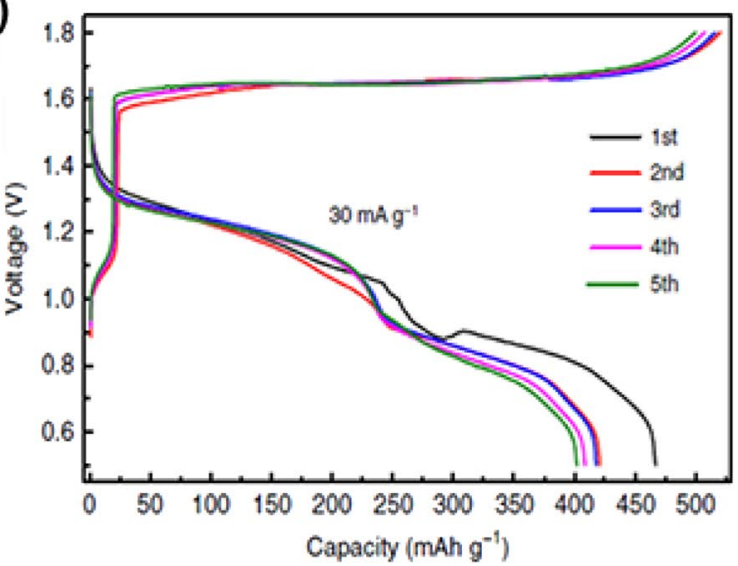

Fig. 20 a Electrochemical stability window of $5 \mathrm{~m} \mathrm{Al}(\mathrm{OTF})_{3}$ aqueous solution (glassy carbon, $10 \mathrm{mV} \mathrm{s}^{-1}$ ). b Constant-current charge-discharge curve of $\mathrm{Al}-\mathrm{Al}$ symmetrical cell $\left(5 \mathrm{~m} \mathrm{Al}(\mathrm{OTF})_{3}\right)$. c Charge- (b)
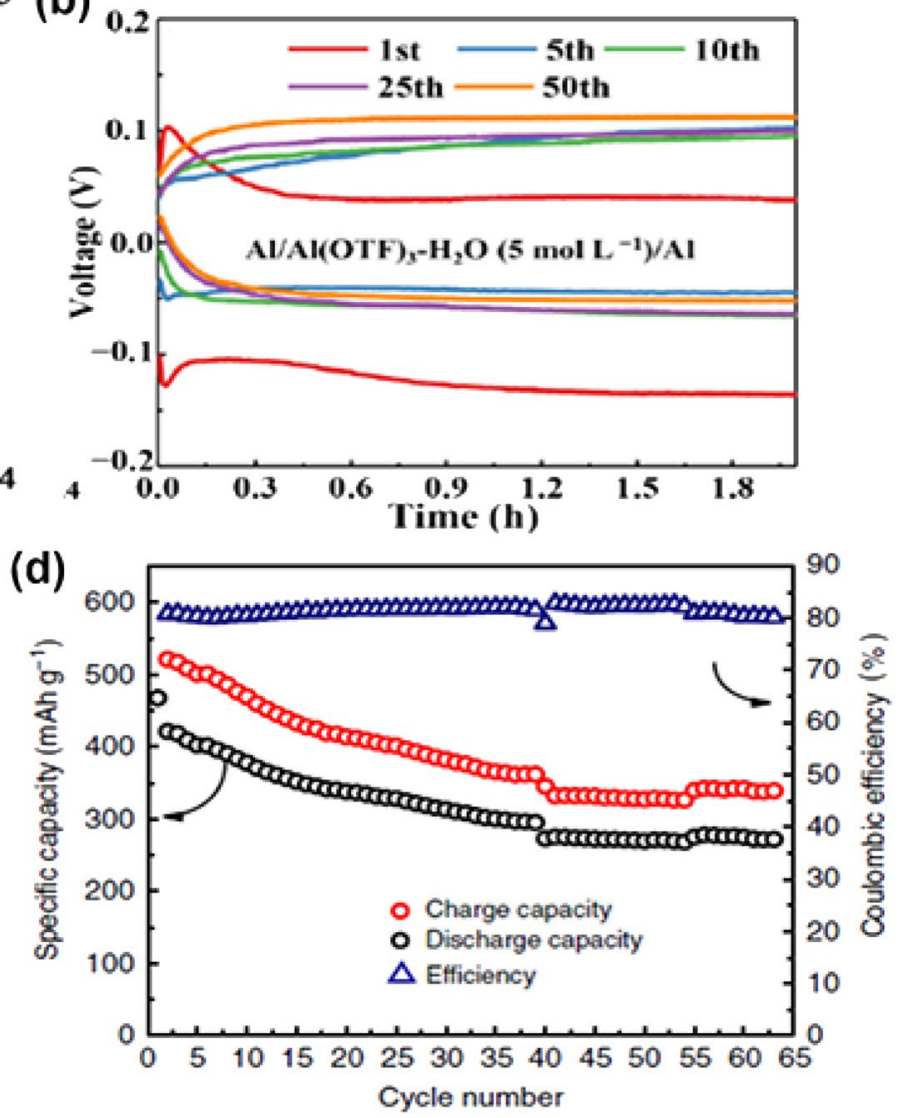

discharge curve of the first five cycles of $\mathrm{Al}-\mathrm{MnO}_{2}$ battery. $\mathbf{d}$ Cycling performance of $\mathrm{Al}-\mathrm{MnO}_{2}$ battery. Reproduced with permission from Ref. [117], Copyright 2019 Nature Publishing Group 

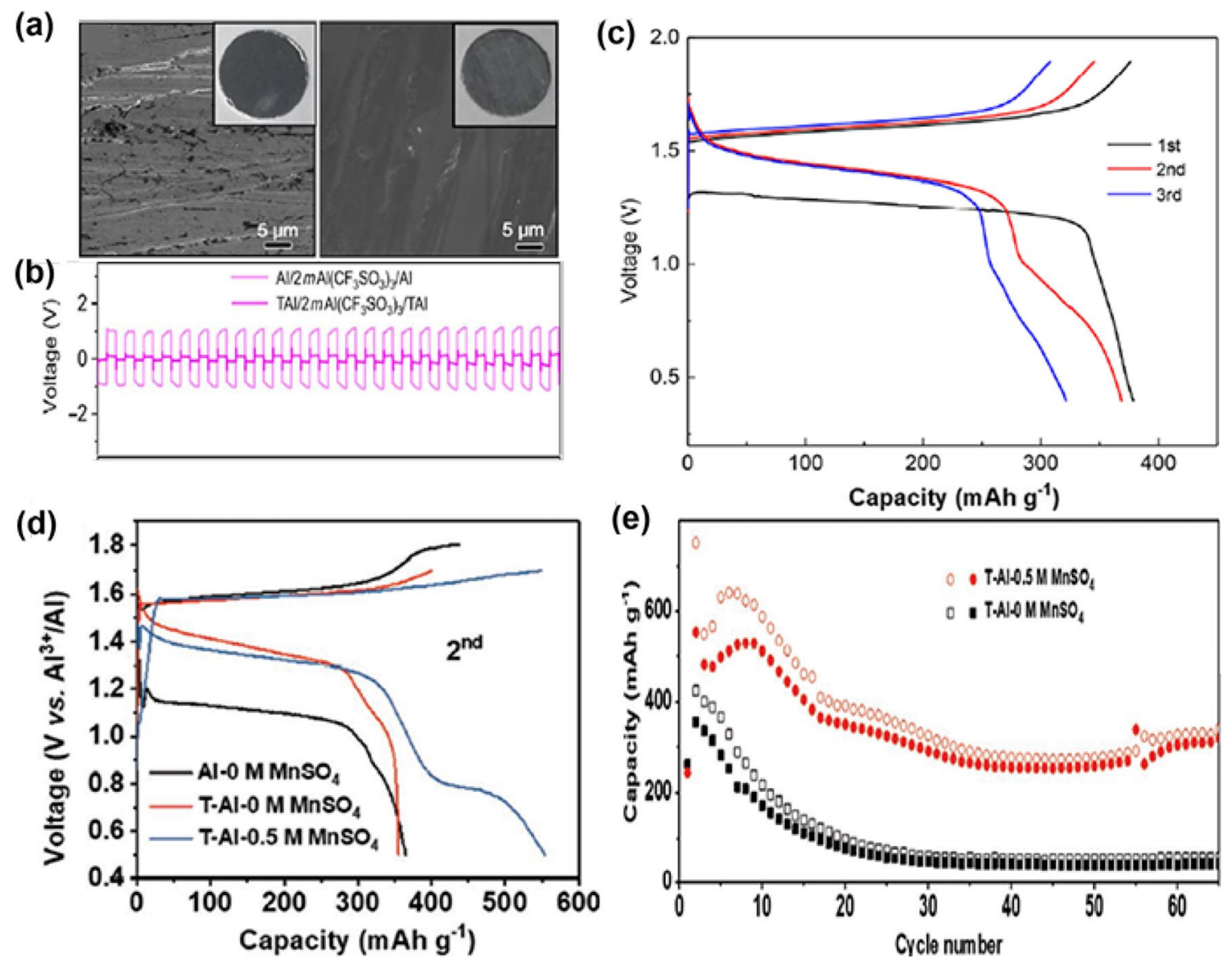

Fig. 21 a SEM image of $\mathrm{Al}$ foil (left) and $\mathrm{T}-\mathrm{Al}$ foil (right). b Constant-current charge-discharge curve of $\mathrm{Al}-\mathrm{Al}$ and $\mathrm{T}-\mathrm{Al} / \mathrm{T}-\mathrm{Al}$ symmetrical cells $\left[2 \mathrm{~m} \mathrm{Al}\left(\mathrm{CF}_{3} \mathrm{SO}_{3}\right)_{3}\right]$. Reproduced with permission from Ref. [116]. Copyright 2018, AAAS. c Galvanostatic discharge/charge curves of aqueous $\mathrm{Al}$ batteries $\left[2 \mathrm{~m} \mathrm{Al}\left(\mathrm{CF}_{3} \mathrm{SO}_{3}\right)_{3}, 100 \mathrm{~mA} \mathrm{~g}{ }^{-1}\right]$. d

IL electrolyte consisting of $\mathrm{AlCl}_{3}$-[EMIm] $\mathrm{Cl}$ for more than 1 day, which corroded the passivation film of $\mathrm{Al}_{2} \mathrm{O}_{3}$ and prevented its subsequent formation [117]. In addition, this kind of interface is permanent and conducive to the migration of $\mathrm{Al}^{3+}$. Using this artificial SEI, a T-Al (a ILtreated $\mathrm{Al}$ anode) $/ / \mathrm{MnO}_{2}$ aqueous battery was built up by using aqueous $\mathrm{Al}\left(\mathrm{CF}_{3} \mathrm{SO}_{3}\right)_{3}$ electrolytes, which could be recycled and exhibited no significant hydrogen evolution. This AAIB showed a midpoint voltage of $1.37 \mathrm{~V}$ and a plateau voltage of $1.40 \mathrm{~V}$, providing specific energy of about $500 \mathrm{Wh} \mathrm{kg}^{-1}$ (Fig. 21). The performance was further improved by pre-addition of $0.5 \mathrm{~m} \mathrm{MnSO}_{4}$ into the $\mathrm{Al}(\mathrm{OTf})_{3}$ aqueous electrolyte, which is similar to the $\mathrm{Zn} /$ $\mathrm{MnO}_{2}$ battery where a $\mathrm{Mn}^{2+}$ salt improves both capacity and cycling performance of the manganese oxide electrode [133]. This T- $\mathrm{Al} / 0.5 \mathrm{Mn} / \mathrm{Bir}-\mathrm{MnO}_{2}$ battery exhibited a remarkable energy density $\left(620 \mathrm{Wh} \mathrm{kg}^{-1}\right.$ based on the mass of birnessite-type $\mathrm{MnO}_{2}$ ) and high capacity retention.

The second constant current discharge-charge curves of the Al/Bir$\mathrm{MnO}_{2}, \mathrm{~T}-\mathrm{Al} / \mathrm{Bir}-\mathrm{MnO}_{2}$, and $\mathrm{T}-\mathrm{Al} / 0.5 \mathrm{Mn} / \mathrm{Bir}-\mathrm{MnO}_{2}$ batteries $(100$ $\mathrm{mAh} \mathrm{g}^{-1}$ ). e Cycling performance of the $\mathrm{T}-\mathrm{Al} / \mathrm{Bir}-\mathrm{MnO}_{2}$ and $\mathrm{T}-$ $\mathrm{Al} / 0.5 \mathrm{Mn} / \mathrm{Bir}-\mathrm{MnO}_{2}$ batteries. Reproduced with permission from Ref. [133]. Copyright 2019, Wiley-VCH

WiS aqueous $\mathrm{AlCl}_{3}$ as electrolytes was applied to build AAIBs based on $\mathrm{Al}$ metal, whose formulation managed to lower the onset potential of the hydrogen evolution reaction to ca. $-2.3 \mathrm{~V}$ (vs. $\mathrm{Ag} / \mathrm{AgCl}$ ), which enabled $\mathrm{Al}^{3+}$ to deposit onto the aluminum negative electrode and expand the electrochemical stability window of AAIBs to roughly $4 \mathrm{~V}$ [134]. Based on this electrolyte, an $\mathrm{Al} /$ graphite battery with a high specific capacity of up to $165 \mathrm{mAh} \mathrm{g}^{-1}$, excellent stability with nearly $99 \%$ capacity retention, and a specific energy of $220 \mathrm{Wh} \mathrm{kg}^{-1}$ was successfully assembled (Fig. 22).

Due to the limited solubility of $\mathrm{Al}(\mathrm{OTf})_{3}$ in water, it is very hard to obtain an analogous WiS electrolyte for AAIBs. However, other highly soluble salts, such as LiTFSI, can be introduced to form WiS electrolytes. For example, a mixed electrolyte comprising $1 \mathrm{~m}$ $\mathrm{Al}(\mathrm{OTf})_{3}+17 \mathrm{~m} \mathrm{LiTFSI}+0.02 \mathrm{~m} \mathrm{HCl}$ was used to establish a rechargeable aqueous Al-S battery [135]. In this mixed electrolyte, the superconcentrated LiTFSI not only 
Fig. 22 a Schematic diagram of an $\mathrm{Al}$ graphite battery during discharge. b Constant-current charge-discharge curves of $\mathrm{Al}$ graphite cells at different current densities. c Cycling performance of $\mathrm{Al}$ graphite batteries $\left(500 \mathrm{~mA} \mathrm{~g}^{-1}\right)$. Reproduced with permission from Ref. [134]. Copyright 2019, Royal Society of Chemistry (a)

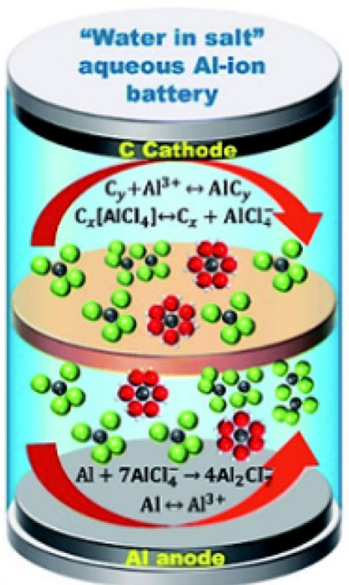

(c)

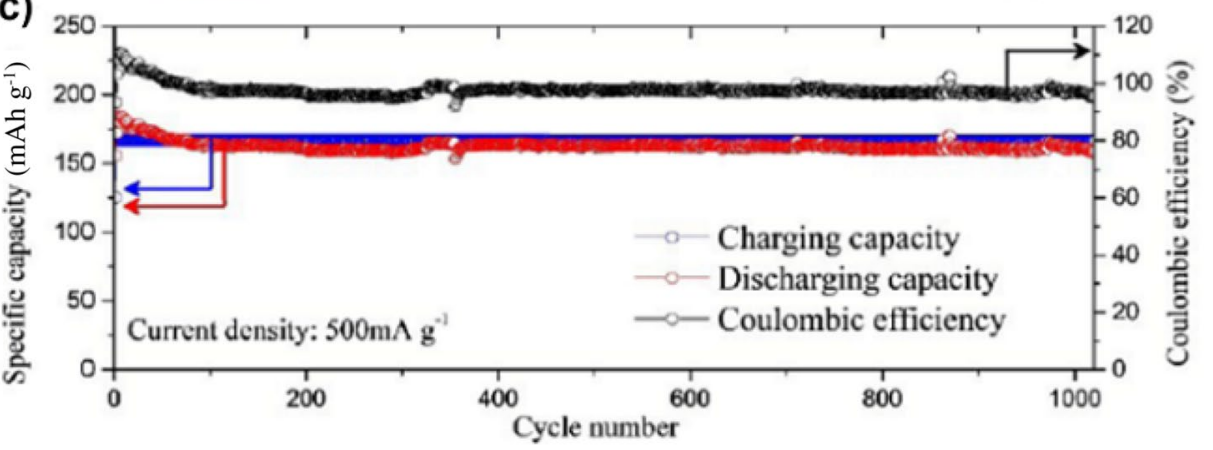

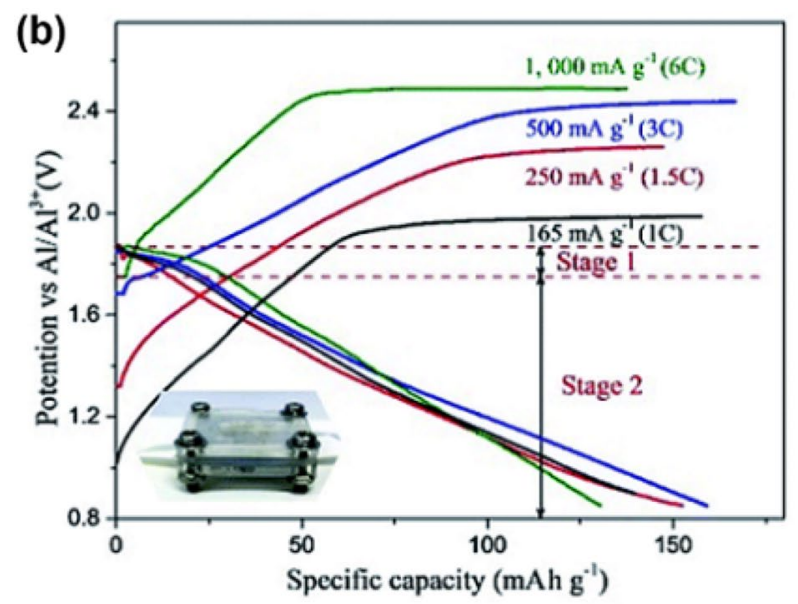

Cycle number

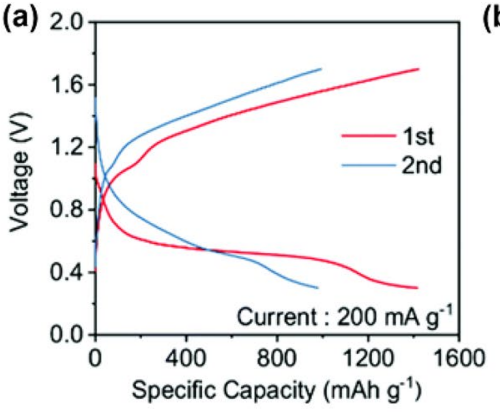

(b)

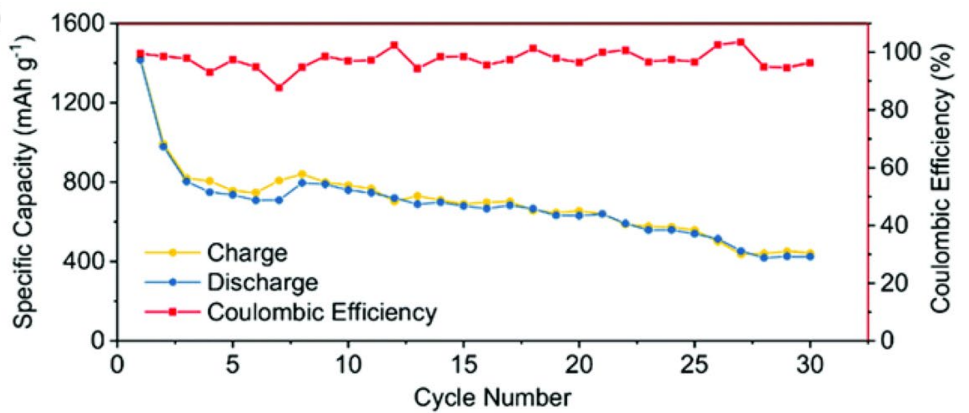

Fig. 23 a Galvanostatic charge-discharge curves of the first two cycles of $\mathrm{Al}\left\|\mathrm{Al}(\mathrm{OTf})_{3}+\mathrm{LiTFSI}+\mathrm{HCl}\right\| \mathrm{S} / \mathrm{C}$ batteries $\left(200 \mathrm{~mA} \mathrm{~g}^{-1}\right)$. b Cycling performance of $\mathrm{Al}\left\|\mathrm{Al}(\mathrm{OTf})_{3}+\mathrm{LiTFSI}+\mathrm{HCl}\right\| \mathrm{S} / \mathrm{C}$ batteries

inhibited the hydrolysis of polysulfide on the positive electrode, but also reduced the hydrogen evolution side reaction on the negative electrode, while the $\mathrm{HCl}$ additive prevented the formation of a passivation layer on the negative electrode surface. The assembled Al-S battery delivered an initial capacity of $1410 \mathrm{mAh} \mathrm{g}^{-1}$ (based on the mass of sulfur) and maintained a reversible capacity of $420 \mathrm{mAh} \mathrm{g}^{-1}$ after 30 cycles with acceptable coulombic efficiency of $97 \%$ (Fig. 23).
(200 mA g $\left.{ }^{-1}\right)$. Reproduced with permission from Ref. [135]. Copyright 2020, Royal Society of Chemistry

\section{Conclusions and Challenges}

Compared with the traditional organic LIBs, aqueous batteries have many unique advantages, such as low cost, high power, safety, and environmental protection. They have great potential in the large-scale fixed energy storage and small-scale electronic fields involving wearable applications. The introduction of aqueous electrolytes results in great advantages, eliminating the use of expensive, flammable, and toxic organic electrolytes. However, due to the narrow electrochemical stability window $(1.23 \mathrm{~V})$ of water, 
the working voltage of aqueous batteries is inevitably limited by an aqueous electrolyte. Therefore, compared with organic electrolyte-based batteries, ARBs usually exhibit lower energy densities. In order to alleviate this problem, effective strategies are proposed to widen the electrolyte solution voltage window, so that ARBs have a higher working voltage. Although many effective strategies were developed for high-voltage ARBs, these strategies are often complex or expensive. Specifically, the effect of adjusting the $\mathrm{pH}$ of the electrolyte is moderate, and the requirements for the cell structure may be higher, leading either to side reactions of electrode materials or to corrosion or to safety problems. Artificial interfaces are much more complex to construct, often requiring an extra layer of lithium-ion conductors and organic electrolytes to enable the use of low-potential lithium metals or carbon negative electrodes, which means that cost and safety issues are actually not well addressed. The new-generation WiS/WibS electrolytes and hydratemelt electrolytes have wide voltage windows and low redox potentials, enabling cycling of electrode materials in aqueous solution. However, costly salts containing large organic groups are mostly used, and too high a concentration can further increase costs. The SEI-like interphase formed by the decomposition of the electrolyte additives is usually composed of organic components and WiS/WibS electrolytes. Consequently, less expensive and more practical approaches must be followed. Much experience has been gained in building artificial SEIs in existing LIBs, which can be applied to ARBs with appropriate tweaking to meet the cost and simplicity aiming for industrial application. In addition, many projects utilizing WiS/WibS electrolytes and hydratemelt electrolytes are based on only a few kinds of organic salts, so that less expensive and more efficient alternatives can be found for building affordable high-voltage batteries. It was reported that some ionic liquids provide good supporting electrolytes, and mixing with water can reduce the disadvantage of high viscosity and low ionic conductivity, which may turn out to be a promising research direction. In addition, gel polymer electrolytes (GPEs) were found to tolerate high voltages, due to water molecules either being "locked" in molecular cages and interacting with polymer chains, or due to ionic conduction facilitated by polymer $\mathrm{O} \rightarrow \mathrm{B}^{-}$coordination bonds. Although more comprehensive studies are needed to uncover the underlying mechanism, it would be encouraging to find a GPE that has a stronger inhibitory effect on water electrolysis.

To further develop high-energy aqueous batteries, some challenges should be solved:

1. Further understanding of the energy storage mechanism. Although great progress has been made in the development of high-energy aqueous batteries, the understanding of the electrochemical reaction mechanism is not very deep, and there are still many controversies on the interpretation of some electrochemical processes. Therefore, it is necessary to find a consistent theoretical basis for the relationship between electrode configurations and electrochemical performance, which will provide a convincing basis for further improvement in electrochemical performance. Considering the diversity of electrochemical systems and electrode materials, it seems nearly impossible to establish a general theoretical system based on the general empirical rules. Although the embedding and deblocking processes of ions in electrode materials are similar, common mechanisms are rare in different ARBs, so most of the existing explanations for the electrochemical mechanisms are put forward one by one. From the point of view of voltage, it can provide a theory with high generality and practicability to build a high-energy ARB system from different perspectives, without considering the type of batteries and electrodes. For example, if the material has a flat discharge plateau, it means that it can release energy stably and has high energy efficiency. If instead the material has an inclined discharge curve, it means that its electrochemical kinetics is relatively slow. Therefore, development of a general method to manage the electrochemical performance of ARBs may be possible by studying the general strategy of modifying the discharge plateau and other voltage features. To this end, accurate analysis technology and conclusive theoretical calculation/simulation are essential.

2. Exploring new electrode materials. New electrode materials should expand the output voltage and energy density of ARBs effectively. Because the voltage windows of aqueous electrolytes are narrow, it is very important to make full use of the voltage window by using appropriate electrode materials. The redox potential of electrode materials is affected by the $\mathrm{pH}$, concentration of electrolyte salt, and crystal orientations of materials, so it is necessary to control the whole electrochemical system more comprehensively and accurately. When choosing suitable electrode materials, materials with a high stable voltage plateau and/or high specific capacity should be selected. In addition, the stability of the material in the electrolyte solution should be considered, which is very important for good cycling performance of the assembled ARB. As a result, further modification methods should also be considered such as doping, coating, and hybridization.

3. Electrolyte additives. So far very little work has been published on the choice of additives. However, they can greatly influence the stability of active electrode materials, the charge transfer process, and electrochemical performance, such as capacity, rate capability, and cycle 
lifes. If further theoretical calculations can be used to guide this aspect, great progress can be achieved.

4. Optimization of battery chemistry. According to Volta's classic theories, a battery can be built if there is a redox potential difference between two electrode materials. However, there is a great variety of battery chemistry. As a result, an optimization should be carried out by considering the above-mentioned mechanisms, electrode materials, electrolytes, the electrochemical window of water, oxygen/hydrogen evolution, and possible corrosion of current collectors.

5. Possible demonstrations. So far, few actual ARBs have been demonstrated. However, the current energy and environmental challenges provide a good opportunity for large-scale energy storage. With government assistance, some demonstration systems will be useful to show the advantages of ARBs, so that their further commercialization can be promoted.

When these challenges are solved, a bright future for ARBs will lie ahead.

Acknowledgements Financial support from Distinguished Young Scientists Program of the National Natural Science Foundation of China (51425301, 21374021, 51673096, and U1601214) and Research Foundation of State Key Laboratory (ZK201805, ZK201717), the Jiangsu Distinguished Professorship Program (2016), the Research Foundation of State Key Lab (ZK201805 and ZK201717), and St. Petersburg State University (Grant No. 26455158) is gratefully acknowledged.

Open Access This article is licensed under a Creative Commons Attribution 4.0 International License, which permits use, sharing, adaptation, distribution and reproduction in any medium or format, as long as you give appropriate credit to the original author(s) and the source, provide a link to the Creative Commons licence, and indicate if changes were made. The images or other third party material in this article are included in the article's Creative Commons licence, unless indicated otherwise in a credit line to the material. If material is not included in the article's Creative Commons licence and your intended use is not permitted by statutory regulation or exceeds the permitted use, you will need to obtain permission directly from the copyright holder. To view a copy of this licence, visit http://creativecommons.org/licenses/by/4.0/.

\section{References}

1. Dunn, B., Kamath, H., Tarascon, J.M.: Electrical energy storage for the grid: a battery of choices. Science 334, 928-935 (2011)

2. Yang, Z., Zhang, J., Kintner-Meyer, M.C., et al.: Electrochemical energy storage for green grid. Chem. Rev. 111, 3577-3613 (2011)

3. Liu, Z., Huang, Y., Huang, Y., et al.: Voltage issue of aqueous rechargeable metal-ion batteries. Chem. Soc. Rev. 49, 180-232 (2020)

4. Li, W., Dahn, J.R., Wainwright, D.S.: Rechargeable lithium batteries with aqueous electrolytes. Science 264, 1115-1118 (1994)

5. Eftekhari, A.: High-energy aqueous lithium batteries. Adv. Energy Mater. 8, 1801156 (2018)
6. Kim, H., Hong, J., Park, K.Y., et al.: Aqueous rechargeable Li and $\mathrm{Na}$ ion batteries. Chem. Rev. 114, 11788-11827 (2014)

7. Liu, J., Xu, C., Chen, Z., et al.: Progress in aqueous rechargeable batteries. Green Energy Environ. 3, 20-41 (2018)

8. Malik, R.: Aqueous Li-Ion batteries: now in striking distance. Joule 1, 17-19 (2017)

9. Demir-Cakan, R., Palacin, M.R., Croguennec, L.: Rechargeable aqueous electrolyte batteries: from univalent to multivalent cation chemistry. J. Mater. Chem. A 7, 20519-20539 (2019)

10. Liu, J., Guan, C., Zhou, C., et al.: A flexible quasi-solid-state nickel-zinc battery with high energy and power densities based on 3D electrode design. Adv. Mater. 28, 8732-8739 (2016)

11. Suo, L., Borodin, O., Gao, T., et al.: "Water-in-salt" electrolyte enables high-voltage aqueous lithium ion chemistries. Science 350, 938-943 (2015)

12. Suo, L., Han, F., Fan, X., et al.: "Water-in-Salt" electrolytes enable green and safe $\mathrm{Li}$-ion batteries for large scale electric energy storage applications. J. Mater. Chem. A 4, 6639-6644 (2016)

13. Sun, W., Suo, L., Wang, F., et al.: "Water-in-Salt" electrolyte enabled $\mathrm{LiMn}_{2} \mathrm{O}_{4} / \mathrm{TiS}_{2}$ lithium ion batteries. Electrochem. Commun. 82, 71-74 (2017)

14. Yang, C., Ji, X., Fan, X., et al.: Flexible aqueous Li-ion battery with high energy and power densities. Adv. Mater. 29, 1701972 (2017)

15. Wang, G., Fu, L., Zhao, N., et al.: An aqueous rechargeable lithium battery with good cycling performance. Angew. Chem. Int. Ed. 46, 295-297 (2007)

16. Ruffo, R., Wessells, C., Huggins, R.A., et al.: Electrochemical behavior of $\mathrm{LiCoO}_{2}$ as aqueous lithium ion battery electrodes. Electrochem. Commun. 11, 247-249 (2009)

17. Wang, G.J., Qu, Q.T., Wang, B., et al.: Electrochemical behavior of $\mathrm{LiCoO}_{2}$ in a saturated aqueous $\mathrm{Li}_{2} \mathrm{SO}_{4}$ solution. Electrochim. Acta 54, 1199-1203 (2009)

18. Tang, W., Liu, L.L., Tian, S., et al.: Nano- $\mathrm{LiCoO}_{2}$ as cathode material of large capacity and high rate capability for aqueous rechargeable lithium batteries. Electrochem. Commun. 12, 1524-1526 (2010)

19. Wang, F., Lin, Y., Suo, L., et al.: Stabilizing high voltage $\mathrm{LiCoO}_{2}$ cathode in aqueous electrolyte with interphase-forming additive. Energy Environ. Sci. 9, 3666-3673 (2016)

20. Wang, F., Suo, L., Liang, Y., et al.: Spinel $\mathrm{LiNi}_{0.5} \mathrm{Mn}_{1.5} \mathrm{O}_{4}$ cathode for high-energy aqueous lithium ion batteries. Adv. Energy Mater. 7, 1600922 (2017)

21. Suo, L., Borodin, O., Sun, W., et al.: Advanced high-voltage aqueous lithium ion battery enabled by "water-in-bisalt" electrolyte. Angew. Chem. Int. Ed. 55, 7136-7141 (2016)

22. Lukatskaya, M.R., Feldblyum, J.I., Mackanic, D.G., et al.: Concentrated mixed cation acetate "water-in-salt" solutions as green and low-cost high voltage electrolytes for aqueous batteries. Energy Environ. Sci. 11, 2876-2883 (2018)

23. Yamada, Y., Usui, K., Sodeyama, K., et al.: Hydrate-melt electrolytes for high-energy-density aqueous batteries. Nat. Energy 1, 16129 (2016)

24. Wu, S., Qiao, Y., Yang, S., et al.: Clean electrocatalysis in a $\mathrm{Li}_{2} \mathrm{O}_{2}$ redox-based $\mathrm{Li}-\mathrm{O}_{2}$ battery built with a hydrate-melt electrolyte. ACS Catal. 8, 1082-1089 (2018)

25. Wang, F., Borodin, O., Ding, M.S., et al.: Hybrid aqueous/nonaqueous electrolyte for safe and high-energy Li-ion batteries. Joule 2, 927-937 (2018)

26. Dou, Q., Lei, S., Wang, D.W., et al.: Safe and high-rate supercapacitors based on an "acetonitrile/water-in-salt" hybrid electrolyte. Energy Environ. Sci. 11, 3212-3219 (2018)

27. Chen, J., Vatamanu, J., Xing, L., et al.: Improving electrochemical stability and low-temperature performance with water/acetonitrile hybrid electrolytes. Adv. Energy Mater. 10, 1902654 (2019) 
28. He, X., Yan, B., Zhang, X., et al.: Fluorine-free water-inionomer electrolytes for sustainable lithium ion batteries. Nat. Commun. 9, 5320 (2018)

29. Yang, C., Chen, J., Qing, T., et al.: $4.0 \mathrm{~V}$ Aqueous Li-ion batteries. Joule 1, 122-132 (2017)

30. Yang, C., Chen, J., Ji, X., et al.: Aqueous Li-ion battery enabled by halogen conversion-intercalation chemistry in graphite. Nature 569, 245-250 (2019)

31. Wang, X., Hou, Y., Zhu, Y., et al.: An aqueous rechargeable lithium battery using coated Li metal as anode. Sci. Rep. 3, 1401 (2013)

32. Wang, X., Qu, Q., Hou, Y., et al.: An aqueous rechargeable lithium battery of high energy density based on coated Li metal and $\mathrm{LiCoO}_{2}$. Chem. Commun. 49, 6179-6181 (2013)

33. Chang, Z., Li, C., Wang, Y., et al.: A lithium ion battery using an aqueous electrolyte solution. Sci. Rep. 6, 28421 (2016)

34. Le, H.T.T., Ngo, D.T., Kim, Y.J., et al.: A perovskite-structured aluminium-substituted lithium lanthanum titanate as a potential artificial solid-electrolyte interface for aqueous rechargeable lithium-metal-based batteries. Electrochim. Acta 248, 232-242 (2017)

35. Li, H., Wang, Y., Na, H., et al.: Rechargeable Ni-Li battery integrated aqueous/nonaqueous system. J. Am. Chem. Soc. 131, 15098-15099 (2009)

36. Zhang, M., Huang, Z., Shen, Z., et al.: High-performance aqueous rechargeable Li-Ni battery based on $\mathrm{Ni}(\mathrm{OH})_{2} / \mathrm{NiOOH}$ redox couple with high voltage. Adv. Energy Mater. 7, 1700155 (2017)

37. Yan, J., Wang, J., Liu, H., et al.: Rechargeable hybrid aqueous batteries. J. Power Sources 216, 222-226 (2012)

38. Zhi, J., Yazdi, A.Z., Valappil, G., et al.: Artificial solid electrolyte interphase for aqueous lithium energy storage systems. Sci. Adv. 3, e1701010 (2017)

39. Zhu, X., Hoang, T.K.A., Tan, G., et al.: Tuning microstructures of graphene to improve power capability of rechargeable hybrid aqueous batteries. ACS Appl. Mater. Interfaces 10, 37110-37118 (2018)

40. Wu, X., Li, Y., Li, C., et al.: The electrochemical performance improvement of $\mathrm{LiMn}_{2} \mathrm{O}_{4} / \mathrm{Zn}$ based on zinc foil as the current collector and thiourea as an electrolyte additive. J. Power Sources 300, 453-459 (2015)

41. Lu, C., Hoang, T.K.A., Doan, T.N.L., et al.: Rechargeable hybrid aqueous batteries using silica nanoparticle doped aqueous electrolytes. Appl. Energy 170, 58-64 (2016)

42. Hoang, T.K.A., Doan, T.N.L., Lu, C., et al.: Performance of thixotropic gel electrolytes in the rechargeable aqueous $\mathrm{Zn} /$ $\mathrm{LiMn}_{2} \mathrm{O}_{4}$ battery. ACS Sustain. Chem. Eng. 5, 1804-1811 (2016)

43. Hoang, T.K.A., Doan, T.N.L., Cho, J.H., et al.: Sustainable gel electrolyte containing pyrazole as corrosion inhibitor and dendrite suppressor for aqueous $\mathrm{Zn} / \mathrm{LiMn}_{2} \mathrm{O}_{4}$ battery. ChemSusChem 10, 2816-2822 (2017)

44. Wang, F., Borodin, O., Gao, T., et al.: Highly reversible zinc metal anode for aqueous batteries. Nat. Mater. 17, 543-549 (2018)

45. Zhao, J., Zhang, J., Yang, W., et al.: "Water-in-deep eutectic solvent" electrolytes enable zinc metal anodes for rechargeable aqueous batteries. Nano Energy 57, 625-634 (2019)

46. Yang, C., Suo, L., Borodin, O., et al.: Unique aqueous Li-ion/ sulfur chemistry with high energy density and reversibility. Proc. Natl. Acad. Sci. USA 114, 6197-6202 (2017)

47. Wang, F., Liu, Y., Wang, X., et al.: Aqueous rechargeable battery based on zinc and a composite of $\mathrm{LiNi}_{1 / 3} \mathrm{Co}_{1 / 3} \mathrm{Mn}_{1 / 3} \mathrm{O}_{2}$. ChemElectroChem 2, 1024-1030 (2015)
48. Zhao, J., Li, Y., Peng, X., et al.: High-voltage $\mathrm{Zn} / \mathrm{LiMn}{ }_{0.8} \mathrm{Fe}_{0.2} \mathrm{PO}_{4}$ aqueous rechargeable battery by virtue of "water-in-salt" electrolyte. Electrochem. Commun. 69, 6-10 (2016)

49. Qu, Q.T., Shi, Y., Tian, S., et al.: A new cheap asymmetric aqueous supercapacitor: activated carbon//NaMnO ${ }_{2}$. J. Power Sources 194, 1222-1225 (2009)

50. Gao, H., Goodenough, J.B.: An aqueous symmetric sodium-ion battery with NASICON-structured $\mathrm{Na}_{3} \mathrm{MnTi}\left(\mathrm{PO}_{4}\right)_{3}$. Angew. Chem. Int. Ed. 55, 12768-12772 (2016)

51. Wang, H., Zhang, T., Chen, C., et al.: High-performance aqueous symmetric sodium-ion battery using NASICON-structured $\mathrm{Na}_{2} \mathrm{VTi}\left(\mathrm{PO}_{4}\right)_{3}$. Nano Res. 11, 490-498 (2017)

52. Qiu, S., Wu, X., Wang, M., et al.: NASICON-type $\mathrm{Na}_{3} \mathrm{Fe}_{2}\left(\mathrm{PO}_{4}\right)_{3}$ as a low-cost and high-rate anode material for aqueous sodiumion batteries. Nano Energy 64, 103941 (2019)

53. Suo, L., Borodin, O., Wang, Y., et al.: "Water-in-salt" electrolyte makes aqueous sodium-ion battery safe, green, and long-lasting. Adv. Energy Mater. 7, 1701189 (2017)

54. Kühnel, R.-S., Reber, D., Battaglia, C.: A high-voltage aqueous electrolyte for sodium-ion batteries. ACS Energy Lett. 2, 2005-2006 (2017)

55. Jiang, L., Liu, L., Yue, J., et al.: High-voltage aqueous Na-ion battery enabled by inert-cation-assisted water-in-salt electrolyte. Adv. Mater. 32, 1904427 (2019)

56. Hou, Z., Zhang, X., Ao, H., et al.: Passivation effect for current collectors enables high-voltage aqueous sodium ion batteries. Mater. Today Energy 14, 100337 (2019)

57. Zhang, B., Liu, Y., Wu, X., et al.: An aqueous rechargeable battery based on zinc anode and $\mathrm{Na}_{0.95} \mathrm{MnO}_{2}$. Chem. Commun. 50, 1209-1211 (2014)

58. Kumar, P.R., Jung, Y.H., Lim, C.H., et al.: $\mathrm{Na}_{3} \mathrm{~V}_{2} \mathrm{O}_{2 x}\left(\mathrm{PO}_{4}\right)_{2} \mathrm{~F}_{3-2 x}$ : a stable and high-voltage cathode material for aqueous sodiumion batteries with high energy density. J. Mater. Chem. A 3, 6271-6275 (2015)

59. Hou, Z., Zhang, X., Li, X., et al.: Surfactant widens the electrochemical window of an aqueous electrolyte for better rechargeable aqueous sodium/zinc battery. J. Mater. Chem. A 5, 730-738 (2017)

60. Jiang, L., Lu, Y., Zhao, C., et al.: Building aqueous K-ion batteries for energy storage. Nat. Energy 4, 495-503 (2019)

61. Wu, X., Qi, Y., Hong, J.J., et al.: Rocking-chair ammoniumion battery: a highly reversible aqueous energy storage system. Angew. Chem. Int. Ed. 56, 13026-13030 (2017)

62. Zhang, Y., An, Y., Yin, B., et al.: A novel aqueous ammonium dual-ion battery based on organic polymers. J. Mater. Chem. A 7, 11314-11320 (2019)

63. Holoubek, J.J., Jiang, H., Leonard, D., et al.: Amorphous titanic acid electrode: its electrochemical storage of ammonium in a new water-in-salt electrolyte. Chem. Commun. 54, 9805-9808 (2018)

64. Li, C., Zhang, D., Ma, F., et al.: A high-rate and long-life aqueous rechargeable ammonium zinc hybrid battery. ChemSusChem 12, 3732-3736. https://doi.org/10.1002/cssc.201901622

65. Li, C., Wang, J., Ma, F., et al.: High-rate and high-voltage aqueous rechargeable zinc ammonium hybrid battery from selective cation intercalation cathode. ACS Appl. Energy Mater. 2, 6984-6989 (2019)

66. Gaikwad, A.M., Zamarayeva, A.M., Rousseau, J., et al.: Highly stretchable alkaline batteries based on an embedded conductive fabric. Adv. Mater. 24, 5071-5076 (2012)

67. Zeng, Y., Meng, Y., Lai, Z., et al.: An ultrastable and highperformance flexible fiber-shaped $\mathrm{Ni}-\mathrm{Zn}$ battery based on a $\mathrm{Ni}-\mathrm{NiO}$ heterostructured nanosheet cathode. Adv. Mater. 29, 1702698 (2017)

68. Wang, R., Han, Y., Wang, Z., et al.: Nickel@ nickel oxide core-shell electrode with significantly boosted reactivity for 
ultrahigh-energy and stable aqueous $\mathrm{Ni}-\mathrm{Zn}$ battery. Adv. Funct. Mater. 28, 1802157 (2018)

69. Wang, X., Li, M., Chang, Z., et al.: $\mathrm{Co}_{3} \mathrm{O}_{4} @$ MWCNT nanocable as cathode with superior electrochemical performance for supercapacitors. ACS Appl. Mater. Interfaces 7, 2280-2285 (2015)

70. Wang, X., Wang, F., Wang, L., et al.: An aqueous rechargeable $\mathrm{Zn} / / \mathrm{Co}_{3} \mathrm{O}_{4}$ battery with high energy density and good cycling behavior. Adv. Mater. 28, 4904-4911 (2016)

71. Liu, W., Zhang, J., Bai, Z., et al.: Controllable urchin-like $\mathrm{NiCo}_{2} \mathrm{~S}_{4}$ microsphere synergized with sulfur-doped graphene as bifunctional catalyst for superior rechargeable $\mathrm{Zn}$-air battery. Adv. Funct. Mater. 28, 1706675 (2018)

72. Wang, W., Tang, M., Zheng, Z., et al.: Alkaline polymer membrane-based ultrathin, flexible, and high-performance solid-state Zn-air battery. Adv. Energy Mater. 9, 1803628 (2019)

73. Li, H., Ma, L., Han, C., et al.: Advanced rechargeable zinc-based batteries: recent progress and future perspectives. Nano Energy 62, 550-587 (2019)

74. Zeng, X., Hao, J., Wang, Z., et al.: Recent progress and perspectives on aqueous $\mathrm{Zn}$-based rechargeable batteries with mild aqueous electrolytes. Energy Storage Mater. 20, 410-437 (2019)

75. Fang, G., Zhou, J., Pan, A., et al.: Recent advances in aqueous zinc-ion batteries. ACS Energy Lett. 3, 2480-2501 (2018)

76. Jia, H., Wang, Z., Tawiah, B., et al.: Recent advances in zinc anodes for high-performance aqueous $\mathrm{Zn}$-ion batteries. Nano Energy 70, 104523 (2020)

77. Selvakumaran, D., Pan, A., Liang, S., et al.: A review on recent developments and challenges of cathode materials for rechargeable aqueous Zn-ion batteries. J. Mater. Chem. A 7, 18209-18236 (2019)

78. Chen, L., An, Q., Mai, L.: Recent advances and prospects of cathode materials for rechargeable aqueous zinc-ion batteries. Adv. Mater. Interface 6, 1900387 (2019)

79. Yu, P., Zeng, Y., Zhang, H., et al.: Flexible Zn-ion batteries: recent progresses and challenges. Small 15, e1804760 (2019)

80. Li, C., Xie, X., Liang, S., et al.: Issues and future perspective on zinc metal anode for rechargeable aqueous zinc-ion batteries. Energy Environ. Mater. 3,146-159 (2020). https://doi. org/10.1002/eem2.12067

81. Huang, M., Li, M., Niu, C., et al.: Recent advances in rational electrode designs for high-performance alkaline rechargeable batteries. Adv. Funct. Mater. 29, 1807847 (2019)

82. Xie, J., Zhang, Q.: Recent progress in multivalent metal (Mg, Zn, $\mathrm{Ca}$, and $\mathrm{Al}$ ) and metal-ion rechargeable batteries with organic materials as promising electrodes. Small 15, 1805061 (2019)

83. Shin, J., Lee, J., Park, Y., et al.: Aqueous zinc ion batteries: focus on zinc metal anodes. Chem. Sci. 11, 2028-2044 (2020)

84. Huang, S., Zhu, J., Tian, J., et al.: Recent progress in the electrolytes of aqueous zinc-ion batteries. Chem. Eur. J. (2019). https ://doi.org/10.1002/chem.201902660

85. He, P., Chen, Q., Yan, M., et al.: Building better zinc-ion batteries: a materials perspective. Energy Chem. 1, 100022 (2019)

86. Song, M., Tan, H., Chao, D., et al.: Recent advances in Zn-ion batteries. Adv. Funct. Mater. 28, 1802564 (2018)

87. Pan, H., Shao, Y., Yan, P., et al.: Reversible aqueous zinc/manganese oxide energy storage from conversion reactions. Nat. Energy 1, 1-7 (2016)

88. Zhang, N., Cheng, F., Liu, J., et al.: Rechargeable aqueous zincmanganese dioxide batteries with high energy and power densities. Nat. Commun. 8, 405 (2017)

89. Xu, C., Li, B., Du, H., et al.: Energetic zinc ion chemistry: the rechargeable zinc ion battery. Angew. Chem. Int. Ed. 51, 933$935(2012)$
90. Chao, D., Zhou, W., Ye, C., et al.: An electrolytic $\mathrm{Zn}-\mathrm{MnO}_{2}$ battery for high-voltage and scalable energy storage. Angew. Chem. Int. Ed. 58, 7823-7828 (2019)

91. Sun, W., Wang, F., Hou, S., et al.: $\mathrm{Zn} / \mathrm{MnO}_{2}$ battery chemistry with $\mathrm{H}^{+}$and $\mathrm{Zn}^{2+}$ coinsertion. J. Am. Chem. Soc. 139, 97759778 (2017)

92. Fan, W., Liu, F., Liu, Y., et al.: A high voltage aqueous zinc-manganese battery using a hybrid alkaline-mild electrolyte. Chem. Commun. 56, 2039-2042 (2020)

93. Liu, C., Chi, X., Han, Q., et al.: A high energy density aqueous battery achieved by dual dissolution/deposition reactions separated in acid-alkaline electrolyte. Adv. Energy Mater. 10, 1903589 (2020)

94. Ma, L., Chen, S., Long, C., et al.: Achieving high-voltage and high-capacity aqueous rechargeable zinc ion battery by incorporating two-species redox reaction. Adv. Energy Mater. 9, 1902446 (2019)

95. Yan, M., He, P., Chen, Y., et al.: Water-lubricated intercalation in $\mathrm{V}_{2} \mathrm{O}_{5} \cdot \mathrm{nH}_{2} \mathrm{O}$ for high-capacity and high-rate aqueous rechargeable zinc batteries. Adv. Mater. 30, 1703725 (2018)

96. Wan, F., Zhang, L., Dai, X., et al.: Aqueous rechargeable zinc/ sodium vanadate batteries with enhanced performance from simultaneous insertion of dual carriers. Nat. Commun. 9, 1656 (2018)

97. Xia, C., Guo, J., Li, P., et al.: Highly stable aqueous zinc-ion storage using a layered calcium vanadium oxide bronze cathode. Angew. Chem. Int. Ed. 57, 3943-3948 (2018)

98. He, P., Quan, Y., Xu, X., et al.: High-performance aqueous zincion battery based on layered $\mathrm{H}_{2} \mathrm{~V}_{3} \mathrm{O}_{8}$ nanowire cathode. Small 13, 1702551 (2017)

99. Pang, Q., Sun, C., Yu, Y., et al.: $\mathrm{H}_{2} \mathrm{~V}_{3} \mathrm{O}_{8}$ nanowire/graphene electrodes for aqueous rechargeable zinc ion batteries with high rate capability and large capacity. Adv. Energy Mater. 8, 1800144 (2018)

100. Sambandam, B., Soundharrajan, V., Kim, S., et al.: $\mathrm{K}_{2} \mathrm{~V}_{6} \mathrm{O}_{16} \cdot 2.7 \mathrm{H}_{2} \mathrm{O}$ nanorod cathode: an advanced intercalation system for high energy aqueous rechargeable $\mathrm{Zn}$-ion batteries. J. Mater. Chem. A 6, 15530-15539 (2018)

101. Zhang, W., Liang, S., Fang, G., et al.: Ultra-high mass-loading cathode for aqueous zinc-ion battery based on graphene-wrapped aluminum vanadate nanobelts. Nano Micro Lett. 11, 69 (2019)

102. Ma, L., Li, N., Long, C.B., et al.: Achieving both high voltage and high capacity in aqueous zinc-ion battery for record high energy density. Adv. Funct. Mater. 29, 1906142 (2019)

103. Li, G., Yang, Z., Jiang, Y., et al.: Towards polyvalent ion batteries: a zinc-ion battery based on NASICON structured $\mathrm{Na}_{3} \mathrm{~V}_{2}\left(\mathrm{PO}_{4}\right)_{3}$. Nano Energy 25, 211-217 (2016)

104. Li, W., Wang, K., Cheng, S., et al.: A long-life aqueous Zn-ion battery based on $\mathrm{Na}_{3} \mathrm{~V}_{2}\left(\mathrm{PO}_{4}\right)_{2} \mathrm{~F}_{3}$ cathode. Energy Storage Mater. 15, 14-21 (2018)

105. Ma, L., Chen, S., Li, H., et al.: Initiating a mild aqueous electrolyte $\mathrm{Co}_{3} \mathrm{O}_{4} / \mathrm{Zn}$ battery with $2.2 \mathrm{~V}$-high voltage and 5000 -cycle lifespan by a Co(III) rich-electrode. Energy Environ. Sci. 11, 2521-2530 (2018)

106. Wang, F., Fan, X., Gao, T., et al.: High-voltage aqueous magnesium ion batteries. ACS Cent. Sci. 3, 1121-1128 (2017)

107. Chang, Z., Yang, Y., Wang, X., et al.: Hybrid system for rechargeable magnesium battery with high energy density. Sci. Rep. 5, $1-8(2015)$

108. Son, S.B., Gao, T., Harvey, S.P., et al.: An artificial interphase enables reversible magnesium chemistry in carbonate electrolytes. Nat. Chem. 10, 532-539 (2018)

109. Wang, R.Y., Wessells, C.D., Huggins, R.A., et al.: Highly reversible open framework nanoscale electrodes for divalent ion batteries. Nano Lett. 13, 5748-5752 (2013) 
110. Padigi, P., Goncher, G., Evans, D., et al.: Potassium barium hexacyanoferrate- a potential cathode material for rechargeable calcium ion batteries. J. Power Sources 273, 460-464 (2015)

111. Richard, Y.W., Shyam, B., Stone, K.H., et al.: Reversible multivalent (monovalent, divalent, trivalent) ion insertion in open framework materials. Adv. Energy Mater. 5, 1401869 (2015)

112. Gheytani, S., Liang, Y., Wu, F., et al.: An aqueous Ca-ion battery. Adv. Sci. 4, 1700465 (2017)

113. Lin, M.C., Gong, M., Lu, B., et al.: An ultrafast rechargeable aluminium-ion battery. Nature 520, 325-328 (2015)

114. Elia, G.A., Marquardt, K., Hoeppner, K., et al.: An overview and future perspectives of aluminum batteries. Adv. Mater. 28, 7564-7579 (2016)

115. Angell, M., Pan, C.J., Rong, Y., et al.: High Coulombic efficiency aluminum-ion battery using an $\mathrm{AlCl}_{3}$-urea ionic liquid analog electrolyte. Proc. Natl. Acad. Sci. USA 114, 834-839 (2017)

116. Wu, C., Gu, S.H., Zhang, Q.H., et al.: Electrochemically activated spinel manganese oxide for rechargeable aqueous aluminum battery. Nat. Commun. 10, 1-10 (2019)

117. Zhao, Q., Zachman, M.J., Sadat, W.I.A., et al.: Solid electrolyte interphases for high-energy aqueous aluminum electrochemical cells. Sci. Adv. 4, eaau8131 (2018)

118. Tong, D.G.: Retraction: black mesoporous anatase $\mathrm{TiO}_{2}$ nanoleaves: a high capacity and high rate anode for aqueous Alion batteries. J. Mater. Chem. A 7, 20443 (2019)

119. Liu, S., Hu, J.J., Yan, N.F., et al.: Aluminum storage behavior of anatase $\mathrm{TiO}_{2}$ nanotube arrays in aqueous solution for aluminum ion batteries. Energy Environ. Sci. 5, 9743-9746 (2012)

120. Keltie, S.: Expression of concern: black mesoporous anatase $\mathrm{TiO}_{2}$ nanoleaves: a high capacity and high rate anode for aqueous Al-ion batteries. J. Mater. Chem. A 2, 1721-1731 (2014)

121. Holland, A.W., McKerracher, R., Cruden, A., et al.: $\mathrm{TiO}_{2}$ nanopowder as a high rate, long cycle life electrode in aqueous aluminium electrolyte. Mater. Today Energy 10, 208-213 (2018)

122. Lahan, H., Das, S.K.: Reversible $\mathrm{Al}^{3+}$ ion insertion into tungsten trioxide $\left(\mathrm{WO}_{3}\right)$ for aqueous aluminum-ion batteries. Dalton Trans. 48, 6337-6340 (2019)

123. Lahan, H., Das, S.K.: $\mathrm{Al}^{3+}$ ion intercalation in $\mathrm{MoO}_{3}$ for aqueous aluminum-ion battery. J. Power Sources 413, 134-138 (2019)

124. Joseph, J., O'Mullane, A.P., Ostrikov, K.: Hexagonal-molybdenum trioxide $\left(\mathrm{h}-\mathrm{MoO}_{3}\right)$ as an electrode material for rechargeable aqueous aluminum ion batteries. ChemElectroChem (2019). https://doi.org/10.1002/celc.201901890

125. Kumar, S., Satish, R., Verma, V., et al.: Investigating $\mathrm{FeVO}_{4}$ as a cathode material for aqueous aluminum-ion battery. J. Power Sources 426, 151-161 (2019)

126. Liu, S., Pan, G.L., Li, G.R., et al.: Copper hexacyanoferrate nanoparticles as cathode material for aqueous Al-ion batteries. J. Mater. Chem. A 3, 959-962 (2015)

127. Ru, Y., Zeng, S.S., Xue, H.G., et al.: Potassium cobalt hexacyanoferrate nanocubic assemblies for high-performance aqueous aluminum ion batteries. Chem. Eng. J. 382, 122853 (2019)

128. Gao, Y.N., Yang, H., Wang, X.R., et al.: The compensation effect mechanism of $\mathrm{Fe}-\mathrm{Ni}$ mixed prussian blue analogues in aqueous rechargeable aluminum-ion batteries. Chemsuschem. 13, 732-740 (2019). https://doi.org/10.1002/cssc.201903067

129. Verma, V., Kumar, S., Manalastas, W., et al.: Progress in rechargeable aqueous zinc- and aluminum-ion battery electrodes: challenges and outlook. Adv. Sustain. Syst. 3, 1800111 (2019)

130. Ru, Y., Zheng, S., Xue, H.G., et al.: Different positive electrode materials in organic and aqueous systems for aluminium ion batteries. J. Mater. Chem. A 7, 14391-14418 (2019)
131. Liu, T., Cheng, X., Yu, H., et al.: An overview and future perspectives of aqueous rechargeable polyvalent ion batteries. Energy Storage Mater. 18, 68-91 (2019)

132. Yuan, D., Zhao, J., Manalastas Jr., W., et al.: Emerging rechargeable aqueous aluminum ion battery: status, challenges, and outlooks. Nano Mater. Sci. 4, 5 (2019). https://doi.org/10.1016/j. nanoms.2019.11.001

133. He, S.M., Wang, J., Zhang, X., et al.: A high-energy aqueous aluminum-manganese battery. Adv. Funct. Mater. 29, 1905228 (2019)

134. Pan, W., Wang, Y., Zhang, Y., et al.: A low-cost and dendrite-free rechargeable aluminium-ion battery with superior performance. J. Mater. Chem. A 7, 17420-17425 (2019)

135. Hu, Z., Guo, Y., Jin, H., et al.: A rechargeable aqueous aluminum-sulfur battery through acid activation in water-in-salt electrolyte. Chem. Commun. 56, 2023-2026 (2020)

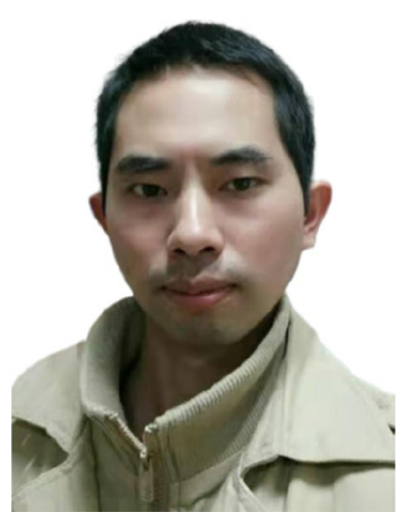

Mr. Xinhai Yuan is currently a doctoral student majoring in optoelectronic function and information materials in the Institute of Advanced Materials, Nanjing Tech University. His research centers on advanced materials and systems for high energy density aqueous batteries (including aqueous rechargeable lithium batteries, aqueous $\mathrm{Zn}$-ion batteries, aqueous Al-ion batteries, aqueous $\mathrm{Mg}$-ion batteries and so on).

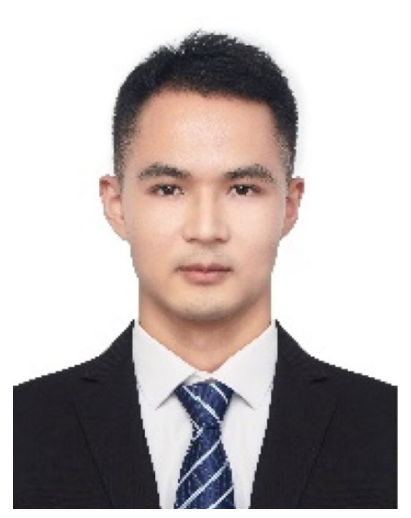

Mr. Fuxiang Ma is currently a master student majoring in power engineering, Nanjing tech University. His research centers on advanced materials and systems for long life and high energy density aqueous rechargeable batteries (including aqueous rechargeable zinc-sodium hybrid batteries, aqueous Na-ion batteries, aqueous Ca-ion batteries).

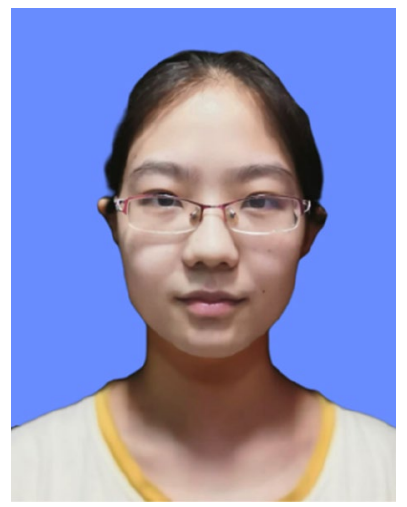

Ms. Linqing Zuo is a master student majoring in physical chemistry at Nanjing Tech University. Her research centers on high energy density aqueous zinc ion batteries. 


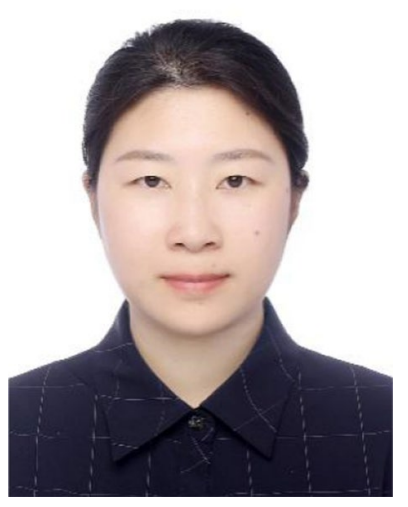

Dr. Jing Wang received her Ph.D. degree from Shanghai Jiaotong University (SJTU) in 2015. In the same year, she joined Nanjing Tech University (College of Energy Science and Engineering). Her research interests include the preparation of nanomaterials and photoelectrochemical catalysis.

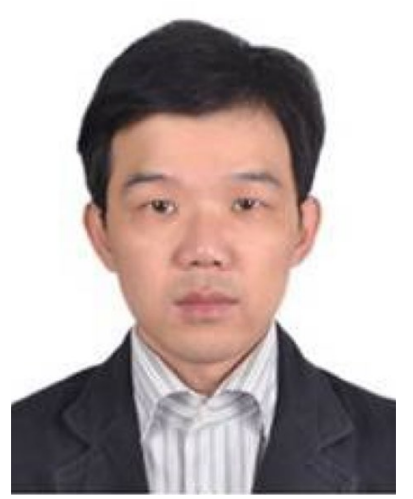

Dr. Nengfei Yu is an Assistant Professor at the School of Energy Science and Engineering, Nanjing Tech University. He received his Master's degree (2009) from Nanchang University and obtained his Ph.D. degree from Xiamen University in 2014. His current research interest is renewable energy storage and conversion, including electrocatalysis, lithium-air batteries, and metal air batteries.

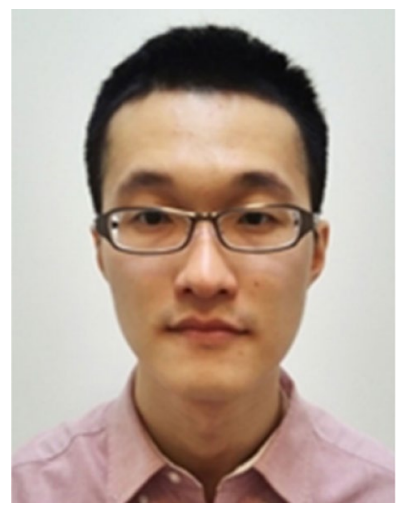

Dr. Yuhui Chen obtained his Ph.D. degree from University of St Andrews in 2014. Later he worked with Prof. Peter Bruce in the University of Oxford on the topic of metal air batteries. In 2017, he joined Nanjing Tech University. His research interests include electrochemical catalysis and novel batteries such as metal air batteries.

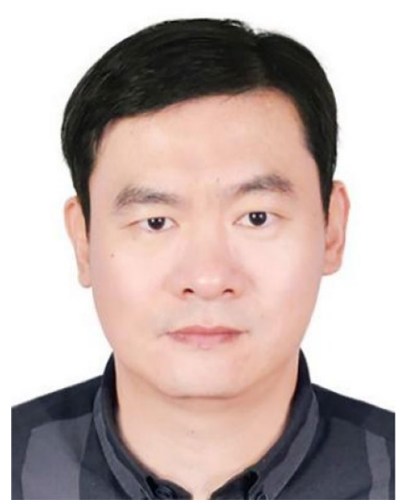

Dr. Yusong Zhu is a professor at the School of Energy Science and Engineering, Nanjing Tech University (NJTech). He received his Ph.D. in 2013 from Fudan University (FDU), and then did research work on polymer materials for energy storage in the Chemical Resources Laboratory in the Tokyo Institute of Technology (TITech). His current research interests focus on the advanced materials for solidstate lithium/sodium/zinc batteries, aqueous rechargeable batteries, supercapacitors and electrochemical reaction mechanisms. He has filed over 15 patents and patent applications and co-authored more than 90 relevant peerreviewed publications.

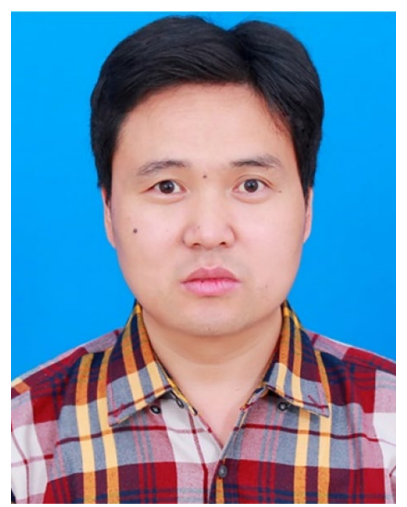

Dr. Qinghong Huang received his Ph.D. degree in Materials Physics and Chemistry in the Nanjing University of Aeronautics and Astronautics (China) in 2015. He worked in Shanghai Advanced Research Institute, the Chinese Academy of Sciences (Shanghai, China) as an associate professor from 2012 to 2017 . He is an associate professor in the College of Energy Science and Engineering (Nanjing Tech University, China). His research interests include fuel cells and nano-structured electrocatalysts.

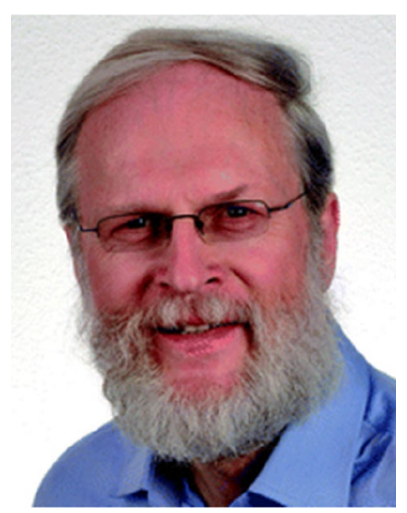

Dr. Rudolf Holze received his Ph.D. in 1983 from the University of Bonn, Germany. Afterwards, he joined Prof. E. B. Yeager at the Case Center for Electrochemical Sciences, Case Western Reserve University, Cleveland, USA, as a post-doctoral fellow and then Oldenburg University in 1987 as an associate professor of Physical Chemistry. Since 1993 he has been a full professor of Physical Chemistry and Electrochemistry at the Chemnitz University of Technology, Germany. His research is focused on spectroelectrochemistry, self-assembled monolayers, electrochemical energy conversion and storage, electrochemical materials science and corrosion. In May 2018 he was appointed head of a new lab on electrochemical energy storage materials and processes at St. Petersburg State University, Russia. He is an ordinary member of the Saxon Academy of Sciences and the founding editor of Electrochemical Energy Technology.

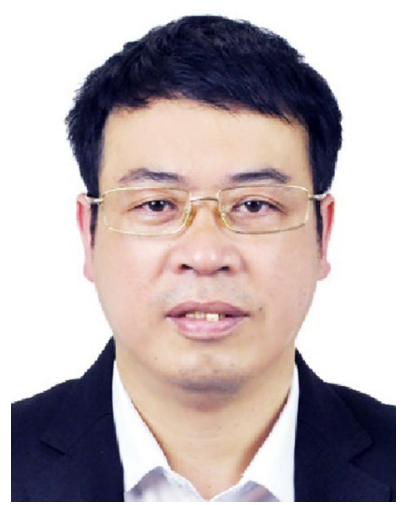

Dr. Yuping Wu is Distinguished Professor of Nanjing Tech University. He got a Ph.D. degree from the Institute of Chemistry, CAS, in 1997. In 2003, he was promoted to full professor in Fudan University, China. In 2015, he moved to Nanjing Tech University as a Distinguished Professor. Since 1994, he has published over 300 papers on peer-reviewed journals with an $h$-index of $>73$. As a main author, he contributed eight monographs on lithium batteries over the world, and their sales are above 45000 copies, and ten chapters. Twenty-five patents have been issued. He was awarded Distinguished Youth Scientists by NSFC (2014), the World's Most Influential Minds (2015) by Thomson Reuters, and the Albert Nelson Marquis Lifetime Achievement Award (2019). He is a pioneering inventor of lead lithium batteries, the second 
generation of ARLBs, the third generation of ARLBs, and pore-free separators for lithium batteries.

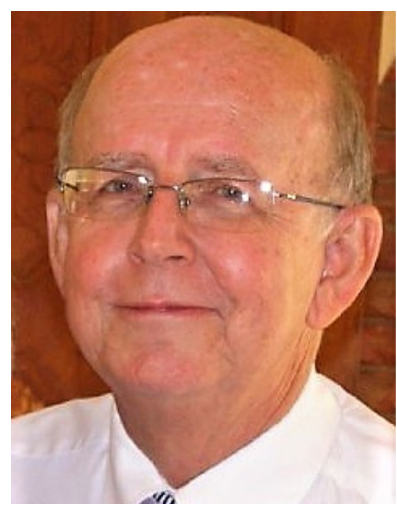

Dr. Teunis van Ree is emeritus Professor of the University of Venda, South Africa. He obtained his DSc degree at the University of Pretoria in 1980. After a stint in industry, he was appointed as lecturer (19751981) and senior lecturer (19821983), and then in January 1984 as the first professor of the Department of Chemistry at the University of Venda. He served as Head of the Department of Chemistry and Dean of the Faculty of Science and is a lifetime member of the South African

Chemical Institute and member of the Suid-Afrikaanse Akademie vir Wetenskap en Kuns. He received several Vice-Chancellor's awards for excellence in research. His eclectic research interests encompass all aspects of lithium-ion batteries, chemistry of traditional medicines, and development of organic synthesis methodology. He has published more than 60 peer-reviewed papers and contributed to 30 book chapters in these fields. 